\title{
Exploring the interactions of bacterial secondary symbionts (BSS) in wheat aphids, Sitobion avenae $\mathrm{F}$. with parasitoids
}

\section{Dissertation}

to obtain the Ph. D. degree in entomology

in the International Ph. D Program for Agricultural Sciences (IPAG) at the

Faculty of Agricultural Sciences, George-August-University Göttingen,

Germany

Presented by

Sajjad Ali

Born in Bahawalnagar, Pakistan

Göttingen, 2015 
Abstract

Chapter 1

General Introduction

References

Chapter 2

Host feeding behaviour of Aphelinus abdominalis (Dalman) in response to bacterial secondary symbionts in Sitobion avenae (F.) ............................................................... 17

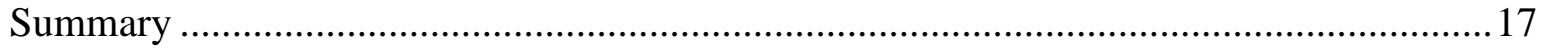

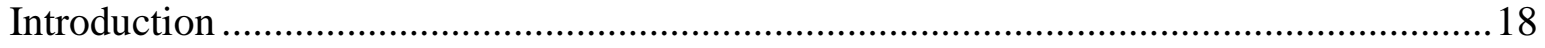

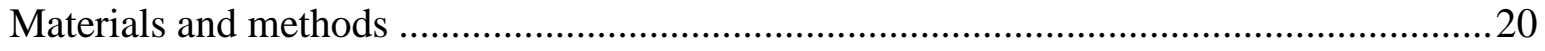

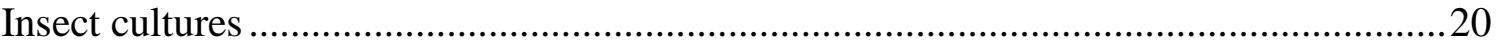

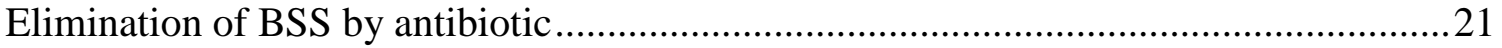

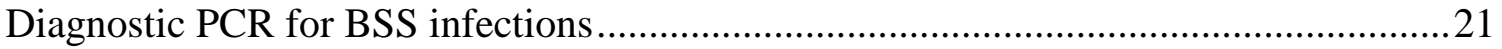

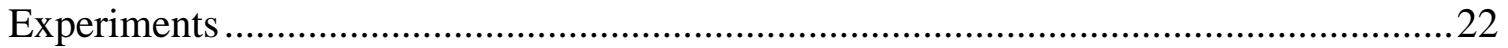

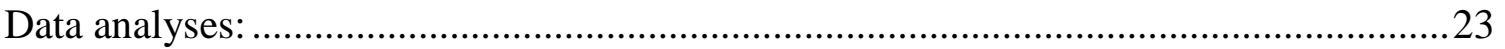

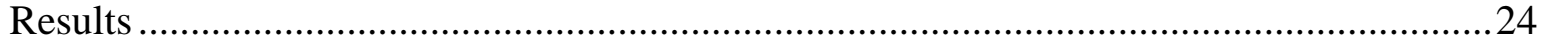

Host feeding behaviour of $A$. abdominalis in response to BSS (No Choice Tests) .........24

Host preference behaviour of A. abdominalis in response to BSS (Choice Tests) ..........25

Host preference behaviour of $A$. abdominalis in response to clonal variation (Choice

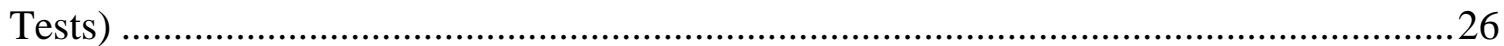

Effect of BSS on A. abdominalis development ............................................................2

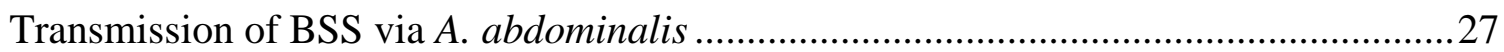

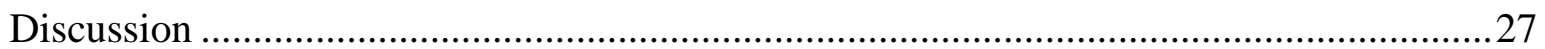

Host feeding behaviour of $A$. abdominalis in response to BSS ......................................2 27

Host feeding behaviour of $A$. abdominalis in response to host densities .......................28

Host preference behaviour of A. abdominalis in response to BSS .................................2 29

Host preference behaviour of A. abdominalis in response to clonal variation .................29

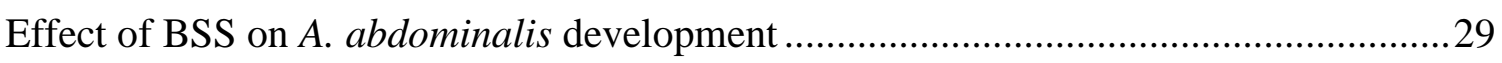

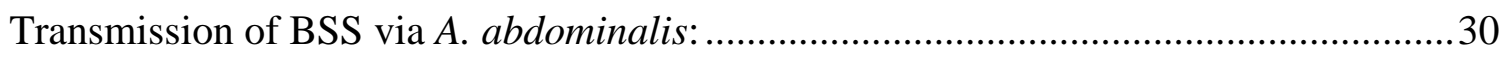

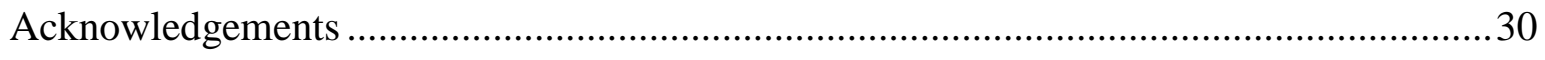

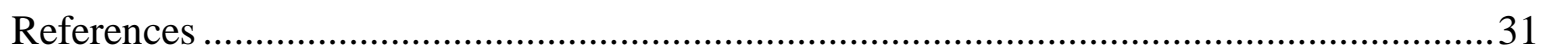




\section{Chapter 3}

Impact of bacterial secondary symbionts on survivorship of Sitobion avenae (Fabricius) against Aphelinus abdominalis (Dalman) host feeding at variable temperatures

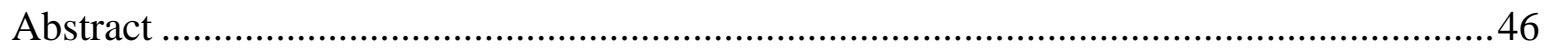

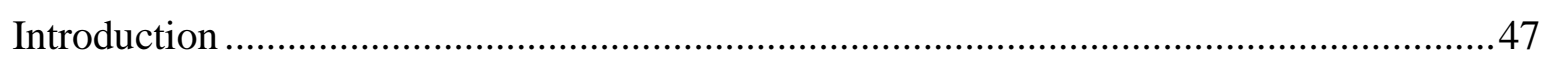

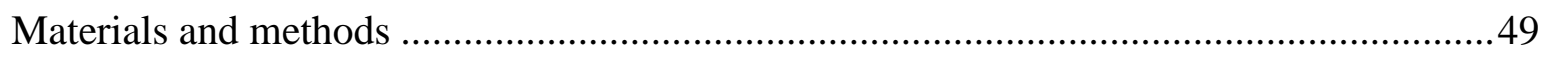

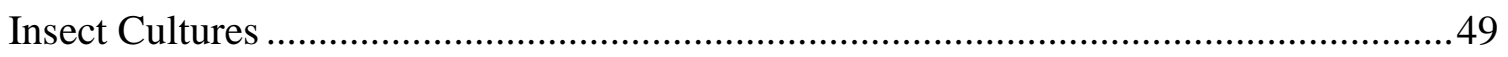

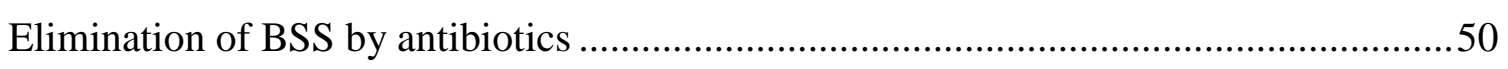

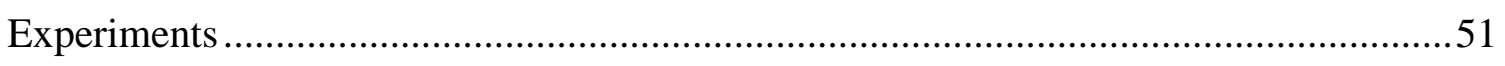

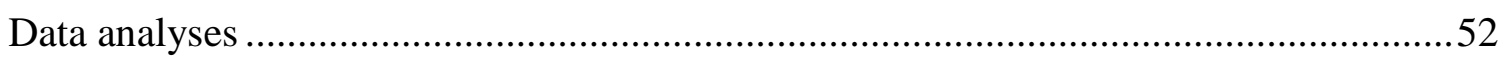

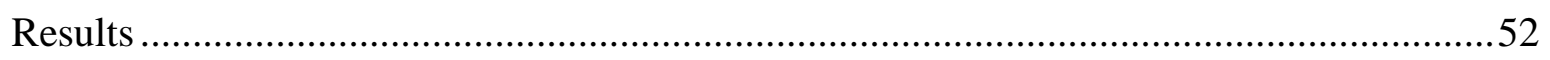

Survivorship of $S$. avenae against host feeding by A. abdominalis at variable

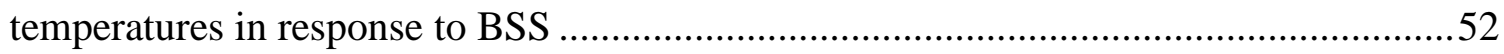

Host preference behaviour of A. abdominalis in response to BSS at variable temperatures

Host preference behaviour of A. abdominalis in response to clonal variation at variable

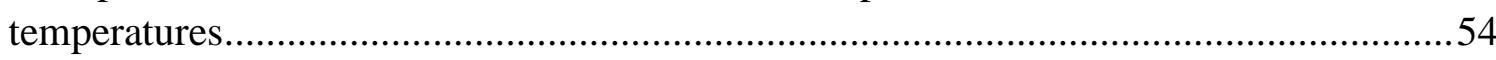

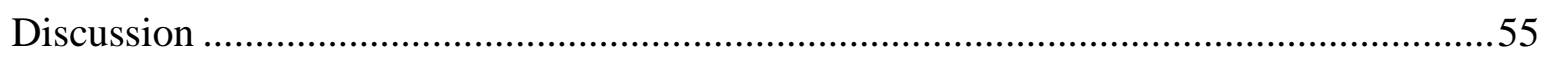

Survivorship of $S$. avenae against $A$. abdominalis host feeding in response to BSS at

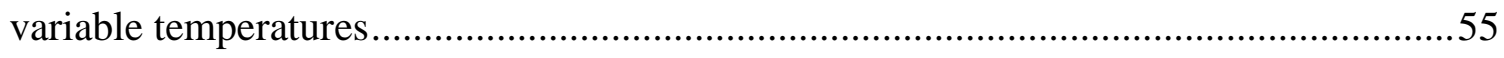

Effect of BSS and temperature interactions on A. abdominalis host feeding...................56

Host preference behaviour of $A$. abdominalis in response to BSS at variable temperatures

Host preference behaviour of A. abdominalis in response to clonal variations at variable

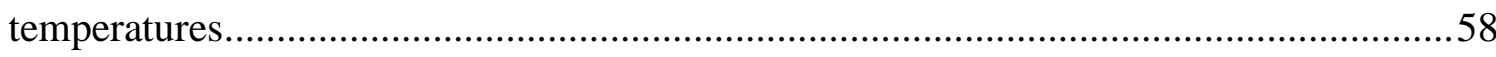

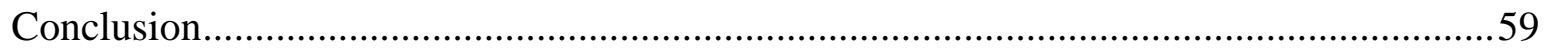

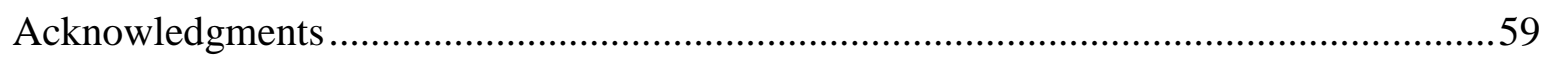

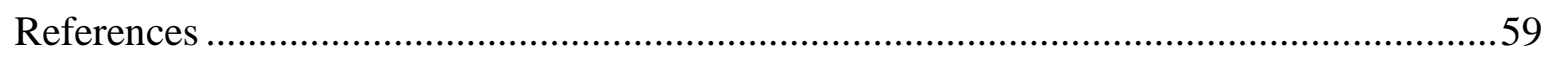

Chapter 4

Specificity of bacterial secondary symbionts of Sitobion avenae in resistance against host

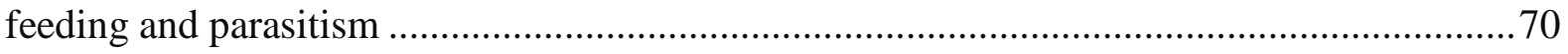

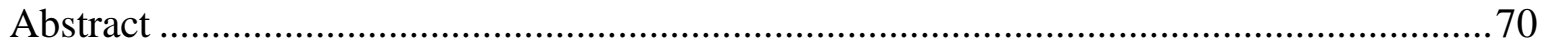

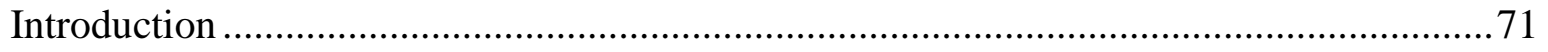

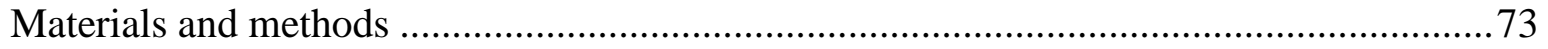

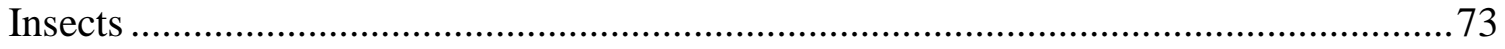

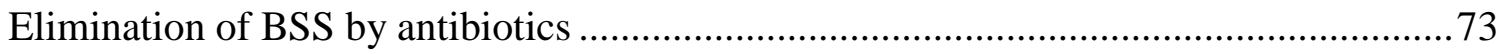

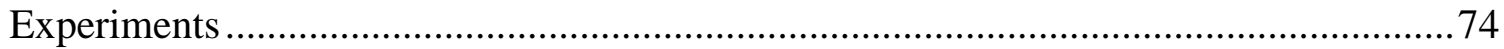




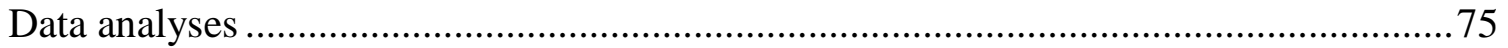

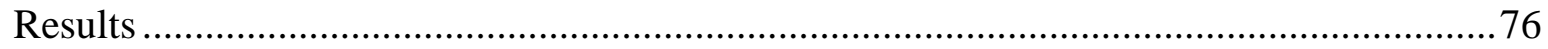

Response of bacterial secondary symbionts in Sitobion avenae against host feeding and

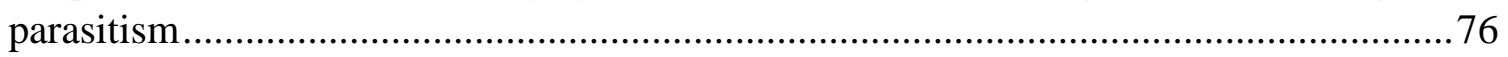

Host preference behaviour of parasitoids in response to BSS ......................................... 76

Host preference behaviour of parasitoids in response to clonal variation ......................... 77

Impact of BSS on larval development of parasitoids ................................................ 78

Horizontal transmission of BSS via parasitoids ......................................................... 78

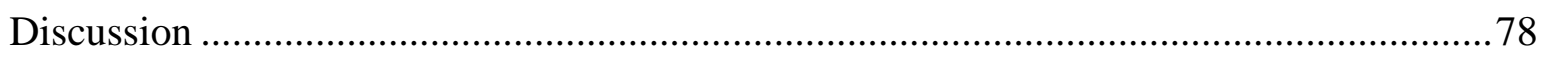

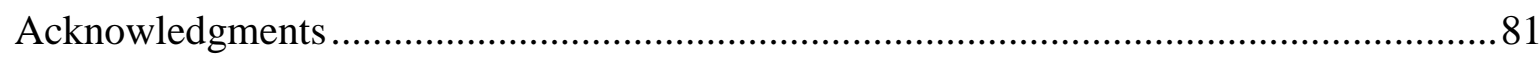

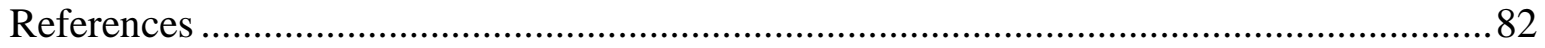

Chapter 5

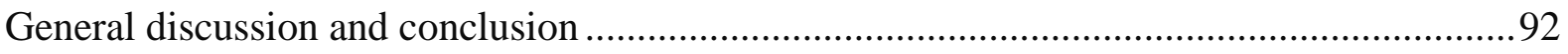

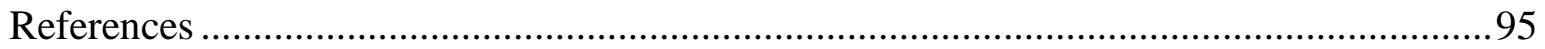




\begin{abstract}
Bacterial secondary symbionts (BSS) are renowned for their capacity to protect their hosts against natural enemies. Sitobion avenae (F.) is recently reported for Hamiltonella defensa and Regiella insecticola infections. Among natural enemies, parasitoids are the most effective bio-control agents. Host feeding strategy has been adopted by many parasitoids to increase their longevity and fecundity. Parasitoid-host interactions are highly specialized and depend upon the environmental factors and the genotypic backgrounds of the species involved. Besides the innate defence system, BSS composition of hosts may also alter the outcome of aphid-parasitoid interactions.
\end{abstract}

Genetically identical S. avenae clones possessed and lacked $H$. defensa and $R$. insecticola were used to assess host feeding and parasitism behaviour, host defence generality or specificity of these symbionts in this particular wheat aphid-symbiont system involving two parasitoids, Aphelinus abdominalis and Aphidius rhopalosiphi. A. abdominalis host feeding Reponses, towards of wheat aphids possessing and lacking BSS and genetic variations, studied at varying host densities and temperatures. In the last part of this study, H. defensa and $R$. insecticola were evaluated for defense against genetically different parasitoids $A$. abdominalis and A. rhopalosiphi for host feeding and parasitism.

BSS confer resistance to wheat aphids against $A$. abdominalis host feeding in both choice and no choice tests at all aphid host densities and temperatures tested. A. abdominalis host feeding response was positively correlated with host densities and temperatures up to a certain limit. S. avenae survivorship decreased significantly from lower to higher aphid densities and temperatures in choice and no choice tests. The most striking result was $A$. abdominalis host preference in feeding $S$. avenae without BSS in choice tests. Genetic or clonal preference in host feeding was also observed when A. abdominalis were exposed to genetically different $S$. avenae clones in all experiments. Wheat aphid-symbiont bond for its outcome was not affected by variable host densities and temperatures.

$H$. defensa conferred a general defence against both parasitoids but $R$. insecticola was significantly resistant against host feeding of A. abdominalis while it didn't provide defence to $S$. avenae against A. rhopalosiphi. A. abdominalis development in $S$. avenae was negatively affected by both of these bacterial symbionts but A. rhopalosiphi got negative impact only from $H$. defensa. Parasitoids were not involved in horizontal transmission of $H$. defensa and $R$. insecticola among $S$. avenae populations. These fitness advantages confer to their host aphids by these endosymbiotic bacteria expound the adaptive significance of their heritable and successful spread over many insect populations especially in aphids. 


\section{Chapter 1}

\section{General Introduction}

Symbiosis, a purposeful interspecific association between two organisms, is omnipresent in the nature. Mostly, one of the partners is microbial organism referred to as symbiont. Symbioses vary in its dimensions of associations, role in host biology, partners' coevolutionary history, and in genetic features of symbionts (Moran, 2006). Almost 15-20\% of all insect species harbour symbiotic bacterial microorganisms. Generally, symbiotic bacteria are intracellularly reside in their host insect and are known as endosymbionts. They are grouped into primary and secondary symbionts depending upon their speciality. Primary symbionts are obligate for host survival and possess constant and highly specialized role in evolutionary life of host populations. They are facilitating their host insects to occupy a wide range of habitats through feeding flexibility (Douglas, 1998; Baumann, 2005; Moran, 2006).

Almost all aphid species harbour Buchnera aphidicola which is ranked among primary symbionts which reside in specialized cells called bacteriocytes (Douglas, 1998; Kikuchi, 2009). Buchnera aphidicola improves nutritional physiology in Hemiptera by compensating host aphids with deficit essential amino acids in their diet to increase host fitness and survival (Gündüz \& Douglas, 2009). Many aphid species have adapted a wide range of symbiotic microorganisms in addition to their obligate bacterial associates known as bacterial secondary symbionts "BSS" (Moran et al., 2008; Ferrari et al., 2011). Bacterial symbionts are typically vertically transmitted from mother to offspring by manipulating the host reproduction system but inter- and intra-specific horizontal transmissions of BSS may occur at low rates (Moran \& Dunbar, 2006; Chiel et al., 2009; Gehrer \& Vorburger, 2012).

Aphids rely on symbiotic bacteria for their life activities like nutritional requirements (Gündüz \& Douglas, 2009), thermal tolerance (Montllor et al., 2002), host protection from enemies (Haine, 2008), insecticide detoxification (Kikuchi et al., 2012), host plant adaptation (Tsuchida et al., 2002), body colouration (Tsuchida et al., 2010), sexual aberrations (Simon et al., 2011; Kageyama et al., 2012) and reproduction and development (Barribeau et al., 2010). The fitness advantages to the insect hosts and the dynamic transmission over host generations favour the wide spread of heritable microbial symbionts (Russell \& Moran, 2005). In return, these bacterial endosymbionts manipulate the reproductive system of their hosts (White, 2011). 
Hamiltonella defensa and Regiella insecticola are among the major BSS which occur with a frequency distribution of approximately $14-16 \%$ in aphid species and recently reported in $S$. avenae (Oliver et al., 2010; Łukasik et al., 2011). Both of them offer a wide variety of protection services to their insect hosts against their natural enemies including parasitic wasps, predators and fungal pathogens (Oliver et al., 2003; Piel et al., 2004; Łukasik et al., 2013). The protection mechanism adopted by $R$. insecticola is yet not clear but $H$. defensa rely on a toxin-encoding bacteriophage (APSE) for its virulence against parasitoids. These toxins appear to affect the parasitoids negatively (Oliver et al., 2009). Even parasitoid development may also be reduced by BSS after successful egg laying into the aphids (Nyabuga et al., 2010; Schmid et al., 2012) which may reduce parasitoid survival fitness. In addition to protection services, $R$. insecticola is also linked with host plant utilization of many aphid species. It is widely associated with pea aphid populations feeding on Trifolium plants (Tsuchida et al., 2002). S. symbiotica and $H$. defensa widen host fitness under high temperature (Montllor et al., 2002). Pea aphids, harbouring S. symbiotica and H. defensa, exceed their reproduction rate when they are confronted to alarm pheromones as an indicator of death risk (Barribeau et al., 2010). BSS can, thus, be regarded important evolutionary partners of their insect hosts (Feldhaar, 2011) through their journey of evolution.

The English grain aphid Sitobion avenae (F.) is a potential pest of cereal crops all over the word but especially in temperate climate (Alkhedir et al., 2010). It can establish and multiply tremendously in short time. It can cause direct and indirect damage to wheat crop which causes significant yield losses (Xu et al., 1998). Conventional breeding to develop resistant cultivars is important tool to cope with wheat aphids (Stoger et al., 1999) but about 5\% of wheat crop is also chemically treated in European regions to avoid such loses (European Agricultural Statists, 2007). Aphids have the ability to reproduce very quickly and can establish insecticide resistance over time. So, it is hard to control aphids in the field (Foster et al., 2014). Above this fact, insecticides are also causing environmental pollution, changes in the ecological patterns and harmful effects to natural enemies (Bommarco et al., 2011). In twenty-first century, effective biological control opportunities are focused than ever to overcome such risks and sustainability in farming production (Bale et al., 2008). Biological control is controlling insect pests of economic importance by releasing their natural enemies instead of using insecticides. (Hufbauer, 2002). Among natural enemies, parasitoids are considered as the most effective agents in biological control because of their higher 
reproduction, fast growth, easy rearing and positive response to increasing aphid population densities (Boivin et al., 2012; Yang et al., 2012).

Parasitoids are key player in almost all terrestrial ecosystems. They are diverse, plentiful and good ecological exploiter to influence the host population dynamics (Hassell, 2000; Godfray, 2007). They have intermediate life history between predators and parasites and possess an intrinsic capacity of responses to environmental factors (Godfray, 2007) and maintain natural balance of host populations in ecosystems (Rehman \& Powell, 2010). In addition to parasitisation, many hymenopteran parasitoid species use their host as feed by consuming their host body materials. Parasitoid host feeding might be destructive to the host populations which causes considerable additional host mortality (Burger et al., 2004). Host feeding strategy has been adopted by parasitoids to increase their longevity and fecundity (Heimpel \& Collier, 1996). Non-reproductive host feeding by parasitoids may also be considered to improve the efficiency of biological control (Byeon et al., 2009) in IPM.

Parasitoid-host interactions are highly specialized and antagonistic to exhibit the coevolutionary relationships in nature. Host behavioural response, parasitoid development in hosts and environmental factors specify host ranges for parasitoids ( $\mathrm{Li}$ et al., 2002; Kraaijeveld \& Godfray, 2009). In nature, aphids harbouring bacterial secondary endosymbionts along with their associated natural enemies are exposed to environmental changes. Behavioural, physiological and biochemical systems related to aphid and parasitoid fitness are determined by environmental factors. Parasitoids are positively correlated with host densities and temperature up to a certain limit. Host densities are important factor for parasitoid behaviour to use the available resources efficiently but the whole system is temperature dependent (Kidd \& Jervis, 1989; Thomas \& Blanford, 2003). The population dynamics of natural enemies and their host species depend upon the temperature variations (Leather, 1993). The cost to thermal changes may increase and may become an important factor for mortality and reproduction by interacting directly or indirectly via natural enemies (Dill et al., 1990).

Host-parasitoids interactions are influenced by host population and environmental variations. It is important to predict the outcome of such interactions to improve the biological control strategies (Mostowy \& Engelstädter, 2011). Population dynamics and temperature variations are important factors which can affect the life history traits of aphids, BSS and parasitoids. Extreme temperatures can be deleterious for the population dynamics of aphids and BSS within the host organisms (Montllor et al., 2002) which may decrease aphid's genetic and 
symbiotic resistance towards parasitoids (Bensadia et al., 2006). Temperature can also affect the ability and mobility of parasitoids to exploit the host populations (Hance et al., 2006) and tolerance to environmental stresses enables the parasitoids to regulate their host populations (Thomson et al., 2010).

Parasitoids are quite able to detect the presence of BSS in their host aphids (Oliver et al., 2012) and they also behave differently towards clonal or genetic variations among their target aphid populations ( $\mathrm{Li}$ et al., 2002, von Burg et al., 2008, Vorburger et al., 2009). Their hosts have developed strong defences under selection pressure and in turn parasitoids have to evolve counter-resistance system to exploit the host successfully (Li et al., 2002; Kraaijeveld $\&$ Godfray, 2009). Addition to the innate defence system, aphids have adopted symbiotic microorganisms to enhance their resistance against parasitoids (Kaltenpoth \& Engl, 2014). Adoption, tolerance, maintenance, and transmission of bacterial secondary symbionts among aphid populations are important in defence strategies which are evolved over long time (Haine, 2008). Multiple parasitoid species, encountering single aphid host, can alter the host defence mechanisms (Nuismer and Thompson, 2006) depending upon the genotypic backgrounds of aphids, parasitoids and bacterial symbionts (Schmid et al., 2012).

The literature is piled up with aphid-bacterial symbiont-parasitoid interaction studies with limited scope on pea aphids and to some extent with bean aphids in relation to Aphidius species (Oliver et al., 2003, Vorburger et al., 2009, Nyabuga et al., 2010). A comprehensive view of mechanisms and influences of bacterial symbiont compositions on aphid-parasitoid interactions needs to be established for the maintenance and wide spread of bacterial endosymbiosis among aphids. Wheat aphid Sitobion avenae (F.), Aphelinus abdominalis (Dalman) and Aphidius rhopalosiphi are not well reported in this regard. A. abdominalis is a good biological control agent against many aphid species possessing host feeding behaviour (Schelt, 1994, Enkegaard et al., 2013) while A. rhopalosiphi is one of the most abundant parasitoid species of Aphidiinae in European cereal fields in northern parts of continent (Muratori et al., 2004).

To fill this literature gap, our study is dealing with the A. abdominalis host feeding behaviour with regard to bacterial secondary symbionts (H. defensa and $R$. insecticola) in $S$. avenae host (Alkhedir et al., 2013). Genetically identical wheat aphid clones possessing and lacking these BSS were obtained by applying antibiotics through micro injections to cure BSS from these aphid clones rather than by haemolymph transfer to avoid any genetic mixing. We also used 
genetically different clones without BSS and also with different BSS to confirm the clonal resistance against host feeding.

The following questions were addressed in this study.

- Do $H$. defensa and $R$. insecticola confer resistance to $S$. avenae against $A$. abdominalis host feeding at variable host population densities and temperatures?

- Is host feeding behaviour of A. abdominalis affected by H. defensa and R. insecticola, host population density and temperature interactions?

- Does A. abdominalis show host feeding preference between wheat aphids with and without $H$. defensa and $R$. insecticola at variable host population densities and temperatures?

- Do host wheat aphid genetic variations affect A. abdominalis host feeding behaviour at variable population densities and temperatures?

- Are $H$. defensa and $R$. insecticola general or specific in resistance against genetically different parasitoids A. abdominalis and A. rhopalosiphi for host feeding and parasitism?

- Are A. abdominalis and A. rhopalosiphi involved in horizontal transmission of $H$. defensa and R. insecticola in S. avenae?

- Does A. rhopalosiphi show host preference for parasitism between wheat aphids with and without $H$. defensa and $R$. insecticola?

- Do host wheat aphid genetic variations affect A. rhopalosiphi parasitism behaviour?

- Do H. defensa and $R$. insecticola affect the development of A. abdominalis and A. rhopalosiphi in S. avenae? 


\section{References}

Alkhedir, H., Karlovsky, P., \& Vidal, S. (2010). Effect of light intensity on colour morph formation and performance of the grain aphid Sitobion avenae F. (Homoptera: Aphididae). Journal of Insect Physiology, 56, 1999-2005.

Alkhedir H, Karlovsky P, Vidal S (2013). Relationship between water soluble carbohydrate content, aphid endosymbionts and clonal performance of Sitobion avenae on cocksfoot cultivars. PLoS One, 8:e54327. doi:10.1371/journal.,pone.0054327.

Bale, J. S., Van Lenteren, J. C., \& Bigler, F. (2008). Biological control and sustainable food production. Philosophical Transactions of the Royal Society of London B: Biological Sciences, 363(1492), 761-776.

Barribeau, S. M., Sok, D., \& Gerardo, N. M. (2010) Aphid reproductive investment in response to mortality risks. BMC Evolutionary Biology, 10(1), 251.

Baumann, P. (2005) Biology of bacteriocyte-associated endosymbionts of plant sap sucking insects. Annual Review of Microbiology, 59, 55-89.

Bensadia, F., Boudreault, S., Guay, J. F., Michaud, D., \& Cloutier, C. (2006). Aphid clonal resistance to a parasitoid fails under heat stress. Journal of Insect Physiology, 52(2), 146-157.

Bommarco, R., Miranda, F., Bylund, H., \& Björkman, C. (2011). Insecticides suppress natural enemies and increase pest damage in cabbage. Journal of Economic Entomology, 104(3), 782-791.

Boivin, G., Hance, T., \& Brodeur, J. (2012). Aphid parasitoids in biological control. Canadian Journal of Plant Science, 92(1), 1-12.

Burger, J., Reijnen, T. M., Van Lenteren, J. C., \& Vet, L. E. (2004). Host feeding in insect parasitoids: why destructively feed upon a host that excretes an alternative? Entomologia Experimentalis et Applicata, 112(3), 207-215.

Byeon, Y. W., Tuda, M., akagi, M., Kim, J. H. \& Kim, Y. H. (2009). Non-reproductive host killing caused by Aphelinus asychis (Hymenoptera: Aphelinidae), a parasitoid of cotton aphid, Aphis gossypii (Homoptera: Aphididae). Journal- Faculty of Agriculture Kyushu University, 54, 369-372. 
Chiel, E., Zchori-Fein, E., Inbar, M., Gottlieb, Y., Adachi-Hagimori, T., Kelly, S. E., Asplen, M. K. \& Hunter, M. S. (2009). Almost There: Transmission Routes of Bacterial Symbionts between Trophic Levels. PLoS ONE, 4(3), e4767. doi:10.1371/journal.,pone.0004767

Dill, L. M., Fraser, A. H., \& Roitberg, B. D. (1990). The economics of escape behaviour in the pea aphid, Acyrthosiphon pisum. Oecologia, 83(4), 473-478.

Douglas, A.E. (1998). Nutritional interactions in insect-microbial symbioses: aphids and their symbiotic bacteria Buchnera. Annual Review Entomology, 43, 17-37.

Enkegaard, A., Sigsgaard, L. \& Kristensen, K. (2013). Shallot Aphids, Myzus ascalonicus, in Strawberry: Biocontrol Potential of Three Predators and Three Parasitoids. Journal of Insect Science, $13,83$.

European Agricultural Statistics. (2007). The use of pesticides in Europe. http://ec.europa.eu/agriculture/agrista/2004/table_en/index.htm, status: November 2007.

Feldhaar, H. (2011). Bacterial symbionts as mediators of ecologically important traits of insect hosts. Ecological Entomology, 36, 533-543.

Ferrari, J. \& Vavre, F. (2011). Bacterial symbionts in insects or the story of communities affecting communities. Philosophical Transactions of the Royal Society B, 366, 1389-1400.

Gehrer, L. \& Vorburger, C. (2012) Parasitoids as vectors of facultative bacterial endosymbionts in aphids. Biology letters, 8, 613-615.

Gündüz, E.A. \& Douglas, A.E. (2009) Symbiotic bacteria enable insect to use a nutritionally inadequate diet. Proceedings of the Royal Society of London B: Biological Sciences, 276, 987-991.

Foster, S. P., Paul, V. L., Slater, R., Warren, A., Denholm, I., Field, L. M., \& Williamson, M. S. (2014). A mutation (L1014F) in the voltage-gated sodium channel of the grain aphid, Sitobion avenae, is associated with resistance to pyrethroid insecticides. Pest management science, $70(8), 1249-1253$.

Godfray, H. C. J. (2004). Parasitoids. Current Biology, 14(12), R456.

Haine, E. R. (2008). Symbiont-mediated protection. Proceedings of the Royal Society B: Biological Sciences, 275(1633), 353-361.

Hance, T., Van Baaren, J., Vernon, P., \& Boivin, G. (2006). Impact of extreme temperatures on parasitoids in a climate change perspective. Annual review of entomology, 52(1), 107. 
Hassell, M. P. (2000). Host-parasitoid population dynamics*. Journal of Animal Ecology, 69(4), 543-566.

Heimpel, G. E., \& Collier, T. R. (1996). The evolution of host-feeding behaviour in insect parasitoids. Biological Reviews, 71(3), 373-400.

Hufbauer, R. A. (2002). Aphid population dynamics: does resistance to parasitism influence population size? Ecological Entomology, 27, 25-32.

Kageyama, D., Narita, S. \& Watanabe, M. (2012). Insect sex determination manipulated by their endosymbionts: incidences, mechanisms and implications. Insects 3, 161-199.

Kaltenpoth, M., \& Engl, T. (2014). Defensive microbial symbionts in Hymenoptera. Functional Ecology, 28(2), 315-327.

Kidd, N.A.C. \& Jervis, M.A. (1989). The effects of host feeding behaviour on the dynamics of parasitoid-host interactions, and the implications for biological control. Researches in Population Ecology, 31, 235-274.

Kikuchi, Y. (2009). Endosymbiotic bacteria in insects: their diversity and culturability. Microbes and environments/JSME, 24(3), 195-204.

Kikuchi, Y., Hayatsu, M., Hosokawa, T., Nagayama, A., Tago, K., \& Fukatsu, T. (2012). Symbiont-mediated insecticide resistance.Proceedings of the National Academy of Sciences, 109(22), 8618-8622.

Kraaijeveld, A. R., \& Godfray, H. C. J. (2009). Evolution of host resistance and parasitoid counter-resistance. Advances in parasitology, 70, 257-280.

Leather, S. R. (1993). Overwintering in six arable aphid pests: a review with particular relevance to pest management. Journal of Applied Entomology, 116(1-5), 217-233.

Li, S., Falabella, P., Giannantonio, S., Fanti, P., Battaglia, D., Digilio, M. C., Völkl, W., Sloggett, J. J., Weisser, W. \& Pennacchio, F. (2002). Pea aphid clonal resistance to the endophagous parasitoid Aphidius ervi. Journal of Insect Physiology, 48, 971-980.

Muratori, F., Le Lannic, J., Nénon, J. P., \& Hance, T. (2004). Larval morphology and development of Aphidius rhopalosiphi (Hymenoptera: Braconidae: Aphidiinae). The Canadian Entomologist, 136(02), 169-180. 
Montllor, C.B., Maxmen, A. \& Purcell, A.H. (2002). Facultative bacterial endosymbionts benefit pea aphids Acyrthosiphon pisum under heat stress. Ecological Entomology, 27, 189195.

Moran, N.A. (2006). Symbiosis. Current Biology, 16, 866-871.

Moran, N.A., \& Dunbar, H.E. (2006). Sexual acquisition of beneficial symbionts in aphids. Proceedings of National Academy of Sciences, 103, 12803-12806.

Moran, N.A., McCutcheon, J.P. \& Nakabachi, A. (2008). Genomics and evolution of heritable bacterial symbionts. Annual Review of Genetics, 42,165-190.

Mostowy, R., \& Engelstädter, J. (2011). The impact of environmental change on hostparasite coevolutionary dynamics. Proceedings of the Royal Society of London B: Biological Sciences, 278(1716), 2283-2292.

Nuismer, S. L., \& Thompson, J. N. (2006). Coevolutionary alternation in antagonistic interactions. Evolution, 60(11), 2207-2217.

Nyabuga, F.N., Outreman, Y., Simon, J.C., Heckel, D.G. \& Weisser, W.W. (2010). Effects of pea aphid secondary endosymbionts on aphid resistance and development of the aphid parasitoid Aphidius ervi: a correlative study. Entomologia Experimentalis et Applicata, 136, 243-253.

Oliver, K.M., Russell, J.A., Moran, N.A. and Hunter, M.S. (2003). Facultative bacterial symbionts in aphids confer resistance to parasitic wasps. Proceedings of the National Academy of Sciences, 100, 1803-1807.

Oliver, K. M., Degnan, P. H., Hunter, M. S., \& Moran, N. A. (2009). Bacteriophages encode factors required for protection in a symbiotic mutualism. Science, 325(5943), 992-994.

Oliver, K. M., Degnan, P. H., Burke, G. R., \& Moran, N. A. (2010). Facultative symbionts in aphids and the horizontal transfer of ecologically important traits. Annual review of entomology, 55, 247-266.

Oliver, K.M., Noge, K., Huang, E.M., Campos, J.M., Becerra, J.X. \& Hunter, M.S. (2012). Parasitic wasp responses to symbiont-based defense in aphids. BMC Biology, 10, 11.

Piel, J., Höfer, I., \& Hui, D. (2004). Evidence for a symbiosis island involved in horizontal acquisition of pederin biosynthetic capabilities by the bacterial symbiont of Paederus fuscipes beetles. Journal of Bacteriology, 186(5), 1280-1286. 
Rehman, A., \& Powell, W. (2010). Host selection behaviour of aphid parasitoids (Aphidiidae: Hymenoptera). Journal of Plant Breeding and Crop Science, 2(10), 299-311.

Russell, J. A., \& Moran, N. A. (2005). Horizontal transfer of bacterial symbionts: heritability and fitness effects in a novel aphid host. Applied and Environmental Microbiology, 71(12), 7987-7994.

Schelt, J. van. (1994) The selection and utilisation of parasitoids for aphid control in glasshouses. Exp. Appl. Entomol, pp. 151-155.

Schmid, M., Sieber, R., Zimmermann, Y-S., \& Vorburger, C. (2012). Development, specificity and sublethal effects of symbiont conferred resistance to parasitoids in aphids. Functional Ecology, 26, 207-215.

Simon, J-C., Boutin, S., Tsuchida, T., Koga, R., Le Gallic, J-F., Frantz, A., Outreman, Y., \& Fukatsu, T. (2011). Facultative Symbiont Infections Affect Aphid Reproduction. PLoS ONE, 6(7), e21831. doi:10.1371/journal.,pone.0021831.

Stoger, E., Williams, S., Christou, P., Down, R.E. \& Gatehouse, J.A., (1999). Expression of the insecticidal lectin from snowdrop (Galanthus nivalis agglutinin; GNA) in transgenic wheat plants: effects on predation by the grain aphid Sitobion avenae. Molecular Breeding, 5, $65-73$

Tsuchida T, Koga R., \& Fukatsu, T. (2004) Host plant specialization governed by facultative symbiont. Science, 303, 1989.

Tsuchida, T., Koga, R., Horikawa, M., Tsunoda, T., Maoka, T., Matsumoto, S., Simon, J., \& Fukatsu, T. (2010). Symbiotic bacterium modifies aphid body color. Science, 330, 11021104.

Thomas, M. B., \& Blanford, S. (2003). Thermal biology in insect-parasite interactions. Trends in Ecology \& Evolution, 18(7), 344-350.

Thomson, L. J., Macfadyen, S., \& Hoffmann, A. A. (2010). Predicting the effects of climate change on natural enemies of agricultural pests. Biological control, 52(3), 296-306.

Von Burg, S., Ferrari, J., Muller, C.B. \& Vorburger, C. (2008). Genetic variation and covariation of susceptibility to parasitoids in the aphid Myzus persicae: no evidence for tradeoffs. Proceedings of Royal Society, London B, 275, 1089-1094. 
Vorburger, C., Sandrock, C., Gouskov, A., Castaneda, L. E. \& Ferrari, J. (2009). Genotypic variation and the role of defensive endosymbionts in an all-parthenogenetic host-parasitoid interaction. Evolution, 63, 1439-1450.

White, J.A. (2011) Caught in the act: Rapid, symbiont-driven evolution. Bioessays. 33:823829.

Xu, L.M., Qi, F.M., Zhang, J.P., Zhang, J.Z., Cao, C.M., \& Chen, J.L. (1998). Initial measurement of wheat output loss due to Macrosiphum avenae. Inner Mongolia Agricultural Science Technology, 5, 27-28.

Yang, N-W., Ji, L-L., Lövei, G.L. \& Wan, F-H. (2012). Shifting Preference between Oviposition vs. Host-Feeding under Changing Host Densities in Two Aphelinid Parasitoids. PLoS ONE, 7(7), e41189. doi:10.1371/journal.,pone.0041189. 


\title{
Chapter 2
}

\section{Host feeding behaviour of Aphelinus abdominalis (Dalman) in response to bacterial secondary symbionts in Sitobion avenae (F.)}

\author{
Sajjad Ali ${ }^{\mathrm{a}}$, Petr Karlovsky ${ }^{\mathrm{b}}$ and Stefan Vidal ${ }^{\mathrm{a}}$ \\ ${ }^{a}$ Department of Crop Sciences, Agricultural Entomology, Georg-August University, Göttingen, Germany, ${ }^{\mathrm{b}}$ Department of \\ Crop Sciences, Molecular Phytopathology and Mycotoxin Research, Georg-August University, Göttingen, Germany
}

\section{Summary}

1. Aphelinus abdominalis (Dalman) is a solitary parasitoid of many aphid species which also possess host feeding ability. Sitobion avenae (F.) is recently reported for bacterial secondary symbionts "BSS" Hamiltonella defensa and Regiella insecticola. BSS are renowned for their capacity to protect their hosts against natural enemies. Parasitoids are able to detect BSS infection and genetic variation of their host for parasitism.

2. Genetically identical wheat aphid clones harbouring BSS and free of BSS were developed by using antibiotics via micro-injection technique. Host feeding and host preference response of $A$. abdominalis to BSS was studied at varying host densities in no choice and choice tests by exposing them to developed clones S. avenae. Impact of BSS on parasitoid development in host wheat aphids was also determined.

3. BSS confer resistance to wheat aphids against $A$. abdominalis host killing in both choice and no choice tests at all aphid host densities tested. A. abdominalis host feeding response was positively correlated with host densities. S. avenae killing due to A. abdominalis host feeding increased significantly from lower to higher aphid densities in choice and no choice tests. A. abdominalis development in wheat aphids was negatively affected from BSS. BSS from $S$. avenae were not horizontally transmitted via A. abdominalis.

4. The most striking result was A. abdominalis host preference in killing $S$. avenae without BSS in choice tests. Genetic or clonal preference in host killing was also observed when A. abdominalis were exposed to genetically different $S$. avenae clones.

5. Based on our findings, we might conclude that BSS not only confer resistance to their hosts against parasitism but also against host feeding or killing strategy of $A$. abdominalis in wheat aphids. Parasitoid can still be negatively affected by BSS during development after parasitizing wheat aphids. In addition, BSS and genetic variations both can change the host preference behaviour of parasitoids.

Keywords: Host feeding, symbionts, Aphelinus abdominalis, Sitobion avenae, host densities 


\section{Introduction}

Symbiosis is the purposeful interspecific association of two or more organisms. Almost 15$20 \%$ of all insect species harbour symbiotic microorganisms and are grouped into primary and secondary symbionts. The symbiotic microorganisms are facilitating the insects to occupy wide range of habitats through feeding flexibility (Dow 1986; Baumann 2005; Moran 2006). Almost all aphid species harbour Buchnera aphidicola which is ranked among the primary symbionts (Douglas 1998). Buchnera aphidicola improves the nutritional ecology of aphids by compensating them with the deficit amino acids in their diet to increase their survival (Gündüz and Douglas 2009). In addition to Primary symbionts, bacterial secondary symbionts "BSS" are also common among many aphid species (Moran et al., 2008; Ferrari et al., 2011). In aphids BSS are known for their ability to confer resistance to their host against biotic (natural enemies) and abiotic (temperature) stresses (Montllor et al., 2002; Scarborough et al., 2005, Oliver et al., 2010, Himler et al., 2011, Lukasik et al., 2013). Host plant specialization and aphid body colour may also be affected by BSS (Tsuchida et al., 2004 and 2010). In case of conferring partial resistance to parasitoid species, BSS may also reduce the growth of parasitoid larvae developing in the parasitized host and prolong the larval developmental time (Nyabuga et al., 2010, Schmid et al., 2012) which may reduce parasitoid survival success. BSS are typically vertically transmitted from the mother to the offspring by manipulating the host reproduction system (Chiel et al., 2009) but inter- and intra-specific horizontal transmissions of BSS may occur at low rates (Moran et al., 2006, Chiel et al., 2009, Jaenike et al., 2007, Gehrer \& Vorburger 2012). BSS can thus be regarded important evolutionary partners of their insect hosts (Feldhaar, H. 2011, Ferrari and Vavre 2011) through their journey of evolution.

The English grain aphid Sitobion avenae (F.) is a potential pest of cereal crops all over the word but especially in temperate climate (Leather1993, Alkhedir et al., 2010). It can establish and multiply tremendously in short time. It can cause direct and indirect damage to the crop (Blackman and Eastop, 2000). As a result, S. avenae causes significant yield losses in wheat crop (George and Gair, 1979; Xu et al., 1998). About 5\% of wheat crop is chemically treated in European regions to avoid such loses (European Agricultural Statists 2007). Conventional breeding for resistant cultivars is another tool to cope with wheat aphids (Stoger et al., 1999).

Sitobion avenae is recently reported for two Bacterial Secondary Symbionts "BSS" Hamiltonella defensa and Regiella insecticola (Lukasik et al., 2011). 
Parasitoid-host interactions play a pivotal role in trophic levels by exploiting and regulating a wide range of insect communities (Godfray 1994). In addition to parasitisation, the adults of many hymenopteran parasitoid species also use their insect host for host feeding (Heimpel and Collier, 1996, Ueno \& Ueno 2007) which causes considerable additional host mortality (Byeon et al., 2010, Enkegaard et al., 2013). Host feeding by parasitoids enhances their longevity and fecundity (Giron et al., 2004, Rivero and West 2005, Ueno and Ueno, 2007). Non-reproductive host killing by many parasitoid species may also be considered to improve the efficiency of biological control agent (Byeon et al., 2009) in IPM. Feeding and killing by parasitoids is positively correlated with host densities but host killing proportion is oppositely linked with it (Kidd and Jervis, 1989). So, host densities are important factor for parasitoid behaviour to use the available resources efficiently. Parasitoids are not only able to detect the BSS infection status of their host aphids (Oliver et al., 2012) but also they behave differently towards clonal or genetic variations among their target host populations of aphids (Ferrari et al., 2001, Li. et al., 2002, Von Burg et al., 2008, Vorburger et al., 2009).

Aphelinus abdominalis (Dalman) (Hymenoptera; Aphelinidae) is a good biological control agent against many aphid species and also possess host killing behaviour (Schelt 1994, Enkegaard et al., 2013).

The impact of BSS in aphid-parasitoid-interactions has been investigated in detail in pea aphids and to some extent in bean aphids in relation to Aphidius species (Oliver et al., 2003, Nyabuga et al., 2010, Vorburger et al., 2010). Most of the researchers focused on parasitism behaviour of parasitoids towards BSS. To the best of our knowledge we are not aware of papers dealing with the host feeding behaviour of parasitoids with regard to the BSS constitution of the aphid hosts and genetic variations in aphids at variable aphid densities. Sitobion avenae (F.) and Aphelinus abdominalis (Dalman) are not well reported in this regard. To fill this literature gap, we designed a study involving Sitobion avenae, its BSS (Hamiltonella defensa, and Regiella insecticola) and Aphelinus abdominalis interactions. Our study system was consisted of four genetically identical wheat aphid clones possessing different BSS. The antibiotics were applied to these aphid clones through micro injections to cure the BSS from these aphid clones to obtain genetically identical clones without BSS rather than haemolymph transfer to avoid any genetically mixing. The previous studies showed only clonal variations to parasitism without BSS. We also used genetically different clones without BSS and also with different BSS to confirm the clonal resistance against host feeding. Genetically identical aphid clones with and without BSS were more helpful to study 
the host preference behaviour of Aphelinus abdominalis feeding. We disentangle the role of BSS and the genetic background with regard to the behaviour of Aphelinus abdominalis.

We addressed the following issues:

- Do BSSs impart resistance to Sitobion avenae against Aphelinus abdominalis host feeding? (No Choice Experiment)

- Does Aphelinus abdominalis show host preference for feeding on aphids with and without BSSs? (Choice Experiment)

- Is host feeding behaviour of Aphelinus abdominalis affected by BSS and host population density interactions?

- Do BSSs affect the development of Aphelinus abdominalis in Sitobion avenae?

- Is Aphelinus abdominalis involved in horizontal transmission of BSS in Sitobion avenae?

\section{Materials and methods}

\section{Insect cultures}

Sitobion avenae: Two clones (in the following named 5 and 7) of Sitobion avenae were used in this study, which were established from single asexual female aphids, collected in Giessen (Germany) from wheat plants (Alkhedir et al., 2010). The two clones have a different genotypic background and harbour either Hamiltonella defensa in clone 5 or Regiella insecticola in clone 7 as bacterial secondary symbionts (BSS) (Alkhedir et al., 2013), respectively. These clones were continuously reared on the wheat plants, cultivar "Dekan" (KWS GmbH. Germany). The wheat plants were grown in $11 \mathrm{~cm}$ diameter plastic pots containing a 2:1 mixture of soil and sand. The pots were covered with transparent ventilated plastic cylinders, which were $10 \mathrm{~cm}$ wide and $30 \mathrm{~cm}$ high. Aphids were transferred to newly grown wheat plants at 15 days interval., The aphid cultures were kept at $20 \pm 1{ }^{\circ} \mathrm{C}$ and $70 \pm 10 \%$ RH with a 16:8 (L:D) hour light period in climatic chambers (WB 750 KFL; Mytron Bio-Und Solartechnik GmbH. Germany). The wheat plants were irrigated on alternate days. The wheat aphid clones reproduced parthenogenetically provided these conditions.

Aphelinus abdominalis: The parasitoid species Aphelinus abdominalis, used in this study, were obtained from re-natur GmBH. Germany. The parasitoids were provided with 50\% honey solution on arrival and the female parasitoids were used for experiments next day. 


\section{Elimination of BSS by antibiotic}

Hamiltonella defensa harboured by the wheat aphid clone 5 was selectively eliminated by using an antibiotic treatment. A mixture of ampicillin, cefotaxime and gentamycin, each at a dose of $250 \mathrm{mg} / \mathrm{ml}$, was applied through micro-injection using fine glass needles (Simon et al., 2011). The antibiotic solutions were injected at the rate of $0.1-0.2 \mu 1 / \mathrm{mg}$ of body weight of the aphid specimens. For the removal of Regiella insecticola from clone 7, ampicillin was injected to the aphids in the same way at the rate of $1 \mu \mathrm{g} / \mathrm{mg}$ of the body weight of aphid specimens (Koga et al., 2003). $\mathrm{CO}_{2}$ anaesthetized wheat aphids of the second nymphal stage were used for this treatment. These antibiotic treated wheat aphids were transferred to wheat plants individually and allowed to reproduce for 48 hours. The newly produced nymphs were defined as G1. From the G1, five nymphs were randomly chosen from each of the injected wheat aphid clones and reared on the wheat plants until they became adult and produced a sufficient number of G2 offspring. The G1 mothers were then subjected to diagnostic PCR for their BSS infection status. The G2 nymphs from BSS negative G1 mothers were chosen for further rearing only. The wheat aphids were subjected to diagnostic PCR to confirm the elimination of BSS until G8 (Koga et al., 2007) being further used in our experiments. These treatments resulted in four genetically identical wheat aphid clones either harbouring $H$. defensa (referred to as +5 in the following), or devoid of this BSS (referred to as -5 in the following) and aphid clones harbouring $R$. insecticola (referred to as +7 in the following), or devoid of this BSS (referred to as -7 in the following).

\section{Diagnostic PCR for BSS infections}

DNA from the four aphid clones was extracted following the CTAB protocol of Chen et al., (2010). The presence of Hamiltonella defensa and Regiella insecticola in the clones was determined using a diagnostic PCR with specific primers for amplifying the 16S rDNA gene fragments: HDFn [5-ATGAAGTCGCGAGACCAAA-3], HDRn [5GCTTTCCCTCGCAGGTTC-3], RIFn [5-GAAGGCGGTAAGAGTAATATGC-3], and RIRn [5-CCCCGAAGGTTAAGCTACCTA-3] respectively. PCR conditions were: $94^{\circ} \mathrm{C}$ for $3 \mathrm{~min}$ followed by 30 cycles of $94^{\circ} \mathrm{C}-30 \mathrm{~S} ; 60^{\circ} \mathrm{C}-40 \mathrm{~S} ; 72^{\circ} \mathrm{C}-90 \mathrm{~S}$ and final incubation at $72^{\circ} \mathrm{C}$ for 8 minutes. Reactions were carried in a $25 \mu \mathrm{l}$ volume with one $\mu 1$ of the DNA template containing $0.32 \mu \mathrm{M}$ of each primer, $2 \mathrm{mM} \mathrm{MgCl}$, $200 \mu \mathrm{M}$ dNTP's, $1 \mathrm{x}$ "Bioline" buffer and 0.25 units of Taq DNA polymerase. PCR products were visualized on $1.7 \%$ 
agarose gel using Ethidium bromide. To verify the identity of the PCR products, DNA from PCR products was purified from the gel after visualization and sent for direct sequencing to LGC Genomics GmbH, Germany. The resulting sequences were compared to known sequences using the BLAST algorithm in NCBI for confirmations of BSS.

\section{Experiments}

\section{Host feeding behaviour of $A$. abdominalis in response to BSS (No Choice Tests)}

Second and third instar nymphs of $S$. avenae clone $+5,-5,+7$, and -7 , respectively, were exposed to A. abdominalis females at the rate of $6,12,18,24$ and 30 wheat aphid nymphs for 24 hours in separate $90 \mathrm{~mm}$ Petri dishes. The Petri dishes were provided with filter papers and washed rooted wheat seedlings covered with wet cotton. The experimental conditions were $20 \pm 1{ }^{\circ} \mathrm{C}$ and $70 \pm 10 \% \mathrm{RH}$ with 16:8 hour light and dark period. The experiments were replicated 16 times for each treatment with 16 controls without A. abdominalis female parasitoids. The A. abdominalis females were removed after 24 hours and used for DNA extraction. The dead aphids were counted after 24 and 48 hours. Aphids still alive were allowed to feed on the wheat seedlings until mummifying. Hatching A. abdominalis were used for hind tibia length measurement and DNA extraction. Replicates in which the introduced parasitoids escaped or died were discarded from the analyses, and these treatments were set-up again for data collection and analyses.

\section{Host preference behaviour of $A$. abdominalis in response to BSS (Choice Tests)}

Second and third instar nymphs of $S$. avenae clones $+5,-5,+7$, and -7 , respectively, were exposed to A. abdominalis females at the rate of 6, 12, 18, 24 and 30 nymphs for 24 hours in $90 \mathrm{~mm}$ Petri dishes in the same petri dish at 50:50 ratio. To differentiate between the BSS positive and negative wheat aphids, the hind tarsi of one leg of one of the clones were cut under a magnifying glass with sterilized blades. This was performed with BSS positive aphids in half replications and with BSS negative aphids in the other half replications. The Petri dishes were provided with filter papers and wash rooted wheat seedlings covered with wet cotton. The experimental conditions were $20 \pm 1{ }^{\circ} \mathrm{C}$ and $70 \pm 10 \% \mathrm{RH}$ with $16: 8$ hour light and dark period. For this experiment we used 16 replications for each treatment with 16 controls without $A$. abdominalis females. The A. abdominalis females were removed after 24 hour and the dead aphids were counted after 24 and 48 hours. 
Host preference behaviour of A. abdominalis in response to clonal variation (Choice Tests)

Second and third instar nymphs of $S$. avenae clones either +5 and +7 or -5 and -7 were exposed to A. abdominalis females at the rate of 6, 12, 18, 24 and 30 nymphs for 24 hours in $90 \mathrm{~mm}$ Petri dishes combined at a ratio of 50:50. To differentiate between the aphids of clones +5 and +7 , and -5 and -7 the tarsi of one hind leg of one of the clones were cut under a magnifying glass. This was performed with +5 clone aphids in half replications and with +7 clone aphids in the other half replications. The same method was used when using the BSS negative clones in the choice tests. Data collection was similar to the previous experiments.

\section{Effect of BSS on A. abdominalis development:}

To determine the impact of BSS on the larval development of A. abdominalis reared in wheat aphids with and without BSS, the length of hind tibia of each emerged offspring of $A$. abdominalis from mummified wheat aphids was measured in $\mu \mathrm{m}$ as a proxy for their total body size (Godfray 1994).The individuals from the no choice tests were used for measurement under a magnifying binocular (Stemi 2000-C, Carl Zeiss, Germany) with a predefined scale. These data were measured for at least $30 \mathrm{~A}$. abdominalis individuals per mummified aphids of clones $+5,-5,+7$, and -7 , respectively.

\section{Transmission of BSS via A. abdominalis:}

To check, whether the BSSs are transmitted vertically to the parasitoids hatching from BSSharbouring aphids, total DNA was extracted by using the CTAB method from the $A$. abdominalis females recovered from the no choice experimental set up after 24 hours. The extracted DNA was used in a diagnostic PCR with the same protocol as it was used for wheat aphids to confirm BSS infection in A. abdominalis. The same procedure was also repeated for A. abdominalis specimens who emerged from aphid mummies in the no choice tests for BSS detection. The DNA was extracted from 30 A. abdominalis individuals collected from mummified wheat aphids of clones $+5,-5,+7$, and -7 , respectively. 48 A. abdominalis individuals, removed from no choice tests of wheat aphid clones $+5,-5,+7$, and -7 , respectively, after 24 hours, were used for DNA extraction.

\section{Data analyses:}

In no choice and choice experiments, the data of wheat aphids' mortality by A. abdominalis parasitoid host feeding was analysed using the factorial ANOVA (Statistix version 8.1 
software) with the independent factors of host density and BSS. Differences among the means related to wheat aphid killing were compared with Fisher's Least Significant Difference (LSD) test at the significance level $\mathrm{p}=0.05$. Data were square-root transformed $[\mathrm{SQRT}(\mathrm{x}+0.5)]$, because host mortality in the controls compared to treatments did not meet the assumption of normal distribution. The graphs show the non-transformed data values (mean $\pm \mathrm{SE}$ ) of aphids killed in the respective experiments.

For the determination of host preference behaviour of $A$. abdominalis host killing towards wheat aphids with and without BSS, percent mortality data were corrected by Abbott's formula (Abbott 1925) prior to the analyses. The difference of corrected mortality percentage $($ mean \pm SE) in aphids without and with BSS was used as an indicator of host preference in double choice test.

Formula $=$ Corrected $\%$ mortality in aphids without BSS - Corrected $\%$ mortality in aphids harbouring BSS

The differences of corrected mortality percentage (mean $\pm \mathrm{SE}$ ) of choice and no choice tests were compared with a paired t-test (Statistix version 8.1 software) at the $5 \%$ significance level for each of the aphids population densities individually.

To determine the impact of BSS-harbouring aphid specimens on A. abdominalis adult fitness, the differences among the means of hind tibia length of A. abdominalis emerged from wheat aphids with and without BSS were compared with a paired t-test (Statistix version 8.1 software) at the $5 \%$ significance level.

\section{Results}

\section{Host feeding behaviour of $A$. abdominalis in response to BSS (No Choice Tests)}

No choice tests data, using clone 5 harbouring Hamiltonella defensa and clone 7 harbouring Regiella insecticola, show that BSS imparted resistance to $S$. avenae against host killing of $A$. abdominalis as compared to aphids without BSS (Fig. 1a \& 1b). The negative impact of BSS on host killing of $A$. abdominalis was consistent at all aphid densities exposed to the parasitoid. Aphids killed by A. abdominalis host feeding varied significantly $(\mathrm{p}<0.005)$ when 6 to 18 aphids were offered per test. However, at higher aphid densities the aphid mortalities varied non-significantly when 18,24 and 30 aphids were offered irrespective of BSS 
presence or absence in wheat aphids. A. abdominalis host killing response towards different host densities was similar in both of the no choice tests. The lowest host killing was 1.25 and 2.12 aphids in clone 5 and 1.31 and 2.18 aphids in clone 7 respectively when 6 aphids with and without BSS were exposed to A. abdominalis. 7.31and 10.31 aphids in clone 5 and 7.12 and 10.37 aphids in clone 7 were killed when 30 aphids with and without BSS were offered to A. abdominalis respectively. The aphid mortality in controls was zero at 6,12 and 18 aphids per test in both of the no choice tests. 0.125 and 0.25 aphids were dead at 24 aphids and 0.375 and 0.5 aphids were dead at 30 aphids per test in clone 5 while in clone $7,0.25$ aphids were dead at 24 aphids and 0.25 and 0.375 aphids were dead at 30 aphids in controls with and without BSS respectively. A. abdominalis host feeding capacity is positively correlated with host densities up to a plateau where it remains constant even more hosts are available for feeding and killing. These results also show that there is no possible effect of interaction between BSS and host densities on host killing behaviour of A. abdominalis in our no choice tests.

\section{Host preference behaviour of $A$. abdominalis in response to BSS (Choice Tests)}

The choice tests for clone 5 harbouring Hamiltonella defensa and clone 7 harbouring Regiella insecticola showed that BSS changed the aphid killing patterns by A. abdominalis as compared to no choice tests. The aphid mortalities increased significantly $(\mathrm{p}<0.005)$ in aphids without BSS (Fig. 2a \& 2b) and reduced in aphids harbouring BSS (Table 1). The differences of corrected $\%$ mortalities in choice tests were more than twofold $(p<0.005)$ of the differences of corrected $\%$ mortalities in no choice test at all the aphid densities for all of the wheat aphid clones (Table 1). The differences of corrected \% mortalities were $14.58 \%$, $17.7 \%, 15.99 \%, 15.94$ and $9.84 \%$ in no choice test as compared to $41.67 \%, 33.33 \%, 30.56 \%$, $25.85 \%$ and $18.69 \%$ in choice test at $6,12,18,24$ and 30 aphids in clone +5 and -5 . The results were also similar for the clone +7 and -7 . The higher difference of corrected $\%$ mortality by A. abdominalis host killing in choice test indicates host preference for wheat aphids without BSS when A. abdominalis has to choose between wheat aphids with and without BSS. A. abdominalis host killing increased significantly $(\mathrm{p}<0.005)$ with increase in aphid numbers offered from 6 to 30 aphids irrespective of BSS (Fig. 2a \& 2b). Host killing and aphid densities are positively correlated. The lowest host killing was observed at 6 aphids and the highest host killing was seen at 30 aphids per test with and without BSS respectively. 
The aphid mortality in controls was zero at 6,12 and 18 aphids but 0.125 aphids were dead at 24 aphids and 0.25 aphids were dead at 30 aphids in clone 5 while in clone 7, 0 and 0.125 aphids were dead at 24 aphids and 0.125 and 0.25 aphids were dead at 30 aphids in controls with and without BSS respectively. These results also show that there is no possible effect of interaction between BSS and host densities on host killing behaviour of $A$. abdominalis in our choice tests.

\section{Host preference behaviour of $A$. abdominalis in response to clonal variation (Choice Tests)}

We further studied the effect of genetic or clonal variation on host killing behaviour of $A$. abdominalis in another choice test. We offered wheat aphids from clone 5 and 7 together with different genetic background (Alkhedir et al., 2013). One test was performed with aphids from clone +5 and +7 and the other test with aphids from clones -5 and -7 . The result showed that genetic or clonal variation also playing its role in the host killing behaviour of $A$. abdominalis. The aphids of clone 5 were significantly less fed and killed $(\mathrm{p}<0.005)$ by $A$. abdominalis host killing as compared to clone 7 irrespective of their BSS but this mortality was not significantly different when 6 aphids were offered for feeding (Fig. 3a \& 3b). The aphids from clone -5 were also significantly less fed by $A$. abdominalis as compared to aphids of clone -7in the other choice test (Fig. 3a and 3b). A. abdominalis showed the same host killing behaviour towards different aphid densities irrespective of BSS (Fig. 3a \& 3b) as it was observed in no choice tests. Host killing is positively correlated with aphid densities up to 18 aphids offered and then it becomes constant. The lowest host killing was observed at 6 aphids offered and the highest host killing was seen at 30 aphids with and without BSS respectively (Fig. 3a and 3b). The aphid mortality in controls was zero at 6,12 and 18 aphids in both of the choice tests. 0 and 0.125 aphids were dead at 24 aphids and 0.25 and 0.125 aphids were dead at 30 aphids in clone 5 and 7 respectively. In the other test 0.125 aphids were dead when 24 aphids offered, in clone -5 and -7 , respectively and 0.125 and 0.375 aphids were dead at 30 aphids in controls of -5 and -7 , respectively. The clonal resistance of clone 5 and -5 against host feeding was consistent at all the aphid densities offered to $A$. abdominalis for feeding irrespective of the BSS presence. 


\section{Effect of BSS on A. abdominalis development}

The hind tibia length measurements show that BSSs stressed the development of $A$. abdominalis in mummified wheat aphids among parasitized aphids and have significantly negative impact $(\mathrm{p}<0.005)$ on larval growth of $A$. abdominalis (Fig. 4). The hind tibiae of $A$. abdominalis were shorter when they reared in clone +5 and +7 as compared to clone -5 and 7 , respectively. The highest hind tibia length was $369.92 \mu \mathrm{m}$ in clone -7 verses $352.64 \mu \mathrm{m}$ in clone +7 while these lengths were $367.36 \mu \mathrm{m}$ and $353.28 \mu \mathrm{m}$ in clone -5 and 5 , respectively. A. abdominalis larval growth was higher in the wheat aphids without BSS as compared to aphid hosts harbouring BSSs.

\section{Transmission of BSS via A. abdominalis}

Diagnostic PCR for DNA extractions from A. abdominalis, removed from no choice tests after 24 hours, did not show any positive indication of BSS infection from wheat aphids. DNA extractions from A. abdominalis emerged from mummies of aphid clones $+5,-5,+7$, and -7 , respectively, were also subjected to diagnostic PCR. The result was not different from the previous PCR result. It is obvious from our PCR results that A. abdominalis is not playing any role in horizontal transmission of BSS in S. avenae and A. abdominalis, emerged from aphids harbouring BSS, are also not infected by BSS.

\section{Discussion}

\section{Host feeding behaviour of $A$. abdominalis in response to BSS}

Aphids may possess certain bacterial secondary symbionts (BSS) and need to prove a positive contribution for the survival of their hosts for their own persistence and spread among the insect host community. Many BSS have been described for their ability to provide protection to their host insects against natural enemies i.e. parasitoids and pathogens (Oliver et al., 2003\&2005, Scarborough et al., 2005, Vorburger et al., 2009 \& 2010, Lukasik et al., 2013, Hansen et al., 2012 and Schmid et al., 2012). Łukasik et al., reported first time Hamiltonella defensa imparted parasitoid resistance to wheat aphids in 2013. There should be more functional responses of these BSS in insect hosts for their existence and utilizing hosts' living system for their own benefits. Until now, all the studies told us about parasitism resistance of BSS in pea, wheat and bean aphids. BSS resistance against parasitoids host 
feeding is not reported in literature to the best of our knowledge which is an important factor in biological control of aphids. Our results revealed that the resistant ability of BSS to benefit their host aphids against their natural enemies with regard to host feeding is also significant to increase the host survival at all aphid densities offered for feeding. As we could not find a single study about host feeding resistance of BSS, so, we can speculate that BSS imparted significant resistance to wheat aphids because there was no or negligible mortality in wheat aphids in control treatments. Another assumption might be possible that bacterial symbionts have helped to recover from host feeding injuries and hence increased their host survival. It is concluded that these bacterial symbionts proved another reason for their wide spread existence and spread in their insect hosts. This is also important because BSS may become a problem for biological control of pest aphids with the time if they provide resistance against all kinds of parasitoid and predator utility.

\section{Host feeding behaviour of $A$. abdominalis in response to host densities}

Parasitoids respond positively towards host densities for parasitisation and host feeding or killing (Fathipour et al., 2006, Zamani et al., 2006, Zang et al., 2011, Hanan et al., 2012, Tazerouni et al., 2012, Yang et al., 2012). These researchers showed positive correlation for host feeding and parasitism of different parasitoids and host densities of different aphid and whitefly species. Our data for A. abdominalis host feeding at different wheat aphid densities also showed the similar trend. Host mortalities were increased with increasing number of wheat aphids provided for feeding and killing. The host mortalities were not increased significantly at higher densities of wheat aphids as compared to lower aphid densities (Fig. 1a, 1b, 2a \& 2b). This trend was also favoured by the previous studies mentioned above. These trends were clearly visible in both of wheat aphid clones 5 and 7 with and without BSS but there were always significantly fewer hosts killed in wheat aphids harbouring BSS as compared to wheat aphids without BSS $(\mathrm{p}<0.005)$. The host density dependence maight be affected by the searching time and feeding capacity of the parasitoids. We could not find any study on host feeding behaviour with regard to BSS in insect hosts. We did not see any possible effect of BSS and host densities interactions on host feeding behaviour of $A$. abdominalis. The increasing host feeding trend was same at all the host densities with and without BSS and was always lower in aphid clones without BSS. 


\section{Host preference behaviour of $A$. abdominalis in response to BSS}

BSS modified the host preference behaviour of A. abdominalis host feeding towards wheat aphids. This is not reported before in any study. The only study we could find was done by Cheng et al., in 2011 with regard to primary symbiotic bacteria Buchnera aphidicola. He showed that Aphis fabae having Buchnera aphidicola were preferred by parasitoids. So, parasitoids can detect the infection status and decide their actions accordingly (Oliver et al., 2012). In our choice tests, we have seen that A. abdominalis preferred wheat aphids without BSS over wheat aphids with BSS when came in touch with both types of wheat aphids. As wheat aphid clones are genetically identical but they are with and without BSS. We can say that BSS are quite able to modify the host preference behaviour of A. abdominalis host feeding.

\section{Host preference behaviour of $A$. abdominalis in response to clonal variation}

Genetic variations are innate source of host defenses. Wheat aphid clones +5 and -5 were more resistant against host feeding by $A$. abdominalis as compared to clones +7 and -7 with and without BSS in both of the choice tests. This variation in host feeding behaviour is associated with genetic variations of these aphid clones. Li. et al., studied clonal resistance of pea aphid against Aphidius ervi in 2002 and showed that aphid clones can also resist against parasitoids. Clonal variations are able to influence defense phenomenon of Myzus persicae against Aphidius colemani and Diaeretiella rapae (Von Burg et al., 2008). Similarly, clonal resistance in 34 pea aphid clones against two parasitoids and one fungal pathogen were due to genetic variations (Ferrari et al., 2001). Genetic variations among 15 bean aphids clones were a defense source for another parasitoid (Vorburger et al., 2009). They addressed that parasitoids exhibited clear variation for their resistance against parasitoids. So, it is predicted that the genetic variations can also modify the host feeding ability of parasitoids through behavioral or physiological defenses.

\section{Effect of BSS on A. abdominalis development}

BSS reduce the growth of developing larvae of parasitoids in the infected aphids. Nyabuga et al., 2010 studied the impact of Hamiltonella defensa and Regiella insecticola on the growth of Aphidius ervi in terms of their body mass. According to their results the BSS significantly reduce the mass of parasitoids together as compared to individually. Schmid et al., also 
reported in 2012 the similar negative effect of Hamiltonella defensa on the development of parasitoid in bean aphids. We evaluated the impact of BSS on larval development in wheat aphids in terms of hind tibia length measurement. Our data suggested that although parasitoids can survive in the presence of BSS but their fitness may reduce greatly. We have seen that the length of hind tibia was significantly decreased in aphids harbouring BSS as compared to wheat aphids free of BSS. It indicates that BSS can partially impart negative impact on parasitoid when they cannot resist them fully.

\section{Transmission of BSS via A. abdominalis:}

Vertical transmission of BSS is the thumb rule in insect host by manipulating the host reproduction system but horizontal transmission is also reported even at very low rate and rarely (Chielet al., 2009, Jaenike et al., 2007, Gehrer and Vorburger 2012). Sometimes closely related BSS strains may occur in distant relative of the insect hosts (Russell et al., 2003) which may be due to horizontal transmission of BSS. The potential routes for horizontal transmission of BSS in aphids can be Sexual transfer (Moran and Dunbar 2006), Transfer by parasitoids (Gehrer and Vorburger 2012) and Ingestion (Darby and Douglas 2003). Parasitoids cannot acquire BSS easily by host feeding or developing in the infected aphis hosts (Chiel et al., 2009). This was also confirmed by our results of diagnostic PCR for parasitoids DNA extracted from A. abdominalis removed from experimental arena after 24 hours of exposure with BSS infected wheat aphids. The result was also same in case of $A$. abdominalis emerged from BSS infected wheat aphids hosts. This suggests that the parasitoids are not very common route of horizontal transmission of BSS among the insect communities because it would have a negative effect on their own survival and fitness.

\section{Acknowledgements}

We are thankful to Zaheer Abbas and Ruth Pilot for their help during these experiments. Sajjad Ali is thankful to Higher Education Commission (HEC), Pakistan for providing funding for stay in Germany during these experiments. 


\section{References}

Abbott, W.S. (1925) A method of computing the effectiveness of an insecticide. Journal of Economic Entomology, 18, 265-267.

Alkhedir, H., Karlovsky, P., \& Vidal, S. (2010) Effect of light intensity on colour morph formation and performance of the grain aphid Sitobion avenae F. (Homoptera: Aphididae). Journal of Insect Physiology, 56, 1999-2005.

Alkhedir, H., Karlovsky, P., \& Vidal, S. (2013) Relationship between Water Soluble Carbohydrate Content, Aphid Endosymbionts and Clonal Performance of Sitobion avenae on Cocksfoot Cultivars. PLoS ONE, 8(1), e54327. doi:10.1371/journal.,pone.0054327.

Analytical Software. (2003) Statistix 8.1. Tallahassee, FL: Analytical Software.

Baumann, P. (2005) Biology of bacteriocyte-associated endosymbionts of plant sap sucking insects. Annual Review of Microbiology, 59, 55-89.

Blackman, R.L. \& Eastop, V.F. (2000) Aphids on the World's Crops: An Identification and Information Guide, 2nd edn. John Wiley and Sons, Chichester. U.K.

Byeon, Y. W., Tuda, M., akagi, M., Kim, J. H. \& Kim, Y. H. (2009) Non-reproductive host killing caused by Aphelinus asychis (Hymenoptera: Aphelinidae), a parasitoid of cotton aphid, Aphis gossypii (Homoptera: Aphididae). Journal- Faculty of Agriculture Kyushu University, 54, 369-372.

Byeon, Y.W., Tuda, M., Kim, J.H. \& Choi, M.Y. (2010) Functional responses of aphid parasitoids, Aphidius Colemani (Hymenoptera: Braconidae) and Aphelinus asychis (Hymenoptera: Aphelinidae). Biocontrol, Science and Technology, 21(1), 57-70.

Chen, H., Rangasamy, M., Tan, S.Y., Wang, H. \& Siegfried, B.D. (2010) Evaluation of Five Methods for Total DNA Extraction from Western Corn Rootworm Beetles. PLoS ONE, 5(8), e11963. doi:10.1371/journal.,pone.0011963.

Cheng, R.X., Meng, L., Mills, N.J. \& Li, B. (2011) Host preference between symbiotic and aposymbiotic Aphis fabae, by the aphid parasitoid, Lysiphlebus ambiguus. Journal of Insect Science, 11, 81.doi:10.1673/031.011.8101. 
Chiel, E., Zchori-Fein, E., Inbar, M., Gottlieb, Y., Adachi-Hagimori, T., Kelly, S. E., Asplen, M. K. \& Hunter, M. S. (2009) Almost There: Transmission Routes of Bacterial Symbionts between Trophic Levels. PLoS ONE, 4(3), e4767. doi:10.1371/journal.,pone.0004767.

Darby, A.C. and Douglas, A.E. (2003) Elucidation of the transmission patterns of an insectborne bacterium. Applied and Environmental Microbiology, 69, 4403-4407.

Douglas, A.E. 1998. Nutritional interactions in insect-microbial symbioses: aphids and their symbiotic bacteria Buchnera. Annual Review Entomology, 43, 17-37.

Dow, J.A.T. (1986) Insect midgut function. Advances in Insect Physiology, 19, 187-328.

Enkegaard, A., Sigsgaard, L. \& Kristensen, K. (2013) Shallot Aphids, Myzus ascalonicus, in Strawberry: Biocontrol Potential of Three Predators and Three Parasitoids. Journal of Insect Science, 13, 83.

EUROPEAN AGRICULTURAL STATISTICS. (2007) The use of pesticides in Europe. http://ec.europa.eu/agriculture/agrista/2004/table_en/index.htm, status: November 2007.

Feldhaar, H. (2011) Bacterial symbionts as mediators of ecologically important traits of insect hosts. Ecological Entomology, 36, 533-543.

Ferrari, J., Müller, C. B., Kraaijeveld, A. R. \& Godfray, H. C. J. (2001)Clonal variation and covariation in aphid resistance to parasitoids and a pathogen. Evolution, 55, 1805-1814.

Ferrari, J. \&Vavre, F. (2011) Bacterial symbionts in insects or the story of communities affecting communities. Philosophical Transactions of the Royal Society B, 366, 1389-1400.

Gehrer, L. \& Vorburger, C. (2012) Parasitoids as vectors of facultative bacterial endosymbionts in aphids. Biology letters, 8, 613-615.

George, K. \& Gair, R. (1979) Crop loss assessment on winter wheat attacked by the grain aphid, Sitobion avenae (F.), 1974-77. Plant Pathology, 28(3), 143-149.

Giron, D., Pincebourde, S. \& Casas, J. (2004) Lifetime gains of host-feeding in a synovigenic parasitic wasp. Physiological Entomology, 29, 436-442.

Godfray, H.C.J. (1994) Parasitoids, Behavioural and Evolutionary Ecology. Princeton University Press, Princeton, New Jersey.

Hansen, A.K., Vorburger, C. and Moran, N.A. (2012) Genomic basis of endosymbiontconferred protection against an insect parasitoid. Genome Research, 22, 106-114. 
Heimpel, G.E. \& Collier, T.R. (1996) The evolution of host-feeding behaviour in insect parasitoids. Biological Reviews, 71, 373-400.

Himler, A.G., Adachi-Hagimori, T., Bergen, J.E., Kozuch, A., Kelly, S.E., Tabashnik, B.E., Chiel, E., Duckworth, V.E., Dennehy, T.J., Zchori-Fein, E. \&Hunter, M.S. (2011) Rapid spread of a bacterial symbiont in an invasive whitefly is driven by fitness benefits and female bias. Science, 332, 254-256.

Holling, C.S. (1959) Some characteristics of simple types of predation and parasitism. Canadian Entomologist, 91, 385-398.

Jaenike, J., Polak, M., Fiskin, A., Helou, M. \&Minhas, M. (2007) Interspecific transmission of endosymbiotic Spiroplasma by mites.Biology Letters, 3, 23-25.

Kidd, N.A.C. \& Jervis, M.A. (1989) The effects of host feeding behaviour on the dynamics of parasitoid-host interactions, and the implications for biological control. Researches in Population Ecology, 31, 235-274.

Koga, R., Tsuchida, T. \& Fukatsu, T. (2003) Changing partners in an obligate symbiosis: a facultative endosymbiont can compensate for loss of the essential endosymbiont Buchnera in an aphid. Proceedings of the Royal Society B, 270, 2543-2550.

Koga, R., Tsuchida, T., Sakurai, M. \& Fukatsu, T. (2007) Selective elimination of aphidendosymbionts: effectsof antibiotic dose and host genotype and fitness consequences. FEMS microbiology ecology, 60, 229-39.

Leather, S.R. (1993) Overwintering in six arable aphid pests: a review with particular relevance to pest management. Journal of Applied Entomology, 116, 217-233.

Li, S., Falabella, P., Giannantonio, S., Fanti, P., Battaglia, D., Digilio, M. C., Völk1, W., Sloggett, J. J., Weisser, W. \& Pennacchio, F. (2002) Pea aphid clonal resistance to the endophagous parasitoid Aphidius ervi. Journal of Insect Physiology, 48, 971-980.

Łukasik, P., Hancock, E.L., Ferrari, J. \&Godfray, H.C.J. (2011) Grain aphid clones vary in frost resistance, but this trait is not influenced by facultative endosymbionts. Ecological Entomology, 36, 790-793.

Łukasik, P., Dawid, M.A., Ferrari, J. and Godfray, H.C.J. (2013a) The diversity and fitness effects of infection with facultative endosymbionts in the grain aphid, Sitobion avenae. Oecologia, 173, 985-906. 
Łukasik, P., van Asch, M., Guo, H., Ferrari, J. \& Godfray, H.C.J. (2013b) Unrelated facultative endosymbionts protect aphids against a fungal pathogen. Ecology Letters, 16, 214218.

Moran, N.A. (2006) Symbiosis. Current Biology, 16, 866-871.

Moran, N.A., \& Dunbar, H.E. (2006) Sexual acquisition of beneficial symbionts in aphids. Proceedings of National Academy of Sciences, 103, 12803-12806.

Moran, N.A., McCutcheon, J.P. \& Nakabachi, A. (2008) Genomics and evolution of heritable bacterial symbionts. Annual Review of Genetics, 42,165-190.

Montllor, C.B., Maxmen, A. \& Purcell, A.H. (2002) Facultative bacterial endosymbionts benefit pea aphids Acyrthosiphonpisum under heat stress. Ecological Entomology, 27, 189195.

Murdoch, W. W. \& Briggs, C. J. 81996) Theory for biological control: recent developments. Ecology, 77, 2001-2003.

Nyabuga, F.N., Outreman, Y., Simon, J.C., Heckel, D.G. \& Weisser, W.W. (2010) Effects of pea aphid secondary endosymbionts on aphid resistance and development of the aphid parasitoid Aphidius ervi: a correlative study. Entomologia Experimentalis et Applicata, 136, $243-253$.

Oliver, K.M., Russell, J.A., Moran, N.A. and Hunter, M.S. (2003) Facultative bacterial symbionts in aphids confer resistance to parasitic wasps. Proceedings of the National Academy of Sciences of the United States of America, 100, 1803-1807.

Oliver, K.M., Moran, N.A. and Hunter, M.S. (2005) Variation in resistance to parasitism in aphids is due to symbionts not host genotype. Proceedings of the National Academy of Sciences of the United States of America, 102, 12795-12800.

Oliver, K.M., Degnan, P.H., Burke, G.R. \& Moran, N.A. (2010) Facultative symbionts in aphids and the horizontal transfer of ecologically important traits. Annual Review of Entomology, 55, 247-266.

Oliver, K.M., Noge, K., Huang, E.M., Campos, J.M., Becerra, J.X. \& Hunter, M.S. (2012) Parasitic wasp responses to symbiont-based defense in aphids. BMC Biology, 10, 11.

Rivero, A., and West, S. A. (2005) The costs and benefits of host feeding in parasitoids. Animal Behaviour, 69, 1293-1301. 
Russell, J.A., Latorre, A., Sabater-Münoz, B., Moya, A. and Moran, N.A. (2003) Sidestepping secondary symbionts: widespread horizontal transfer across and beyond the Aphidoidea. Molecular Ecology, 12, 1061-1075.

Scarborough, C.L., Ferrari, J. \&Godfray, H.C.J. (2005) Aphid protected from pathogen by endosymbiont. Science, 310, 1781-1781.

Schelt, J. (1994) The selection and utilisation of parasitoids for aphid control in glasshouses. Proceedings of Experimental and Applied Entomology, 5, 151-157.

Schmid, M., Sieber, R., Zimmermann, Y-S. \& Vorburger, C. (2012) Development, specificity and sublethal effects of symbiont conferred resistance to parasitoids in aphids. Functional Ecology, 26, 207-215.

Simon, J-C., Boutin, S., Tsuchida, T., Koga, R., Le Gallic, J-F., Frantz, A., Outreman, Y. \& Fukatsu, T. (2011) Facultative Symbiont Infections Affect Aphid Reproduction. PLoS ONE, 6(7), e21831. doi:10.1371/journal.,pone.0021831.

Stoger, E., Williams, S., Christou, P., Down, R.E., \& Gatehouse, J.A.(1999) Expression of the insecticidal lectin from snowdrop (Galanthus nivalis agglutinin; GNA) in transgenic wheat plants: effects on predation by the grain aphid Sitobion avenae. Molecular Breeding, 5, $65-73$.

Tsuchida T, Koga R, Fukatsu T (2004) Host plant specialization governed by facultative symbiont. Science, 303, 1989.

Tsuchida, T., Koga, R., Horikawa, M., Tsunoda, T., Maoka, T., Matsumoto, S., Simon, J. \& Fukatsu, T. (2010) Symbiotic bacterium modifies aphid body color.Science, 330, 1102-1104.

Ueno,T. \& Ueno, K. (2007) The effects of host-feeding on synovigenic egg development in an endoparasitic wasp, Itoplectis naranyae. Journal of Insect Science, 7, 46.

Von Burg, S., Ferrari, J., Muller, C.B. \& Vorburger, C. (2008) Genetic variation and covariation of susceptibility to parasitoids in the aphid Myzus persicae: no evidence for tradeoffs. Proceedings of Royal Society, London B, 275, 1089-1094.

Vorburger, C., Sandrock, C., Gouskov, A., Castaneda, L. E. \& Ferrari, J. (2009) Genotypic variation and the role of defensive endosymbionts in an all-parthenogenetic host-parasitoid interaction. Evolution, 63, 1439-1450. 
Vorburger, C., Gehrer, L. and Rodriguez, P. (2010) A strain of the bacterial symbiont Regiella insecticola protects aphids against parasitoids. Biology Letters, 6, 109-111.

Yang, N-W., Ji, L-L., Lövei, G.L. \& Wan, F-H. (2012) Shifting Preference between Oviposition vs. Host-Feeding under Changing Host Densities in Two Aphelinid Parasitoids. PLoS ONE, 7(7), e41189. doi:10.1371/journal.,pone.0041189.

Xu, L.M., Qi, F.M., Zhang, J.P., Zhang, J.Z., Cao, C.M., \& Chen, J.L. (1998) Initial measurement of wheat output loss due to Macrosiphum avenae. Inner Mongolia Agricultural Science Technology, 5, 27-28. Abbott, W.S. (1925) A method of computing the effectiveness of an insecticide. J. econ. Entomol, 18, 265-267.

Alkhedir, H., Karlovsky, P. \& Vidal, S. (2010) Effect of light intensity on colour morph formation and performance of the grain aphid Sitobion avenae F.(Homoptera: Aphididae). Journal of insect physiology, 56, 1999-2005.

Alkhedir, H., Karlovsky, P. \& Vidal, S. (2013) Relationship between water soluble carbohydrate content, aphid endosymbionts and clonal performance of Sitobion avenae on cocksfoot cultivars. PloS one, 8.

Baumann, P. (2005) Biology of bacteriocyte-associated endosymbionts of plant sap-sucking insects. Annu. Rev. Microbiol., 59, 155-189.

Blackman, R.L. \& Eastop, V.F. (2000) Aphids on the World's Crops. An Identification and Information Guide. John Wiley.

Von Burg, S., Ferrari, J., Müller, C.B. \& Vorburger, C. (2008) Genetic variation and covariation of susceptibility to parasitoids in the aphid Myzus persicae: no evidence for tradeoffs. Proceedings of the Royal Society B: Biological Sciences, 275, 1089-1094.

Byeon, Y.W., Tuda, M., Kim, J.H. \& Choi, M.Y. (2011) Functional responses of aphid parasitoids, Aphidius colemani (Hymenoptera: Braconidae) and Aphelinus asychis (Hymenoptera: Aphelinidae). Biocontrol Science and Technology, 21, 57-70.

Byeon, Y.W., Tuda, M., Takagi, M., Kim, J.H. \& Kim, Y.H. (2009) Non-reproductive host killing caused by Aphelinus asychis (Hymenoptera: Aphelinidae), a parasitoid of cotton aphid, Aphis gossypii (Homoptera: Aphididae). Journal of the Faculty of Agriculture, Kyushu University, 54, 369-372.

Chen, H., Rangasamy, M., Tan, S.Y., Wang, H. \& Siegfried, B.D. (2010) Evaluation of five methods for total DNA extraction from western corn rootworm beetles. PLoS one, 5, e11963. 
Cheng, R.-X., Meng, L., Mills, N.J. \& Li, B. (2011) Host preference between symbiotic and aposymbiotic Aphis fabae, by the aphid parasitoid, Lysiphlebus ambiguus. Journal of Insect Science, $11,81$.

Chiel, E., Zchori-Fein, E., Inbar, M., Gottlieb, Y., Adachi-Hagimori, T., Kelly, S.E., Asplen, M.K. \& Hunter, M.S. (2009) Almost there: transmission routes of bacterial symbionts between trophic levels. PLoS One, 4, e4767.

Darby, A.C. \& Douglas, A.E. (2003) Elucidation of the transmission patterns of an insectborne bacterium. Applied and Environmental Microbiology, 69, 4403-4407.

Douglas, A.E. (1998) Nutritional interactions in insect-microbial symbioses: aphids and their symbiotic bacteria Buchnera. Annual review of entomology, 43, 17-37.

Dow, J.A.T. (1986) Insect midgut function. Adv. Insect Physiol, 19, 187-328.

Enkegaard, A., Sigsgaard, L. \& Kristensen, K. (2013) Shallot aphids, Myzus ascalonicus, in strawberry: Biocontrol potential of three predators and three parasitoids. Journal of Insect Science, $13,83$.

Fathipour, Y., Hosseini, A., Talebi, A.A. \& Moharramipour, S. (2006) Functional response and mutual interference of Diaeretiella rapae (Hymenoptera: Aphidiidae) on Brevicoryne brassicae (Homoptera: Aphididae). Entomologica Fennica, 17, 90.

Feldhaar, H. (2011) Bacterial symbionts as mediators of ecologically important traits of insect hosts. Ecological Entomology, 36, 533-543.

Ferrari, J., Müller, C.B., Kraaijeveld, A.R. \& Godfray, H.C.J. (2001) Clonal variation and covariation in aphid resistance to parasitoids and a pathogen. Evolution, 55, 1805-1814.

Ferrari, J. \& Vavre, F. (2011) Bacterial symbionts in insects or the story of communities affecting communities. Philosophical Transactions of the Royal Society B: Biological Sciences, 366, 1389-1400.

Gehrer, L. \& Vorburger, C. (2012) Parasitoids as vectors of facultative bacterial endosymbionts in aphids. Biology letters, rsbl20120144.

George, K.S. \& Gair, R. (1979) Crop loss assessment on winter wheat attacked by the grain aphid, Sitobion avenae (F.), 1974-77. Plant Pathology, 28, 143-149.

Giron, D., Pincebourde, S. \& Casas, J. (2004) Lifetime gains of host-feeding in a synovigenic parasitic wasp. Physiological Entomology, 29, 436-442. 
Godfray, H.C.J. (1994) Parasitoids: Behavioral and Evolutionary Ecology. Princeton University Press.

Gündüz, E.A. \& Douglas, A.E. (2009) Symbiotic bacteria enable insect to use a nutritionally inadequate diet. Proceedings of the Royal Society of London B: Biological Sciences, 276, 987-991.

Hanan, A., He, X.Z. \& Wang, Q. (2012) Host feeding and oviposition strategy of Eretmocerus warrae (Aphelinidae: Hymenoptera) under different host densities. New Zealand Plant Protection, 65, 133-137.

Heimpel, G.E. \& Collier, T.R. (1996) The evolution of host-feeding behaviour in insect parasitoids. Biological Reviews, 71, 373-400.

Himler, A.G., Adachi-Hagimori, T., Bergen, J.E., Kozuch, A., Kelly, S.E., Tabashnik, B.E., Chiel, E., Duckworth, V.E., Dennehy, T.J. \& Zchori-Fein, E. (2011) Rapid spread of a bacterial symbiont in an invasive whitefly is driven by fitness benefits and female bias. Science, 332, 254-256.

Jaenike, J., Polak, M., Fiskin, A., Helou, M. \& Minhas, M. (2007) Interspecific transmission of endosymbiotic Spiroplasma by mites. Biology Letters, 3, 23-25.

Kidd, N.A.C. \& Jervis, M.A. (1989) The effects of host-feeding behaviour on the dynamics of parasitoid-host interactions, and the implications for biological control. Researches on population ecology, 31, 235-274.

Koga, R., Tsuchida, T. \& Fukatsu, T. (2003) Changing partners in an obligate symbiosis: a facultative endosymbiont can compensate for loss of the essential endosymbiont Buchnera in an aphid. Proceedings of the Royal Society of London B: Biological Sciences, 270, 25432550 .

Koga, R., Tsuchida, T., Sakurai, M. \& Fukatsu, T. (2007) Selective elimination of aphid endosymbionts: effects of antibiotic dose and host genotype, and fitness consequences. FEMS microbiology ecology, 60, 229-239.

Leather, S.R. (1993) Overwintering in six arable aphid pests: a review with particular relevance to pest management. Journal of Applied Entomology, 116, 217-233.

Li, S., Falabella, P., Giannantonio, S., Fanti, P., Battaglia, D., Digilio, M.C., Völk1, W., Sloggett, J.J., Weisser, W. \& Pennacchio, F. (2002) Pea aphid clonal resistance to the endophagous parasitoid Aphidius ervi. Journal of Insect Physiology, 48, 971-980. 
Łukasik, P., van Asch, M., Guo, H., Ferrari, J. \& Godfray, H.C.J. (2013a) Unrelated facultative endosymbionts protect aphids against a fungal pathogen. Ecology letters, 16, 214218.

Łukasik, P., Dawid, M.A., Ferrari, J. \& Godfray, H.C.J. (2013b) The diversity and fitness effects of infection with facultative endosymbionts in the grain aphid, Sitobion avenae. Oecologia, 173, 985-996.

Łukasik, P., Hancock, E.L., Ferrari, J. \& Godfray, H.C.J. (2011) Grain aphid clones vary in frost resistance, but this trait is not influenced by facultative endosymbionts. Ecological Entomology, 36, 790-793.

Montllor, C.B., Maxmen, A. \& Purcell, A.H. (2002) Facultative bacterial endosymbionts benefit pea aphids Acyrthosiphon pisum under heat stress. Ecological Entomology, 27, 189195.

Moran, N.A. (2006) Simbiosis. Biología actual, 16, 866-871.

Moran, N.A. \& Dunbar, H.E. (2006) Sexual acquisition of beneficial symbionts in aphids. Proceedings of the National Academy of Sciences, 103, 12803-12806.

Moran, N.A., McCutcheon, J.P. \& Nakabachi, A. (2008) Genomics and evolution of heritable bacterial symbionts. Annual review of genetics, 42, 165-190.

Nyabuga, F.N., Outreman, Y., Simon, J., Heckel, D.G. \& Weisser, W.W. (2010) Effects of pea aphid secondary endosymbionts on aphid resistance and development of the aphid parasitoid Aphidius ervi: a correlative study. Entomologia Experimentalis et Applicata, 136, 243-253.

Oliver, K.M., Degnan, P.H., Burke, G.R. \& Moran, N.A. (2010) Facultative symbionts in aphids and the horizontal transfer of ecologically important traits. Annual review of entomology, 55, 247-266.

Oliver, K.M., Noge, K., Huang, E.M., Campos, J.M., Becerra, J.X. \& Hunter, M.S. (2012) Parasitic wasp responses to symbiont-based defense in aphids. BMC biology, 10, 11.

Oliver, K.M., Russell, J.A., Moran, N.A. \& Hunter, M.S. (2003) Facultative bacterial symbionts in aphids confer resistance to parasitic wasps. Proceedings of the National Academy of Sciences, 100, 1803-1807. 
Rivero, A. \& West, S.A. (2005) The costs and benefits of host feeding in parasitoids. Animal Behaviour, 69, 1293-1301.

Russell, J.A., Latorre, A., Sabater-Muñoz, B., Moya, A. \& Moran, N.A. (2003) Side-stepping secondary symbionts: widespread horizontal transfer across and beyond the Aphidoidea. Molecular Ecology, 12, 1061-1075.

Scarborough, C.L., Ferrari, J. \& Godfray, H.C.J. (2005) Aphid protected from pathogen by endosymbiont. Science, 310, 1781.

Schelt, J. van. (1994) The selection and utilisation of parasitoids for aphid control in glasshouses. Exp. Appl. Entomol, pp. 151-155.

Schmid, M., Sieber, R., Zimmermann, Y. \& Vorburger, C. (2012) Development, specificity and sublethal effects of symbiont-conferred resistance to parasitoids in aphids. Functional Ecology, 26, 207-215.

Simon, J.-C., Boutin, S., Tsuchida, T., Koga, R., Le Gallic, J.-F., Frantz, A., Outreman, Y. \& Fukatsu, T. (2011) Facultative symbiont infections affect aphid reproduction. PLoS One, 6, e21831.

Stoger, E., Williams, S., Christou, P., Down, R.E. \& Gatehouse, J.A. (1999) Expression of the insecticidal lectin from snowdrop (Galanthus nivalis agglutinin; GNA) in transgenic wheat plants: effects on predation by the grain aphid Sitobion avenae. Molecular Breeding, 5, $65-73$.

Tazerouni, Z., Talebi, A.A. \& Rakhshani, E. (2012) Temperature-dependent functional response of Diaeretiella rapae (Hymenoptera: Braconidae), a parasitoid of Diuraphis noxia (Hemiptera: Aphididae). J. Entomol. Res. Soc, 14, 31-40.

Tsuchida, T., Koga, R. \& Fukatsu, T. (2004) Host plant specialization governed by facultative symbiont. Science, 303, 1989.

Tsuchida, T., Koga, R., Horikawa, M., Tsunoda, T., Maoka, T., Matsumoto, S., Simon, J.-C. \& Fukatsu, T. (2010) Symbiotic bacterium modifies aphid body color. Science, 330, 11021104.

Ueno, T. \& Ueno, K. (2007) The effects of host-feeding on synovigenic egg development in an endoparasitic wasp, Itoplectis naranyae. Journal of Insect Science, 7, 46. 
Vorburger, C., Gehrer, L. \& Rodriguez, P. (2010) A strain of the bacterial symbiont Regiella insecticola protects aphids against parasitoids. Biology Letters, 6, 109-111.

Vorburger, C., Sandrock, C., Gouskov, A., Castañeda, L.E. \& Ferrari, J. (2009) Genotypic variation and the role of defensive endosymbionts in an all-parthenogenetic host-parasitoid interaction. Evolution, 63, 1439-1450.

Xu, L.M., Qi, F.M., Zhang, J.P., Zhang, J.Z., Cao, C.M. \& Chen, J.L. (1998) Initial measurement of wheat output loss due to Macrosiphum avenae. Inner Mongolia Agricultural Science Technology, 5, 27-28.

Yang, N.-W., Ji, L.-L., Lövei, G.L. \& Wan, F.-H. (2012) Shifting preference between oviposition vs. host-feeding under changing host densities in two Aphelinid parasitoids. PL o S One, 7.

Zamani, A., Talebi, A., Fathipour, Y. \& Baniameri, V. (2006) Temperature-dependent functional response of two aphid parasitoids, Aphidius colemani and Aphidius matricariae (Hymenoptera: Aphidiidae), on the cotton aphid. Journal of Pest Science, 79, 183-188.

Zang, L., Liu, T., Zhang, F., Shi, S. \& Wan, F. (2011) Mating and host density affect host feeding and parasitism in two species of whitefly parasitoids. Insect Science, 18, 78-83. 


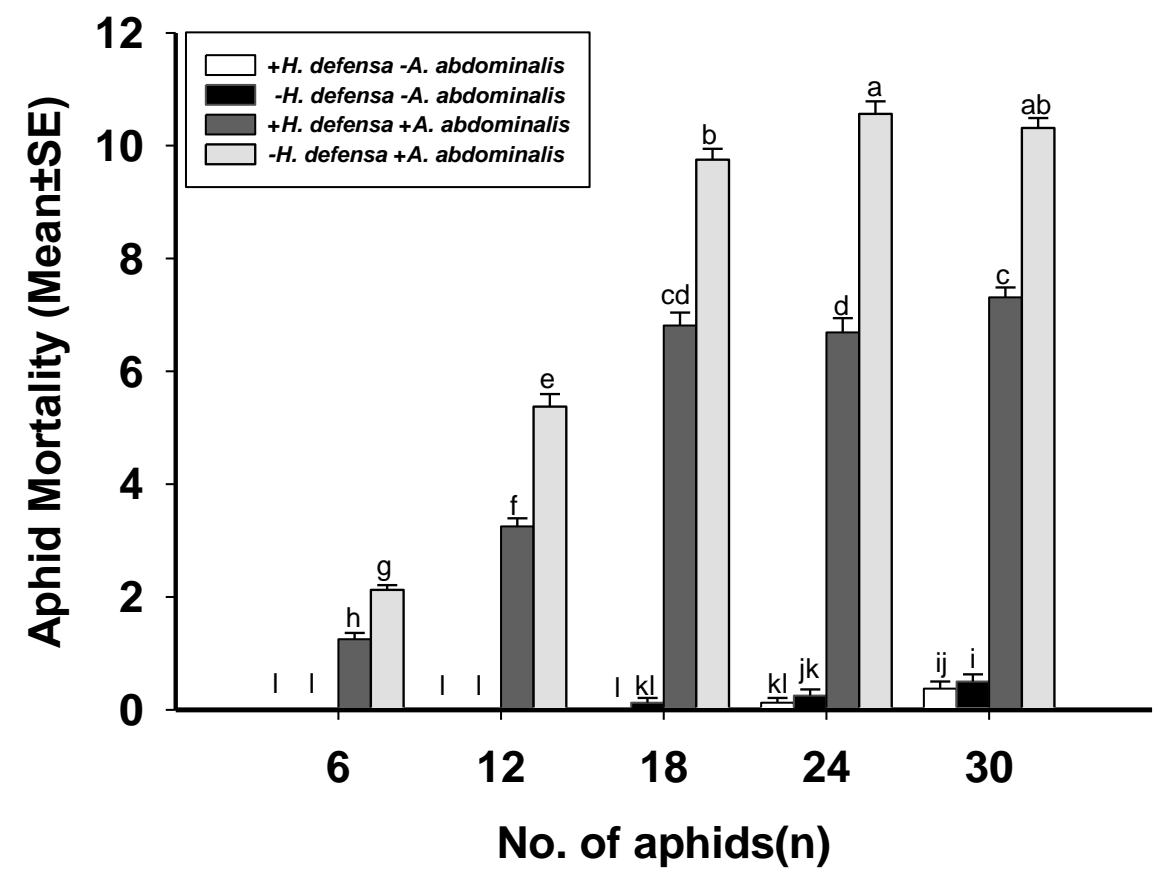

Figure 1a: A. abdominalis host killing in S. avenae (with and without Hamiltonella defensa) at different host densities.

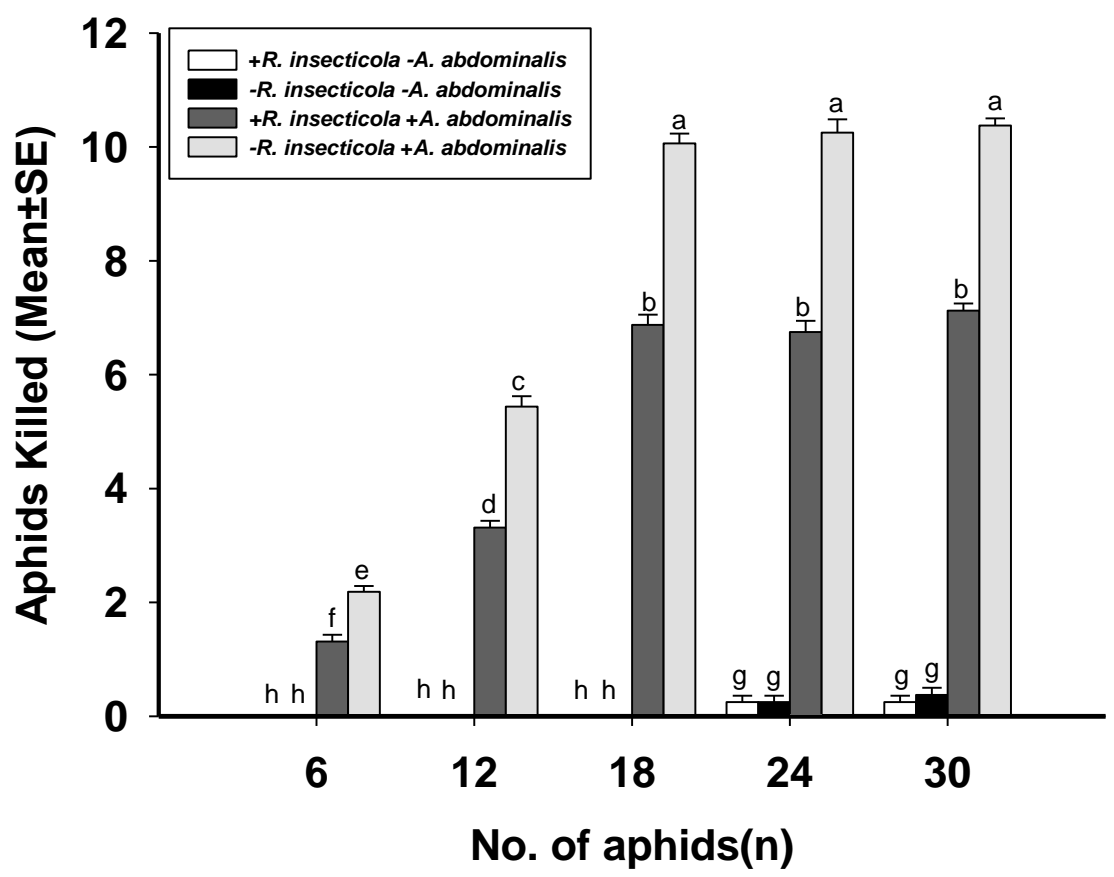

Figure 1b: A. abdominalis host killing of S. avenae (with and without Regiella insecticola) at different host densities. 


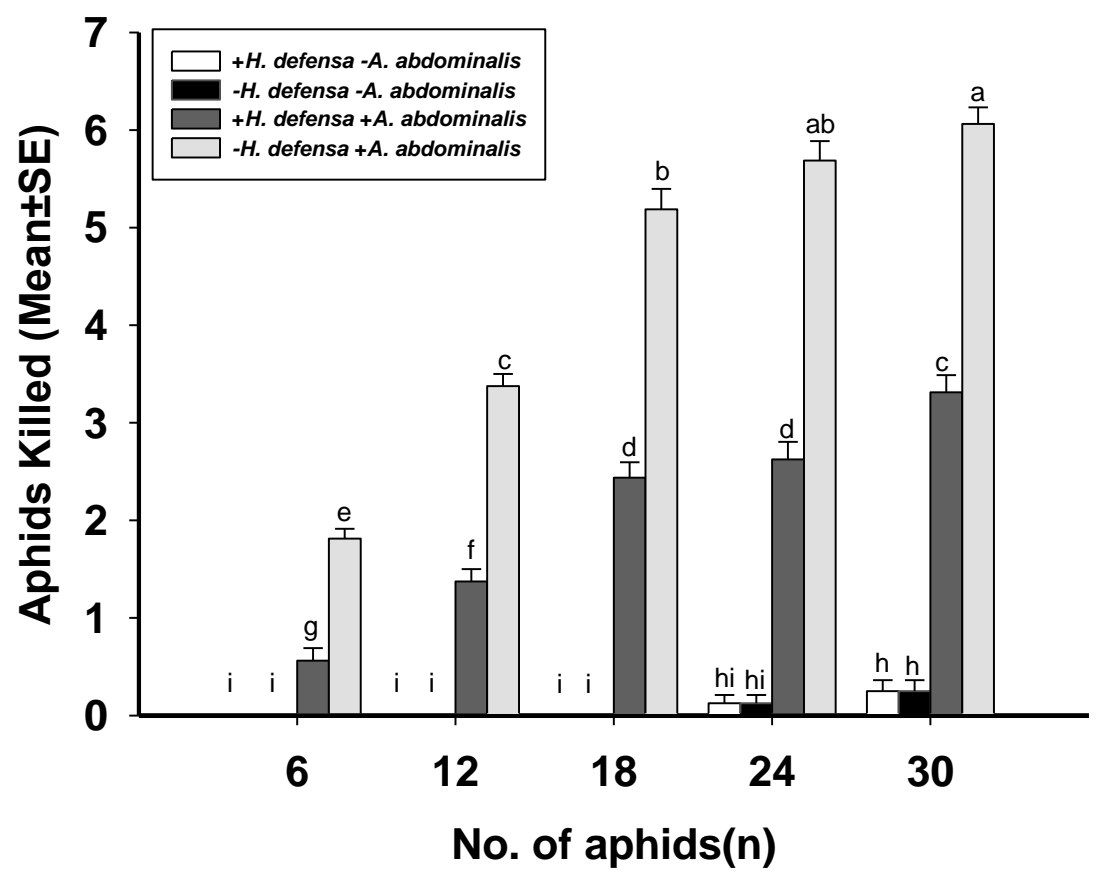

Figure 2a: A. abdominalis host killing of S. avenae (with and without Hamiltonella defensa) at different host densities.

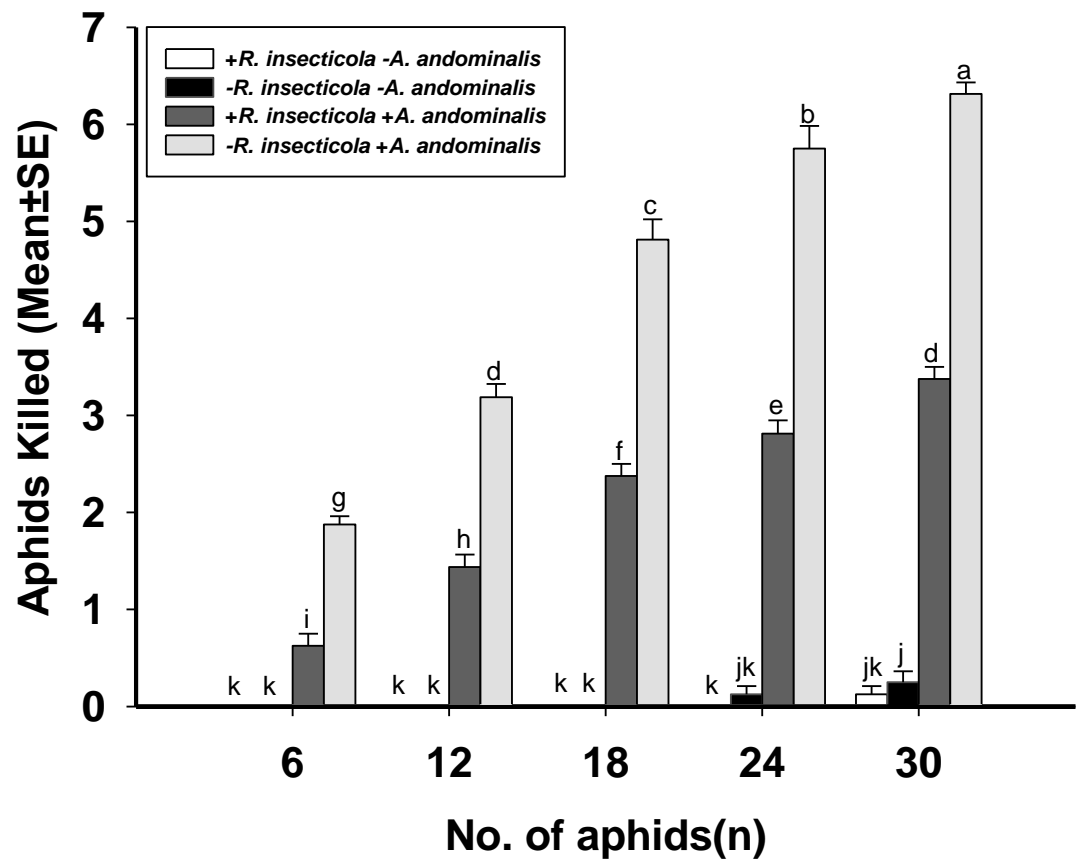

Figure 2b: A. abdominalis host killing of S. avenae (with and without Regiella insecticola) at different host densities. 


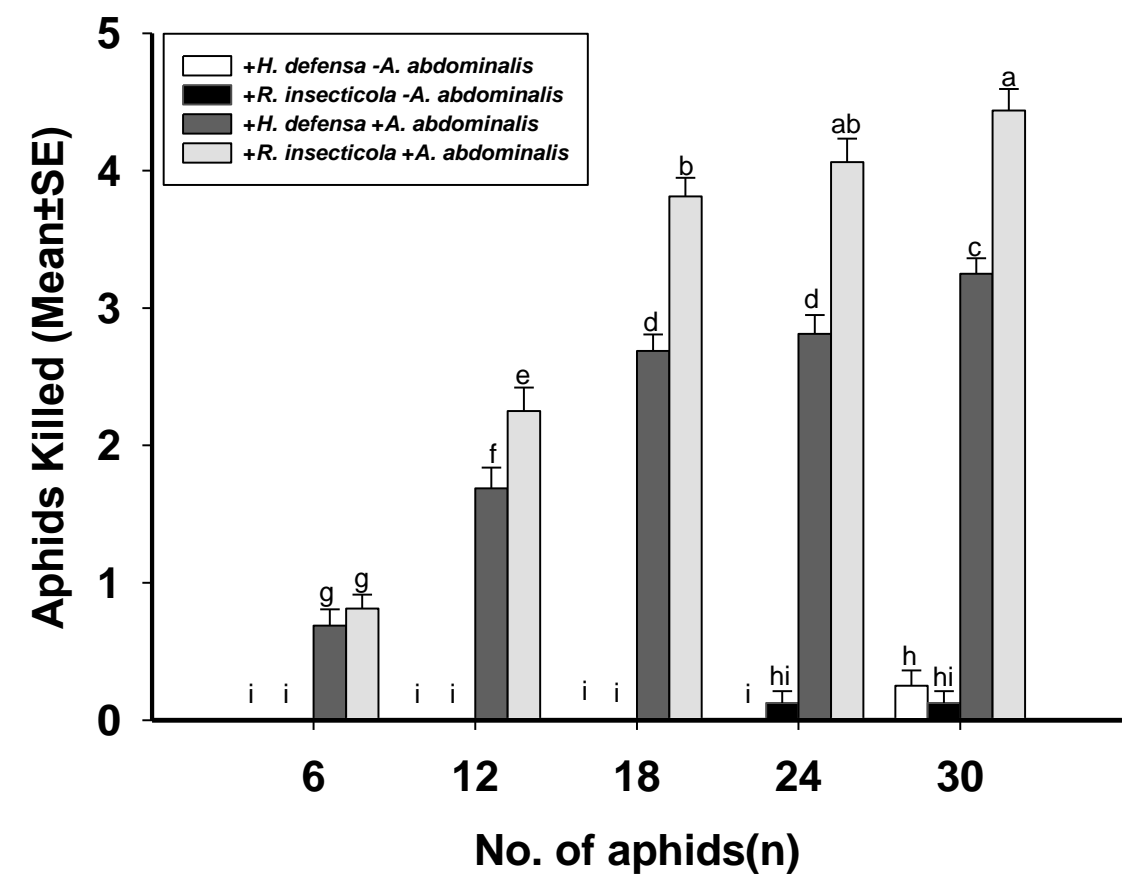

Figure 3a: A. abdominalis host killing of $S$. avenae (with $H$. defensa and $R$. insecticola) at different host densities indicating clonal resistance.

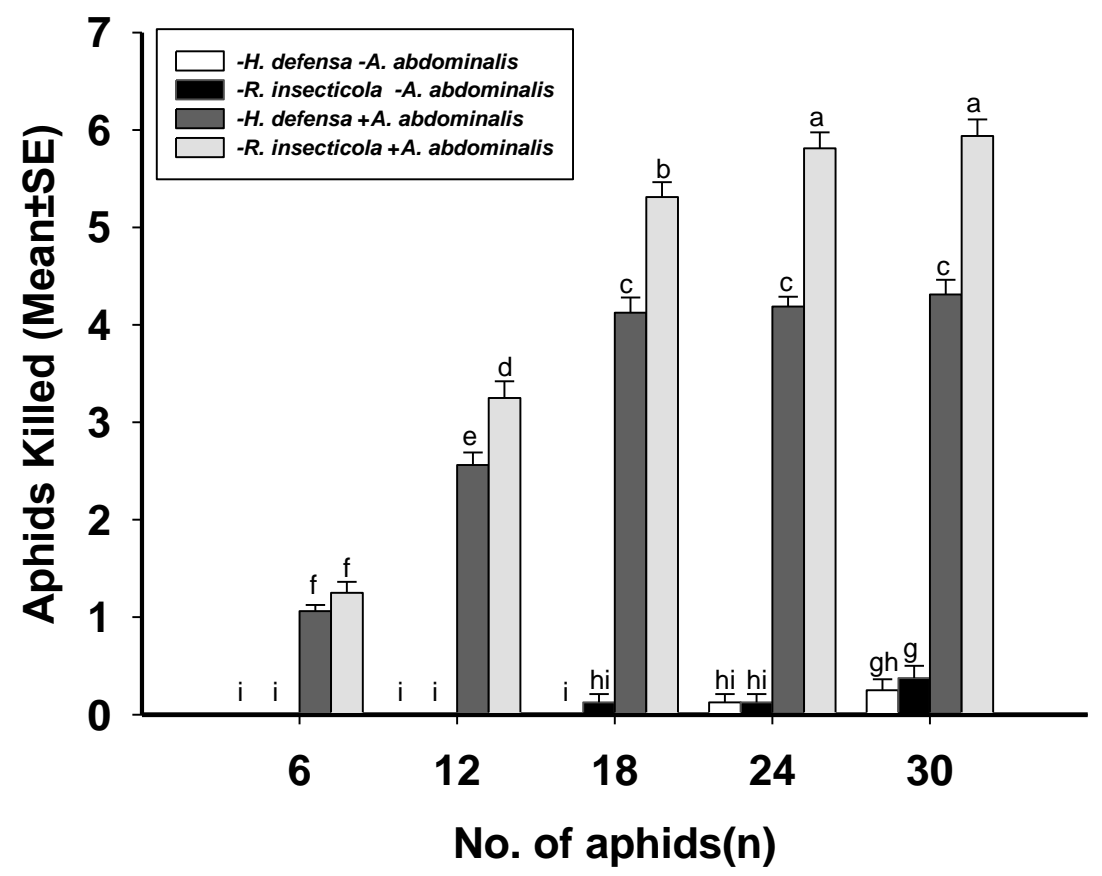

Figure 3b: A. abdominalis host killing of $S$. avenae (without $H$. defensa and $R$. insecticola) at different host densities indicating clonal resistance. 


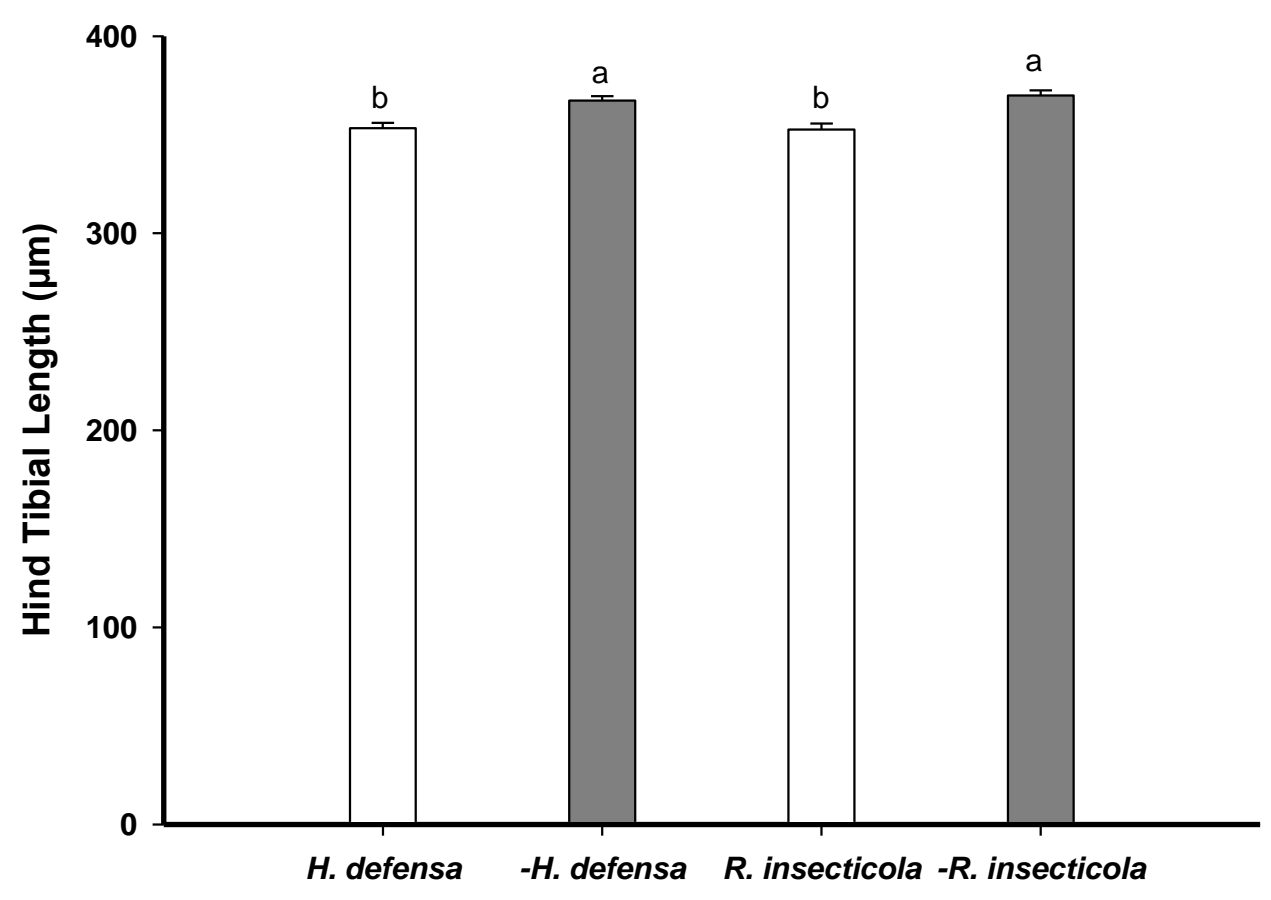

Figure 4: Hind tibia length of A. abdominalis developed in S. avenae (with and without $H$. defensa and $R$. insecticola).

Table 1: Differences of corrected \% mortalities (Mean \pm SE) in S. avenae by A. abdominalis host feeding in no choice and choice tests.

\begin{tabular}{ccccc}
\hline & \multicolumn{2}{c}{ Clone 5 } & \multicolumn{2}{c}{ Clone 7 } \\
\hline Aphids & No choice & Choice & No choice & Choice \\
\hline $\mathbf{6}$ & $14.58 \pm 2.58 \mathrm{~b}$ & $41.67 \pm 3.73 \mathrm{a}$ & $14.58 \pm 1.42 \mathrm{~b}$ & $41.67 \pm 3.73 \mathrm{a}$ \\
$\mathbf{1 2}$ & $17.70 \pm 1.68 \mathrm{~b}$ & $33.33 \pm 3.04 \mathrm{a}$ & $17.71 \pm 1.68 \mathrm{~b}$ & $29.17 \pm 3.23 \mathrm{a}$ \\
$\mathbf{1 8}$ & $15.99 \pm 1.39 \mathrm{~b}$ & $30.56 \pm 2.96 \mathrm{a}$ & $17.71 \pm 1.26 \mathrm{~b}$ & $27.08 \pm 2.48 \mathrm{a}$ \\
$\mathbf{2 4}$ & $15.94 \pm 1.45 \mathrm{~b}$ & $25.85 \pm 2.49 \mathrm{a}$ & $14.76 \pm 139 \mathrm{~b}$ & $23.91 \pm 2.60 \mathrm{a}$ \\
$\mathbf{3 0}$ & $9.841 \pm 1.01 \mathrm{~b}$ & $18.69 \pm 1.92 \mathrm{a}$ & $10.64 \pm 0.73 \mathrm{~b}$ & $19.26 \pm 1.63 \mathrm{a}$ \\
\hline
\end{tabular}




\title{
Chapter 3
}

\section{Impact of bacterial secondary symbionts on survivorship of Sitobion avenae (Fabricius) against Aphelinus abdominalis (Dalman) host feeding at variable temperatures}

\author{
${\text { Sajjad } \text { Ali }^{\mathrm{a}} \text {, Petr Karlovsky }}^{\mathrm{b}}$ and Stefan Vidal ${ }^{\mathrm{a}}$ \\ Department of Crop Sciences, Agricultural Entomology, Georg-August University, Göttingen, Germany ${ }^{\text {a }}$, Department of \\ Crop Sciences, Molecular Phytopathology and Mycotoxin Research, Georg-August University, Göttingen, Germany ${ }^{\text {b }}$
}

\begin{abstract}
Host-parasitoids interactions depend upon the climatic changes and the genotypes of their target hosts. Parasitoids are prone to climatic adversities for their fitness and survival as their feeding efficiency is temperature dependent. Parasitoids are ecologically important components in nearly all terrestrial ecosystems. The host feeding strategy has been adopted by many parasitoids to increase their longevity and fecundity. Almost all aphids possess extracellular bacterial secondary symbiont (BSS). They play a critical role in aphid's defensive system against their natural enemies and also help them to withstand environmental severities like temperature stress. We investigated the impact of bacterial secondary symbionts on the survivorship of Sitobion avenae against Aphelinus abdominalis host feeding at variable temperatures. Genetically identical wheat aphid clones, harbouring BSS and devoid of BSS, were used. BSS confer resistance to wheat aphids against $A$. abdominalis host feeding in both choice and no choice tests at all temperatures tested and hence increased host survivorship. A. abdominalis host feeding response was positively correlated with temperature gradients. Interestingly, A. abdominalis preferred to feed on $S$. avenae without BSS in choice tests. Clonal resistance also increased the survivorship of $S$. avenae when $A$. abdominalis were exposed to genetically different $S$. avenae clones. These fitness advantages conferred to their host aphids by endosymbiotic bacteria expound the adaptive significance of their heritable and successful spread over many insect populations, especially in aphids.
\end{abstract}

Keywords: survivorship, Sitobion avenae, A. abdominalis, Temperature, Host feeding 


\section{INTRODUCTION}

Insect-microbe endosymbiotic interactions can be pathogenic or mutualistic. Mutualistic symbionts might be either primary (obligate) or secondary (facultative) depending upon their necessity (1). The insect populations are heterogeneous for such interactions (2). Aphids possess primary endosymbiotic intracellular bacteria, named Buchnera aphidicola to compensate essential amino acid deficiencies. They reside in specialized cells called bacteriocytes (3). Aphids also possess extracellular bacterial secondary symbionts (BSS) other than the primary symbionts. These BSS are not necessarily required by aphids for their survival but in mutual interactions of aphids and their endosymbiotic bacteria, aphids are reported to increase survivorship. Recent studies reveal that bacterial secondary endosymbionts are playing a critical role in aphid's defensive system against their natural enemies and help them to withstand environmental severities like temperature stress (4-6). The fitness advantages conferred to the hosts by these endosymbiotic bacteria make them successfully spread over host populations especially in aphids (7-9). The bacterial endosymbionts facilitate the host populations while passing through rapid evolution with inevitable ecological interactions (9). In return, these bacterial endosymbionts utilize the reproductive system of their hosts for their own maternal transmission (2).

Parasitoids are ecologically important components in nearly all terrestrial ecosystems. They possess an intrinsic capacity of responses to environmental factors (10) and are contributing to a biological control of host populations in ecosystems (11). Many of the parasitoid species use their host as feed by consuming their haemolymph. Host feeding might be destructive to the host organisms and can lead towards death of the hosts (12). This host feeding strategy has been adopted by parasitoids to increase their longevity and fecundity (13) and it also increases the effectiveness of parasitoids in biological control of insect pests (14).

In nature, aphids harbouring bacterial secondary endosymbionts along with their associated natural enemies are both exposed to environmental changes. Behavioural, physiological and biochemical systems are temperature dependent (15). Under temperature fluctuations, the cost to these changes may increase and may become an important factor for mortality and reproduction by interacting directly or indirectly via natural enemies (16). The population dynamics of natural enemies and their host species depend upon the temperature variations (17). The efficiency of natural enemies is largely affected by abiotic factors especially by temperature $(18,19)$ because of thermal sensitivity $(20)$. Host-parasitoids interactions are 
difficult to predict under environmental variations which may lead to problem for developing biological control strategies (21). Behavioural changes in aphids due to environmental factors can be important for their biological control (22) in agricultural pest management. Temperature variations are among the most important abiotic factors which are known to affect life history traits of aphids, BSS and parasitoids. They can affect longevity, fecundity, sex determination, size, development rate and seasonal occurrence of insects (23-25). Extreme temperatures can be deleterious for the population dynamics of BSS within the host organisms and in the context of global warming and climatic changes it is important to study the impact of thermal changes on the host aphid-parasitoids interactions as they are prone to climatic adversities which can cause lethal or sub lethal damages to them $(4,26)$. Aphid's genetic or clonal and bacterial resistance against parasitoids may decrease under thermal stress (27) but the parasitoids are more active at higher temperatures and they can also undergo diapause at low temperatures (28). The phenotypic plasticity and tolerance to environmental stresses enable them to exploit and regulate their host populations $(29,30)$.

Impact of temperature on host-parasitoid interactions had been studied by various researchers for better manipulation of parasitoids in biological control of aphids (27, 29, 31-34). Temperature affects the parasitism and parasitoids host feeding in a linear way until very high temperatures exert a negative impact on parasitoids $(27,35,36)$. Increased average temperature potentially enhances the efficacy of biological control agents which is always a direct benefit to the parasitoids in parasitoid-host interactions as compared to aphids (22). There is need to match the climatic adaptation of the biological control agent with climatic conditions in the target region, is particularly relevant to classical introduction programs and to augmentative releases of commercially bred antagonists. Considerable progress is being made in our understanding of aphid-natural enemy interactions, leading to improved strategies for biological control, but practical and economic constraints still exist and need to be overcome, particularly in relation to mass-rearing and augmentative releases on outdoor crops (37).

To the best of our knowledge we are not aware of studies dealing with the parasitoids host feeding behaviour with regard to the bacterial secondary symbionts constitution of the aphid hosts and genetic variations in aphids at variable temperatures. We designed a study involving S. avenae, its BSS, Hamiltonella defensa (Moran) and Regiella insecticola (Moran), and A. abdominalis interactions at variable temperatures. In nearly all previous 
studies, aphid clones with or without BSS have been compared, not taking into account the potential influence of the differences in the genetic structure of these clones.

Our study system was consisted of four wheat aphid clones possessing different BSS with an identical genetic background by artificially removing the BSS with antibiotics micro injections to avoid any genetic constraints. We also used genetically different clones without BSS and also with different BSS to confirm the clonal resistance against host feeding.

We addressed the following issues:

- Do BSSs affect the survivorship of $S$. avenae against $A$. abdominalis host feeding at increasing temperatures?

- Is host feeding behaviour of A. abdominalis affected by BSS and Temperature interactions?

- Does A. abdominalis show host preference for feeding on aphids with and without BSSs at variable temperatures?

- Do genetic variations affect the host feeding behaviour of A. abdominalis at variable temperatures?

\section{MATERIALS AND METHODS}

\section{Insect Cultures}

Sitobion avenae: S. avenae used in this study were collected from Giessen (Germany) on wheat plants. Two clones were established (referred as 5 and 7 in the following) from a single asexual female aphid. These two aphid clones harbour $H$. defensa in clone 5 and $R$. insecticola in clone 7 respectively as bacterial secondary symbionts (BSS) and have different genetic backgrounds (38). The wheat cultivar "Dekan" (KWS GmbH. Germany) was used to rear the aphid clones. The wheat plants were grown in soil and sand mixture $(2: 1)$ in $11 \mathrm{~cm}$ diameter plastic pots covered with transparent ventilated plastic cylinders. The aphid cultures were kept at $20 \pm 1{ }^{\circ} \mathrm{C}$ and $70 \pm 10 \% \mathrm{RH}$ with a $16: 8$ hour light and dark period in climatic chamber (WB 750 KFL; Mytron Bio-Und Solartechnik GmbH. Germany). The irrigation was done on alternate days. The wheat aphids reproduced parthenogenetically provided these conditions. 
Aphelinus abdominalis: The parasitoid species A. abdominalis, used in these experiments, were obtained from re-natur GmBH. Germany. The parasitoids were fed on $50 \%$ honey solution on their arrival and the female parasitoids were used for experiments next day.

\section{Elimination of BSS by antibiotics}

The elimination of $H$. defensa harboured by the wheat aphid clone 5 was done by applying a mixture of ampicillin, cefotaxime and gentamycin $(250 \mathrm{mg} / \mathrm{ml}$ each) through micro-injection using fine glass needles (39). The antibiotic solutions were injected at the rate of 0.1-0.2 $\mu 1 /$ mg of body weight of the aphid specimens. Ampicillin was injected to the clone 7 aphids in the same way at the rate of $1 \mu \mathrm{g} / \mathrm{mg}$ of the body weight of aphid specimens for the removal of $R$. insecticola (40). The wheat aphids (second nymphal stage) were $\mathrm{CO}_{2}$ anaesthetized for this treatment. The wheat aphids were shifted to wheat plants singly after treatment and allowed to reproduce for 48 hours. The newly produced nymphs were defined as G1. Five nymphs from the G1 were randomly selected to extract DNA by CTAB protocol (41) for the confirmation of the BSS by diagnostic PCR. The G2 nymphs from BSS negative G1 mothers were chosen for further rearing only. Elimination of BSS from clone 5 and 7 was confirmed by diagnostic PCR until G8 before the experiments. The diagnostic PCR was performed with specific primers to detect the presence of $H$. defensa and $R$. insecticola by amplifying the $16 \mathrm{~S}$ rDNA gene fragments: HDFn [5-ATGAAGTCGCGAGACCAAA-3], HDRn [5GCTTTCCCTCGCAGGTTC-3], RIFn [5-GAAGGCGGTAAGAGTAATATGC-3], and RIRn [5-CCCCGAAGGTTAAGCTACCTA-3] respectively. PCR conditions were: $94^{\circ} \mathrm{C}$ for 3 min followed by 30 cycles of $94^{\circ} \mathrm{C}-30 \mathrm{~S} ; 60^{\circ} \mathrm{C}-40 \mathrm{~S} ; 72^{\circ} \mathrm{C}-90 \mathrm{~S}$ and final incubation at $72^{\circ} \mathrm{C}$ for 8 minutes. Reactions were carried in a $25 \mu \mathrm{l}$ volume with one $\mu 1$ of the DNA template containing $0.32 \mu \mathrm{M}$ of each primer, $2 \mathrm{mM} \mathrm{MgCl} 2,200 \mu \mathrm{M}$ dNTPs, 1x "Bioline" buffer and 0.25 units of Taq DNA polymerase. PCR products were visualized on $1.7 \%$ agarose gel using Ethidium bromide. To identify the PCR products for BSS, DNA from PCR products was purified from the gel after visualization and sent for direct sequencing to LGC Genomics $\mathrm{GmbH}$, Germany. The resulting sequences were then compared to the known sequences of $H$. defensa and $R$. insecticola using the BLAST algorithm in NCBI. Afterwards, we had clones 5 either harbouring $H$. defensa (referred to as +5 in the following), or devoid of this BSS (referred to as -5 in the following) and clone 7 harbouring $R$. insecticola (referred to as +7 in the following), or devoid of this BSS (referred to as -7 in the following). 


\section{Experiments}

Survivorship of $S$. avenae against host feeding by $A$. abdominalis in response to BSS at variable temperatures (No Choice Tests)

10 nymphs of second and third instar $S$. avenae from clone $+5,-5,+7$, and -7 were exposed to A. abdominalis females at temperatures of $15,20,25,30$ and $35{ }^{\circ} \mathrm{C}$, respectively, for 24 hours in $90 \mathrm{~mm}$ Petri dishes containing wheat seedlings with roots covered by wet cotton and

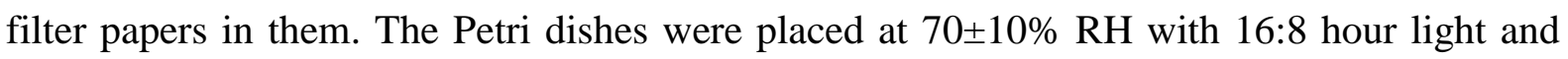
dark period. 16 replications were maintained over times for each treatment with 16 controls without $A$. abdominalis female parasitoids. The A. abdominalis females were removed after 24 hour and the dead aphids were counted after 24 and 48 hours. Replicates in which the introduced parasitoids escaped or died were discarded from the analyses, and these treatments were set-up again for data collection and analyses.

\section{Host preference behaviour of $A$. abdominalis in response to BSS at variable temperatures (Choice Tests)}

10 nymphs of second and third instar $S$. avenae from clone +5 and -5 were exposed to $A$. abdominalis females in the same Petri dish at temperatures of $15,20,25,30$ and $35{ }^{\circ} \mathrm{C}$ respectively for 24 hours at 50:50 ratios. The similar procedure was repeated for clone +7 and -7. To differentiate between the BSS positive and negative wheat aphids, the tarsi of one of the hind legs of the wheat aphids were cut under a magnifying glass with sterilized blades. This was performed with BSS positive aphids in half replications and with BSS negative aphids in the other half replications. A. abdominalis females were removed after 24 hour and wheat aphid clones $+5,-5,+7$ and -7 were separated by placing them into separate plates. The experimental conditions and data collection were the same as for no choice tests.

\section{Host preference behaviour of $A$. abdominalis in response to clonal variations at variable temperatures (Choice Tests)}

10 nymphs of second and third instar $S$. avenae from clone +5 and +7 were exposed to $A$. abdominalis females in the same Petri dish at temperatures of $15,20,25,30$ and $35{ }^{\circ} \mathrm{C}$ respectively for 24 hours at 50:50 ratios. To differentiate between the aphids from clone +5 and +7 , the tarsi of one of the hind legs of the wheat aphids were cut under a magnifying glass with sterilized blades. This was performed with clone +5 wheat aphids in half replications and with clone +7 wheat aphids in the other half replications. The similar 
procedure was repeated for clone -5 and -7 . The experimental conditions, set-up and data collection were the same as for the above test.

\section{Data analyses}

In no choice and choice experiments, the data of wheat aphids' mortality by A. abdominalis parasitoid host feeding was analysed using a factorial ANOVA with the independent factors of host density and BSS. Differences among means related to aphid mortality were compared with Fisher's Least Significant Difference (LSD) test at the significance level of $p=0.05$. Data were square-root transformed $[\mathrm{SQRT}(\mathrm{x}+0.5)]$, because host mortality in the controls compared to treatments did not meet the assumption of normal distribution. The graphs show the non-transformed data values (mean $\pm \mathrm{SE})$ of aphids killed in the respective experiments.

For the determination of host preference behaviour of $A$. abdominalis host killing towards wheat aphids with and without BSS, percent mortality data were corrected by Abbott's formula prior to the analyses (42). The difference of corrected mortality percentage $($ mean \pm SE) in aphids without and with BSS was used as an indicator of host preference in double choice test.

Formula $=$ Corrected $\%$ mortality in aphids without BSS - Corrected $\%$ mortality in aphids harbouring BSS

The differences of corrected mortality percentage (mean $\pm \mathrm{SE}$ ) of choice and no choice tests were compared with a paired t-test at the $5 \%$ significance level for each of the aphid population densities individually. All analyses were performed in Statistix (version 8.1) software (43).

\section{RESULTS}

\section{Survivorship of $S$. avenae against host feeding by $A$. abdominalis at variable temperatures in response to $\mathrm{BSS}$}

The survivorship pattern of wheat aphids, S. avenae, against host feeding behaviour of Aphelinus abdominalis was studied at variable temperatures in no choice tests. Bacterial secondary symbionts $(B S S)$ significantly $(\mathrm{p}<0.005)$ increased the survivorship of wheat aphids from clones +5 ( $H$. defensa) and +7 ( $R$. insecticola) as compared to wheat aphids from clones -5 and -7 without BSS (Fig. 1a \& 1b) against host feeding behaviour of $A$. 
abdominalis. This positive impact of bacterial secondary symbionts on the survivorship of $S$. avenae against host feeding by $A$. abdominalis was consistent at all the temperatures except $15{ }^{\circ} \mathrm{C}$ when A. Abdominalis did not display host feeding behaviour. The pattern of wheat aphid's survivorship against $A$. abdominalis host feeding was similar in both of the no choice tests. The temperature exerted a negative effect on the survivorship of wheat aphids in all treatments. The survivorship of the wheat aphids decreased with an increase in temperature; a temperature $35{ }^{\circ} \mathrm{C}$ proved to be lethal for both the wheat aphids and as well as the parasitoids. The highest numbers of wheat aphids survived at $15{ }^{\circ} \mathrm{C}$ against host feeding by the parasitoid were as 9.5 and 9.56 aphids in clone +5 and -5 and 9.25 and 9.31 aphids in clone +7 and -7 , respectively, while the lowest survivors were seen at $30{ }^{\circ} \mathrm{C}$ as 5.43 and 4.37 aphids in clone +5 and -5 and 6.31 and 4.93 aphids in clone +7 and -7 respectively. The highest temperature $35{ }^{\circ} \mathrm{C}$ caused $100 \%$ mortality of wheat aphids in all the treatments of both tests including the parasitoids. In controls, wheat aphid's survivorship was $100 \%$ at 15 and $20^{\circ} \mathrm{C}$ irrespective of BSS presence or absence. At 25 and $30{ }^{\circ} \mathrm{C}$ minimal wheat aphid's mortality was observed. A. abdominalis host feeding was positively correlated with temperatures up to $30{ }^{\circ} \mathrm{C}$ with their dependency upon the presence or absence of BSS in their host wheat aphids. The survivorship of wheat aphids against $A$. abdominalis host feeding was positively linked with the presence of BSS as we have observed an increased survivorship of wheat aphids possessing BSS also in control treatments although the difference was not significant. The survivorship of wheat aphids against A. abdominalis host feeding is negatively linked with the temperature. A. abdominalis fed on wheat aphids more actively with an increase in the temperature from $15{ }^{\circ} \mathrm{C}$ to $30{ }^{\circ} \mathrm{C}$ but it was always higher on wheat aphids without BSS.

\section{Host preference behaviour of $A$. abdominalis in response to BSS at variable temperatures}

Choice tests were performed to evaluate the host preference behaviour of A. abdominalis host feeding on wheat aphids when these parasitoids face aphids with and without BSS together. The choice tests for clones $+5,-5,+7$ and -7 showed that BSS changed the host feeding behaviour of A. abdominalis significantly $(\mathrm{p}<0.005)$ as compared to no choice tests (Fig. 2a $\& 2 b)$. The differences of means for corrected $\%$ mortality of wheat aphids without and with BSS in no choice and choice tests were compared. The differences of corrected $\%$ mortality in choice tests were twofold of the differences of corrected \% mortality in no choice test 
(table 1) at all the variable temperatures for both of the aphid clones except at $15^{\circ} \mathrm{C}$. Because the parasitoids did not feed actively at $15{ }^{\circ} \mathrm{C}$ but in choice test, A. abdominalis have fed more on wheat aphids without BSS as compared to wheat aphids with BSS, showing their preference for feeding on wheat aphids without BSS. The higher difference of corrected \% mortality by $A$. abdominalis host feeding in choice test indicated clear host preference behaviour when A. abdominalis had to choose between wheat aphids with and without BSS. A. abdominalis host feeding increased significantly $(\mathrm{p}<0.005)$ with increase in temperature from $15{ }^{\circ} \mathrm{C}$ to $30{ }^{\circ} \mathrm{C}$ irrespective of BSS (Fig. $2 \mathrm{a} \& 2 \mathrm{~b}$ ) in all of the treatments of both choice tests. The survivorship of wheat aphids was also depending upon the BSS positively in choice tests and negatively depending upon the temperatures. Host feeding and temperature are positively correlated but $35{ }^{\circ} \mathrm{C}$ was lethal for both of wheat aphids and parasitoids when $100 \%$ mortality was achieved. The lowest host feeding was observed at $15{ }^{\circ} \mathrm{C}$ and the highest host feeding was seen at $30{ }^{\circ} \mathrm{C}$ in both of the choice tests with clones +5 and +7 respectively. The host feeding was always higher on wheat aphids without BSS at all the variable temperatures. The survivorship of wheat aphids in controls was $100 \%$ at 15 and $20{ }^{\circ} \mathrm{C}$ irrespective of BSS presence or absence. At 25 and $30{ }^{\circ} \mathrm{C}$ minimal wheat aphid's mortality was observed both of the choice tests irrespective of BSS.

\section{Host preference behaviour of $A$. abdominalis in response to clonal variation at variable temperatures}

In other choice test, the genetic or clonal variation influenced the host feeding behaviour of A. abdominalis (Fig. $3 \mathrm{a} \& 3 \mathrm{~b})$. Clone +5 was more resistant $(\mathrm{p}<0.005)$ to A. abdominalis host feeding as compared to clone +7 , irrespective of their BSS (Fig. 3a). This genetically based resistance was consistent found at all the temperatures tested and was also found in choice tests using wheat aphids devoid of BSS. Clone -5 was also more resistant against $A$. abdominalis host feeding (Fig. 3b) as compared to clone -7 and was observed at all temperatures tested irrespective of BSS. Host feeding and temperature were positively correlated up to $30{ }^{\circ} \mathrm{C}$; at $35^{\circ} \mathrm{C}$ all wheat aphids and parasitoids were dead. The lowest host feeding was observed $15{ }^{\circ} \mathrm{C}$ and the highest host feeding was seen $30{ }^{\circ} \mathrm{C}$ respectively (Fig. $3 \mathrm{a}$ and 3b). The mortality in control treatments was zero at 15 and $20{ }^{\circ} \mathrm{C}$ but negligible mortalities were seen at 25 and $30^{\circ} \mathrm{C}$ in both of the choice tests irrespective of BSS. 


\section{DISCUSSION}

\section{Survivorship of $S$. avenae against A. abdominalis host feeding in response to BSS at variable temperatures}

The BSS, $H$. defensa and $R$. insecticola, expressed themselves in wheat aphid clones +5 and +7 by conferring significant partial resistance to their hosts against A. abdominalis host feeding behaviour as they have, already, been verified for host defence in pea aphids against parasitism (5). The symbiotic resistance, provided by both symbionts, was stable at all the temperatures tested. Unfortunately, there are no studies available which deal with the parasitoid host feeding interactions with aphids in relation to their bacterial endosymbionts at variable temperatures. We can only compare our results with parasitism studies. Cayetano and Vorburger studied the effects of heat shocks on the endosymbiotic resistance imparted to Aphis fabae (Scopoli) against Lysiphlebus fabarum (Marshall) parasitoid in 2013 (44). They reported that the ability of $H$. defensa to protect their hosts against parasitism was not affected by exposure to elevated temperatures. Likely, the ability of $H$. defensa and $R$. insecticola to protect wheat aphids against parasitoids host feeding was consistent even at elevated temperature regime. Thus, the relative fitness of bacterial endosymbionts, to protect their hosts, remains usually unaffected at elevated temperatures when encountered by parasitoids for host feeding or parasitisation. But at the same time, the host feeding efficiency of the parasitoids is positively linked with the temperature as their feeding and attack rates are increased with elevated temperatures up to a certain limit which shows their maximum capacity to feed on host aphids. Under certain conditions, this can help in the reduction of target insect pest populations (45). Our no choice lab trials revealed that the temperature changes can modify the host feeding capacity of the parasitoid A. abdominalis in his own favour linearly with temperature elevations until they suffered with mortality caused by lethal heat shocks to them. It might be a possibility that host feeding increased due to higher metabolism and activities. The daily host egg feeding of a female parasitoid, Trichogramma turkestanica (Meyer), against Ephestia kuehniella (Zeller) substantially increased with temperature gradients and reached to its maximum at $30{ }^{\circ} \mathrm{C}$. Likely, the same temperature initiated the highest A. abdominalis host feeding on wheat aphids with the lowest host survival and vice versa at $15{ }^{\circ} \mathrm{C}$ (18). In another study, cotton aphids, Aphis gossypii (Glover), were offered to Aphelinus asychis (Walker) for host feeding at 18 and $30{ }^{\circ} \mathrm{C}$. A. 
asychis also killed more cotton aphids at $30{ }^{\circ} \mathrm{C}$ as compared to $18{ }^{\circ} \mathrm{C}$ (36). In case of parasitism, the parasitoid Cephalonomia waterstoni (Gahan) showed higher parasitisation rates on rusty grain beetle, Cryptolestes ferrugineus (Stephens), with increasing temperatures; the highest parasitisation was recorded at 25 and $30{ }^{\circ} \mathrm{C}$ (46). Zamani et al., also showed that aphid parasitoids, Aphidius colemani (Viereck) and Aphidius matricariae (Haliday) attacking on the cotton aphids at five constant temperatures $10,15,20,25$, and $30{ }^{\circ} \mathrm{C} .25$ and $30{ }^{\circ} \mathrm{C}$ proved to be optimum temperature for the highest parasitisation (47). In 2002, Menon et al., reported a similar increasing trend of Rhyzopertha dominica (Fabricius) parasitisation by Anisopteromalus calandrae (Howard) with increase in temperature (48). Another parasitoid, Praon volucre (Haliday), also showed positive thermal dependency to parasitize $S$. avenae up to $25{ }^{\circ} \mathrm{C}$; at temperatures above this level parasitisation rates declined (49). This might be due to the fact that parasitoids are more active feeders at elevated temperatures as compared to low temperature regimes and thermal dependency of parasitoids feeding and parasitisation is assumed from higher metabolism. On the other hand the foraging behaviour of another parasitoid, A. matricariae, was not influenced by the extreme temperature fluctuations (22). It is interesting that environmental fluctuations affect the aphis-parasitoid interactions but it depends upon the genotypes of the species involved also.

\section{Effect of BSS and temperature interactions on $A$. abdominalis host feeding}

No studies are available to explain the ability of bacterial endosymbionts to confer resistance to their hosts against parasitoid host feeding at variable temperatures or even under normal conditions. However, several studies published by Oliver et al., (2003 \& 2005), Scarborough et al., (2005), Vorburger et al., (2010), Łukasik et al., (2013), Hansen et al., (2012), and Schmid et al., (2012), respectively, described bacterial endosymbionts for their ability to confer protection to their host aphids against different parasitoid species (50-56). This study would be first report to show more diversified function of BSS that they can also protect their hosts against host feeding parasitoids at elevated temperatures also. Predatory beetles such as Adalia bipunctata (Linnaeus) and Hippodamia convergens (Guérin-Méneville) killed more pea aphids harbouring $H$. defensa as compared to those who did not carry the symbiotic bacteria by host feeding. It could be an ecological cost of bacterial symbiont mediated resistance to pea aphids against parasitism $(57,58)$. The virulence of Aphidius ervi (Haliday) against pea aphids harbouring $H$. defensa was increased with temperature gradients thus decreased the survivorship of pea aphids at higher temperatures as temperature can be, 
sometime, deleterious to the benefiting bacterial symbionts in aphids (27) depending upon the genotypes involved. Bacterial endosymbionts density can be reduced within individual host aphids to some extent but cannot be eliminated by thermal stress (4) but their ability to sustain host fecundity and to confer resistance to host aphids against parasitoids was not affected by the elevated temperatures $(4,59)$. Pea aphids infected with $H$. defensa became more susceptible to A. ervi attacks after thermal stress but pea aphids additionally harbouring PAXS secondary symbionts were able to maintain resistance against parasitism (60). As our findings are against to the above studies so it might be concluded that host-parasitoids interactions are also depends upon genotypic interactions which are able to change the feeding behavoir of natural enemies. Mainly parasitoids-protective endosymbionts interactions remain unchanged along the temperature gradients but survivorship of aphids harbouring bacterial symbionts may slightly reduce at elevated temperature (58). Moreover, bacterial secondary symbionts like $R$. insecticola, $H$. defensa and Serratia symbiotica (Moran) confer thermal tolerance to their host aphids to increase their fitness under heat stress and sustain their fecundity and longevity $(61,62)$ which enhance their survival., Low mortality of wheat aphids with BSS in control treatments also indicated that survival benefits were conferred to their host aphids as compared to wheat aphids without BSS although the difference was non-significant. This ability of thermal tolerance expounds the adaptive significance of heritable symbionts in the aphids with their interactions to abiotic environments.

\section{Host preference behaviour of $A$. abdominalis in response to BSS at variable temperatures}

Parasitoids can detect the presence of defensive bacterial endosymbionts in the aphids and modify their reactions accordingly to increase their fitness and better utilization of the hosts for their own favour (63). The primary symbiotic bacterium, B. aphidicola, was able to mould the host preference behaviour of Lysiphlebus ambiguous (Haliday). The parasitoids discriminated between symbiotic and aposymbiotic A. fabae and preferred symbiotic aphids harbouring $B$. aphidicola (64). It might be a reason that primary symbionts contribute nutritional deficiencies which make the aphids more suitable for parasitoid development. Host feeding behaviour of $A$. abdominalis was remoulded on exposure to wheat aphids with and without BSS. A. abdominalis preferred to feed on wheat aphids without BSS. This host feeding preference trend was observed along the temperature gradients. It is implicated from 
the above discussion that the bacterial symbionts persist their ability to confer benefits their hosts under thermal stress as well and can also modify the feeding behaviour of parasitoids by changing the nutritional physiology of their hosts. It is also implicated that A. abdominalis is also a good opportunist, when encountered with both kind of wheat aphids with and without bacterial symbionts, to choose the least resistant ones.

\section{Host preference behaviour of $A$. abdominalis in response to clonal variations at variable temperatures}

Parasitoid virulence and host resistance to the parasitoids are ultimately depending upon the genotypes of the both species involved. Their interactions are modified by metabolic rates, cellular activities and temperatures (27). Genotypic and clonal variations among the aphid populations are known to confer resistance against parasitoids in addition to bacterial endosymbionts (50). With regard to host aphid-host feeding parasitoids interactions, the picture is not cleared. Clonal variations among pea aphid clones produce significant resistance A. ervi and A. eadyi. Aphid clonal resistance against parasitoid protected pink pea aphid clone from A. ervi as compared to green clone (65). Myzus persicae (Sulzer) showed that parasitism resistance against $A$. colemani and Diaeretiella rapae (McIntosh) is positively correlated to genetic or clonal variations among the host aphids (66). The black bean aphid, A. fabae, possesses genotypic variations in susceptibility to the parasitoid L. fabarum (67). Parasitism resistance was studied in 34 pea aphid clones against two parasitoids and it was assumed that genetic variations are significantly different in their resistance against the natural enemies (68). Likely, genetic variations may also be able to modify the host feeding behaviour of the parasitoids. Wheat aphid Clones +5 and +7 are genetically different. In both of the choice tests, taking individuals from clones $+5 /+7$ together and individuals of clones 5/-7 together, the clone 5 was proved genetically resistant as compared to the clone +7 irrespective of BSS. Thus, genotypic variations are natural defense mechanism not only against parasitisation but also against host feeding parasitoids. It is also inferred that these natural defenses are stable enough to protect the aphids along temperature gradients as well. Pea aphid clones showed significant survival variations to parasitoid virulence but aphid clonal resistance was not affected significantly by slight temperature variations from 18 to 23 ${ }^{\circ} \mathrm{C}$ (69). In our experiments, Clone 5's clonal resistance against A. abdominalis host feeding was also consistent with the temperature gradients. It is assumed that the physiological defenses against parasitoids are positively correlated with temperature gradients (70) but this 
heritable clonal resistance of pea aphids to $A$. ervi at $20{ }^{\circ} \mathrm{C}$ was reduced when temperature was increased to $30^{\circ} \mathrm{C}(27)$.

\section{CONCLUSION}

Environmental conditions matters in host-parasitoid interactions. Bacterial secondary symbionts have enough thermal stability to protect their hosts but it can be concluded that parasitoid virulence increases and host resistance decreases with temperature gradients and the natural enemies can be effective under specific abiotic stresses like environmental warming unless it is not harmful. Long exposure of such stresses can affect the efficiency of the natural enemies as well (71). Additionally, it might be assumed that the phenotypic effects of bacterial secondary symbionts as well as genetic variations modify the host feeding strategies of parasitoids. Finally, genotype x genotype $x$ environment interactions should be addressed for effective biological control of aphids.

\section{ACKNOWLEDGMENTS}

We thank Zaheer Abbas and Aamir Iqbal for their help during these experiments. Sajjad Ali is thankful to Higher Education Commission (HEC) of Pakistan and German Academic Exchange Service (DAAD) for financial support during these experiments.

\section{REFERENCES}

1. Toft C, Andersson SG. 2010. Evolutionary microbial genomics: insights into bacterial host adaptation. Nat. Rev. Genet 11:465-475. doi: 10.1038/nrg2798.

2. White JA. 2011. Caught in the act: Rapid, symbiont-driven evolution. Bioessays. 33:823829. doi: 10.1002/bies.201100095.

3. Kikuchi Y. 2009. Endosymbiotic Bacteria in Iinsects: Their Diversity and Culturability. Microbes. Environ. 24:195-204. doi: 10.1264/jsme2.ME09140S.

4. Montllor CB, Maxmen A, Purcell AH. 2002. Facultative bacterial endosymbionts benefit pea aphids Acyrthosiphon pisum under heat stress. Ecol. Entomol. 27:189-195. doi: 10.1046/j.1365-2311.2002.00393.x.

5. Oliver KM, Degnan PH, Burke GR, Moran. NA. 2010. Facultative symbionts in aphids and the horizontal transfer of ecologically important traits. Annu. Rev. Entomol. 55:247-266. doi: 10.1146/annurev-ento-112408-085305. 
6. Frago E, Dicke M, Godfray HC. 2012. Insect symbionts as hidden players in insectplant interactions. Trends. Ecol. Evol. 27:705-711. http://dx.doi.org/10.1016/j.tree.2012.08.013.

7. Oliver KM, Campos J, Moran NA, Hunter MS. 2008. Population dynamics of defensive symbionts in aphids. Proc. R. Soc. B. 275:293-299. doi:10.1098/rspb.2007.1192.

8. Himler AG, Adachi-Hagimori T, Bergen JE, Kozuch A, Kelly SE, Tabashnik BE, Chiel E, Duckworth VE, Dennehy TJ, Zchori-Fein E. 2011. Rapid spread of a bacterial symbiont in an invasive whitefly is driven by fitness benefits and female bias. Sci. 332:254-256. doi: 10.1126/science.1199410.

9. Jaenike J, Brekke TD. 2011. Defensive endosymbionts: a cryptic trophic level in community ecology. Ecol. Lett. 14:150-155. doi: 10.1111/j.1461-0248.2010.01564.x.

10. Godfray HC. 2004. Parasitoids. Curr. Biol. 14:R456. doi: 10.1016/j.cub.2004.06.004

11. Rehman A, Powell. W. 2010. Host selection behaviour of aphid parasitoids (Aphidiidae: Hymenoptera). J. Plant Breed. Crop Sci. 2:299-311.

12. Burger J, Reijnen TM, Van Lenteren JC, Vet LE, 2004. Host feeding in insect parasitoids: why destructively feed upon a host that excretes an alternative? Entomol. Exp. Appl. 112:207-215. doi: 10.1111/j.0013-8703.2004.00196.x.

13. Heimpel GE, Collier TR. 1996. The evolution of host-feeding behaviour in insect parasitoids. Biol. Rev. 71:373-400. doi: 10.1111/j.1469-185X.1996.tb01279.x.

14. Zang LS, Liu TX. 2009. Food-deprived host-feeding parasitoids kill more pest insects. Biocontrol. Sci. Tech. 19:573-583. doi: http://dx.doi.org/10.1080/09583150902912673.

15. Thomas MB, Blanford S. 2003. Thermal biology in insect-parasite interactions. Trends. Ecol. Evol. 18:344-350. doi: 10.1016/S0169-5347(03)00069-7.

16. Dill LM, Fraser AH, Roitberg BD. 1990. The economics of escape behaviour in the pea aphid, Acyrthosiphon pisum. Oecol. 83:473-478. doi: 10.1007/BF00317197.

17. Leather SR. 1993. Overwintering in six arable aphid pests: a review with particular relevance to pest management. J. Appl. Entomol. 116:217-233. doi: 10.1111/j.14390418.1993.tb01192.x.

18. Hansen LS, Jensen KM. 2002. Effect of temperature on parasitism and host-feeding of Trichogramma turkestanica (Hymenoptera: Trichogrammatidae) on Ephestia kuehniella (Lepidoptera: Pyralidae). J. Econ. Entomol. 95:50-56. doi: http://dx.doi.org/10.1603/0022-0493-95.1.50. 
19. Legrand MA, Colinet, H, Vernon P, Hance T. 2004. Autumn, winter and spring dynamics of aphid Sitobion avenae and parasitoid Aphidius rhopalosiphi interactions. Ann. Appl. Bio. 145:139-144. doi: 10.1111/j.1744-7348.2004.tb00369.x.

20. Irlich UM, Terblanche JS, Blackburn TM, Chown S. L. 2009. Insect rate-temperature relationships: Environmental variation and the metabolic theory of ecology. Am. Nat. 174:819-835. doi: 10.1086/647904.

21. Mostowy R, Engelstädter J. 2011. The impact of environmental change on host-parasite coevolutionary dynamics. Proc. R. Soc. B. 278:2283-2292. doi: 10.1098/rspb.2010.2359.

22. Bannerman JA, Gillespie DR, Roitberg BD. 2011. The impacts of extreme and fluctuating temperatures on trait-mediated indirect aphid-parasitoid interactions. Ecol. Entomol. 36:490-498. doi: 10.1111/j.1365-2311.2011.01292.x.

23. Nunes MV, Hardie J. 1999. The effect of temperature on the photoperiodic 'counters' for female morph and sex determination in two clones of the black bean aphid, Aphis fabae. Physiol. Entomol. 24:339-345. doi: 10.1046/j.1365-3032.1999.00148.x.

24. Lu W, Kuo M. 2008. Life table and heat tolerance of Acyrthosiphon pisum (Hemiptera: Aphididae) in subtropical Taiwan. Entomol. Sci. 11:273-279. doi: 10.1111/j.14798298.2008.00274.x.

25. Fenton B, Kasprowicz L, Malloch G, Pickup J. 2010. Reproductive performance of asexual clones of the peach-potato aphid, (Myzus persicae, Homoptera: Aphididae), colonising Scotland in relation to host plant and field ecology. Bull. Entomol. Res. 100:451-460. doi:10.1017/S0007485309990447.

26. Hance T, van Baaren J, Vernon P, Boivin G. 2006. Impact of extreme temperatures on parasitoids in a climate change perspective. Annu. Rev. Entomol. 52:107. doi: 10.1146/annurev.ento.52.110405.091333.

27. Bensadia F, Boudreault S, Guay JF, Michaud D, Cloutier C. 2006. Aphid clonal resistance to a parasitoid fails under heat stress. J. Insect. Physiol. 52:146-157. doi: 10.1016/j.jinsphys.2005.09.011.

28. Polgár LA, Hardie J. 2000. Diapause induction in aphid parasitoids. Entomol. Exp. Appl. 97:21-27. doi: 10.1023/A:1004004801807.

29. Ismaeil I, Doury G, Desouhant E, Dubois F, Prevost G, Couty A. 2013. Transgenerational effects of mild heat stress on the life history traits of an aphid parasitoid. PLoS one. 8(2):e54306. doi:10.1371/journal.,pone.0054306. 
30. Thomson LJ, Macfadyen S, Hoffmann AA. 2010. Predicting the effects of climate change on natural enemies of agricultural pests. Biol. Control. 52:296-306. doi:10.1016/j.biocontrol.2009.01.022.

31. Bernal J, Gonzalez D. 1993. Temperature requirements of four parasites of the Russian wheat aphid Diuraphis noxia. Entomol. Exp. Appl. 69:173-182. doi: 10.1007/BF02380643.

32. Thireau J, Regniere J. 1995. Development, reproduction, voltinism and host synchrony of Meteorus trachynotus with its hosts Choristoneura fumiferana and C. rosaceana. Entomol. Exp. Appl. 76:67-82. doi: 10.1111/j.1570-7458.1995.tb01947.x.

33. Liu, Y. H. and J. H. Tsai. 2002. Effect of temperature on development, survivorship, and fecundity of Lysiphlebia mirzai (Hymenoptera: Aphidiidae), a parasitoid of Toxoptera citricida (Homoptera: Aphididae). Environ. Entomol. 31(2):418-424. doi: http://dx.doi.org/10.1603/0046-225X-31.2.418.

34. Bell HA, Marris GC, Smethurst F, Edwards JP. 2003. The effect of host stage and temperature on selected developmental parameters of the solitary endoparasitoid Meteorus gyrator (Thun.) (Hym., Braconidae). J. Appl. Ent. 127:332-339. doi: 10.1046/j.1439-0418.2003.00760.x.

35. Kalyebi A, Overholt WA, Schulthess F, Mueke JM, Hassan SA, Sithanantham S. 2005. Functional response of six indigenous trichogrammatid egg parasitoids (Hymenoptera: Trichogrammatidae) in Kenya: influence of temperature and relative humidity. Biol. Control. 32:164-171. doi:10.1016/j.biocontrol.2004.09.006.

36. Schirmer S, Sengonca C, Blaeser P. 2008. Influence of abiotic factors on some biological and ecological characteristics of the aphid parasitoid Aphelinus asychis (Hymenoptera: Aphelinidae) parasitizing Aphis gossypii (Sternorrhyncha: Aphididae). Eur. J. Entomol. 105:121-129. doi: 10.14411/eje.2008.017.

37. van Emden HF, Harrington R. 2007. Aphids as crop pests. CABI. doi:10.1079/9780851998190.0000.

38. Alkhedir H, Karlovsky P, Vidal S. 2013. Relationship between water soluble carbohydrate content, aphid endosymbionts and clonal performance of Sitobion avenae on cocksfoot cultivars. PLoS. One. 8:e54327. doi:10.1371/journal.,pone.0054327.

39. Simon JC, Boutin S, Tsuchida T, Koga R, Gallic JF, Frantz A, Outreman Y, Fukatsu T. 2011. Facultative symbiont infections affect aphid reproduction. PLoS One 6(7):e21831. doi:10.1371/journal.,pone.0021831. 
40. Koga R, Tsuchida T, Fukatsu T. 2003. Changing partners in an obligate symbiosis: a facultative endosymbiont can compensate for loss of the essential endosymbiont Buchnera in an aphid. Proc. R. Soc. B. 270:2543-2550. doi: 10.1098/rspb.2003.2537.

41. Chen H, Rangasamy M, Tan SY, Wang H, Siegfried BD. 2010. Evaluation of five methods for total DNA extraction from western corn rootworm beetles. PLoS One 5:e11963. doi: 10.1371/journal.,pone.0011963.

42. Abbott WS. 1925. A method of computing the effectiveness of an insecticide. J. Econ. Entomol. 18:265-267.

43. Analytical Software. 2003. Statistix 8.1. Tallahassee, FL: Analytical Software.

44. Cayetano L, Vorburger C. 2013. Effects of heat shock on resistance to parasitoids and on life history traits in an aphid/endosymbiont system. PloS One 8(10):e75966. doi:10.1371/journal.,pone.0075966.

45. Romo CM, Tylianakis JM. 2013. Elevated temperature and drought interact to reduce Parasitoid effectiveness in suppressing hosts. PLoS One 8 (3):e58136. doi:10.1371/journal.,pone.0058136.

46. Flinn PW. 1991. Temperature-dependent functional response of the parasitoid Cephalonomia waterstoni (Gahan) (Hymenoptera: Bethylidae) attacking rusty grain beetle larvae (Coleoptera: Cucujidae). Environ. Entomol. 20:872-876. doi: 10.1093/ee/20.3.872.

47. Zamani AA, Talebi AA, Fathipour Y, Baniameri V. 2006. Temperature-dependent functional response of two aphid parasitoids, Aphidius colemani and Aphidius matricariae (Hymenoptera: Aphidiidae), on the cotton aphid. J. Pest Sci. 79:183-188. doi: 10.1007/s10340-006-0132-y.

48. Menon A, Flinn PW, Dover BA. 2002. Influence of temperature on the functional response of Anisopteromalus calandrae (Hymenoptera: Pteromalidae), a parasitoid of Rhyzopertha dominica (Coleoptera: Bostrichidae). J. Stored. Prod. Res. 38:463-469. doi:10.1016/S0022-474X(01)00050-9.

49. Farhad A, Talebi AA, Fathipour Y. 2011. Foraging behavior of Praon volucre (Hymenoptera: Braconidae) a parasitoid of Sitobion avenae (Hemiptera: Aphididae) on wheat. Psyche. J. Entomol. 2011. doi:10.1155/2011/868546.

50. Oliver KM, Russell JA, Moran NA, Hunter MS. 2003. Facultative bacterial symbionts in aphids confer resistance to parasitic wasps. Proc. Natl. Acad. Sci. 100:1803-1807. doi:10.1073/pnas.0335320100. 
51. Oliver KM, Moran NA, Hunter MS. 2005. Variation in resistance to parasitism in aphids is due to symbionts not host genotype. Proc. Natl. Acad. Sci. 102:12795-12800. doi:10.1073/pnas.0506131102.

52. Scarborough CL, Ferrari J, Godfray HC. 2005. Aphid protected from pathogen by endosymbiont. Sci. 310:1781. doi:10.1126/science.1120180.

53. Vorburger C, Gehrer L, Rodriguez P. 2010. A strain of the bacterial symbiont Regiella insecticola protects aphids against parasitoids. Bio. Lett. 6:109-111. doi: 10.1098/rsbl.2009.0642.

54. Lukasik P, Dawid MA, Ferrari J, Godfray HC. 2013. The diversity and fitness effects of infection with facultative endosymbionts in the grain aphid, Sitobion avenae. Oecol. 173:985-996. doi: 10.1007/s00442-013-2660-5.

55. Hansen AK, Vorburger C, Moran NA. 2012. Genomic basis of endosymbiontconferred protection against an insect parasitoid. Genome Res. 22:106-114. doi:10.1101/gr.125351.111.

56. Schmid M, Sieber R, Zimmermann Y, Vorburger C. 2012. Development, specificity and sublethal effects of symbiont-conferred resistance to parasitoids in aphids. Funct. Ecol. 26:207-215. doi: 10.1111/j.1365-2435.2011.01904.x.

57. Polin S, Simon J, Outreman Y. 2014. An ecological cost associated with protective symbionts of aphids. Ecol. Evol. 4(6):836-840. doi: 10.1002/ece3.991.

58. Costopoulos K, Kovacs JL, Kamins A, Gerardo NM. 2014. Aphid facultative symbionts reduce survival of the predatory lady beetle Hippodamia convergens. BMC Ecol. 14:5. doi:10.1186/1472-6785-14-5.

59. Cayetano L, Vorburger C. 2013. Genotype-by-genotype specificity remains robust to average temperature variation in an aphid/endosymbiont/parasitoid system. J. Evol. Biol. 26:1603-1610. doi: 10.1111/jeb.12154.

60. Guay JF, Boudreault S, Michaud D, Cloutier C. 2009. Impact of environmental stress on aphid clonal resistance to parasitoids: role of Hamiltonella defensa bacterial symbiosis in association with a new facultative symbiont of the pea aphid. J. Insect Physiol. 55:919926. doi:10.1016/j.jinsphys.2009.06.006.

61. Russell JA, Moran NA. 2006. Costs and benefits of symbiont infection in aphids: variation among symbionts and across temperatures. Proc. R. Soc. B. 273:603-610. doi: 10.1098/rspb.2005.3348. 
62. Chen D, Montllor CB, Purcell AH. 2000. Fitness effects of two facultative endosymbiotic bacteria on the pea aphid, Acyrthosiphon pisum, and the blue alfalfa aphid, A. kondoi. Entomol. Exp. Appl. 95:315-323. doi: 10.1046/j.1570-7458.2000.00670.x.

63. Oliver KM, Noge K, Huang EM, Campos JM, Becerra JX, Hunter MS. 2012. Parasitic wasp responses to symbiont-based defense in aphids. BMC Biol. 10:11. doi:10.1186/1741-7007-10-11.

64. Cheng R-X, Meng L, Mills NJ, Li B. 2011. Host preference between symbiotic and aposymbiotic Aphis fabae, by the aphid parasitoid, Lysiphlebus ambiguus. J. Insect Sci. 11:81. doi:10.1673/031.011.8101.

65. Li S, Falabella P, Giannantonio S, Fanti P, Battaglia D, Digilio MC, Völkl W, Sloggett JJ, Weisser W, Pennacchio F. 2002. Pea aphid clonal resistance to the endophagous parasitoid Aphidius ervi. J. Insect Physiol. 48:971-980. doi:10.1016/S0022-1910(02)00176-2.

66. von Burg S, Ferrari J.. Müller CB, Vorburger C. 2008. Genetic variation and covariation of susceptibility to parasitoids in the aphid Myzus persicae: no evidence for trade-offs. Proc. R. Soc. B. 275:1089-1094. doi:10.1098/rspb.2008.0018.

67. Vorburger C, Sandrock C, Gouskov A, Castanda LE, and J. Ferrari. 2009. Genotypic variation and the role of defensive endosymbionts in an all-parthenogenetic host-parasitoid interaction. Evol. 63:1439-1450. doi:10.1111/j.1558-5646.2009.00660.x.

68. Ferrari J, Müller CB, Kraaijeveld AR, Godfray HC. 2001. Clonal variation and covariation in aphid resistance to parasitoids and a pathogen. Evol. 55:1805-1814. doi: http://dx.doi.org/10.1554/0014-3820(2001)055[1805:CVACIA]2.0.CO;2.

69. Stacey DA, Fellowes MDE. 2002. Influence of temperature on pea aphid Acyrthosiphon pisum (Hemiptera: Aphididae) resistance to natural enemy attack. Bull. Entomol. Res. 92:351-357. doi: 10.1079/BER2002173.

70. Godfray HC. 1994. Parasitoids: behavioral and evolutionary ecology. Princeton University Press.

71. Lessard E, Boivin G. 2013. Effect of low temperature on emergence, fecundity, longevity and host-feeding by Trichogramma brassicae. BioControl. 58:319-329. doi: 10.1007/s10526-012-9493-8. 


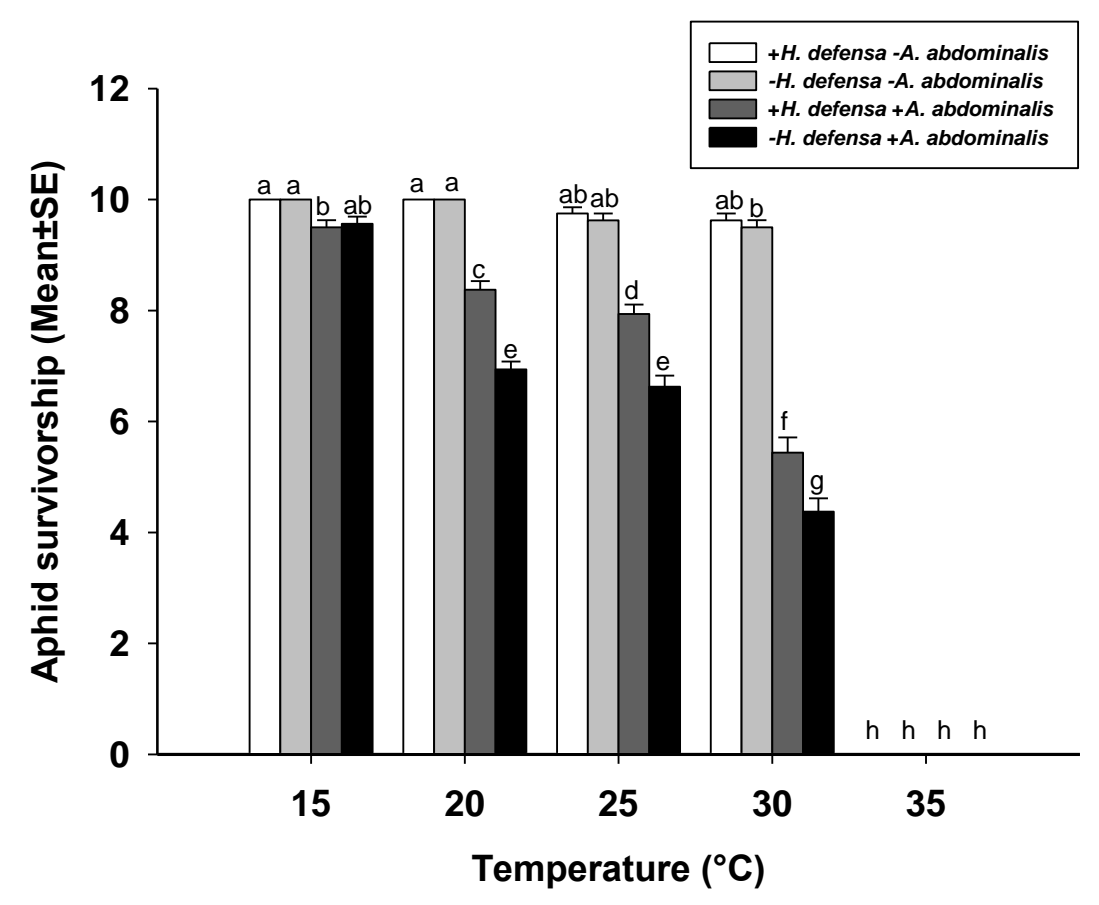

Figure 1a: Survivorship of S. avenae (with and without Hamiltonella defensa) against $A$. abdominalis host feeding at different temperatures.

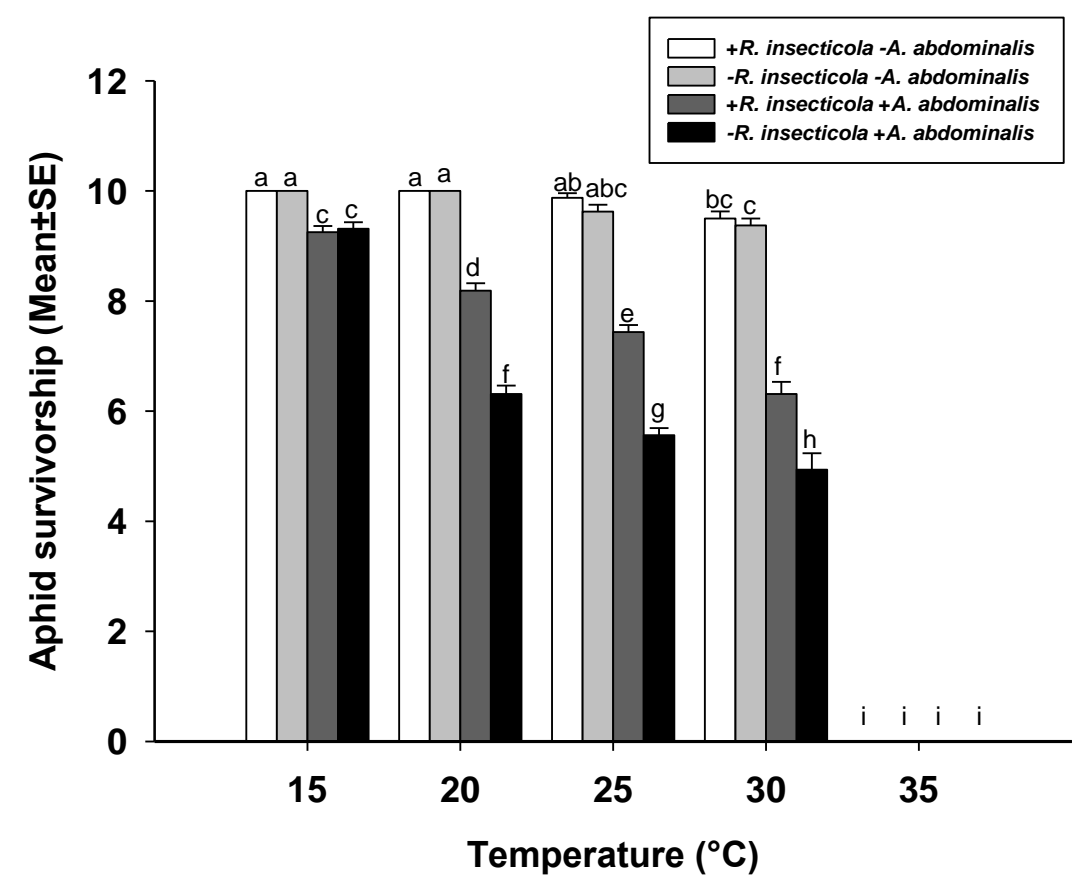

Figure 1b: Survivorship of $S$. avenae (with and without Regiella insecticola) against $A$. abdominalis host feeding at different temperatures. 


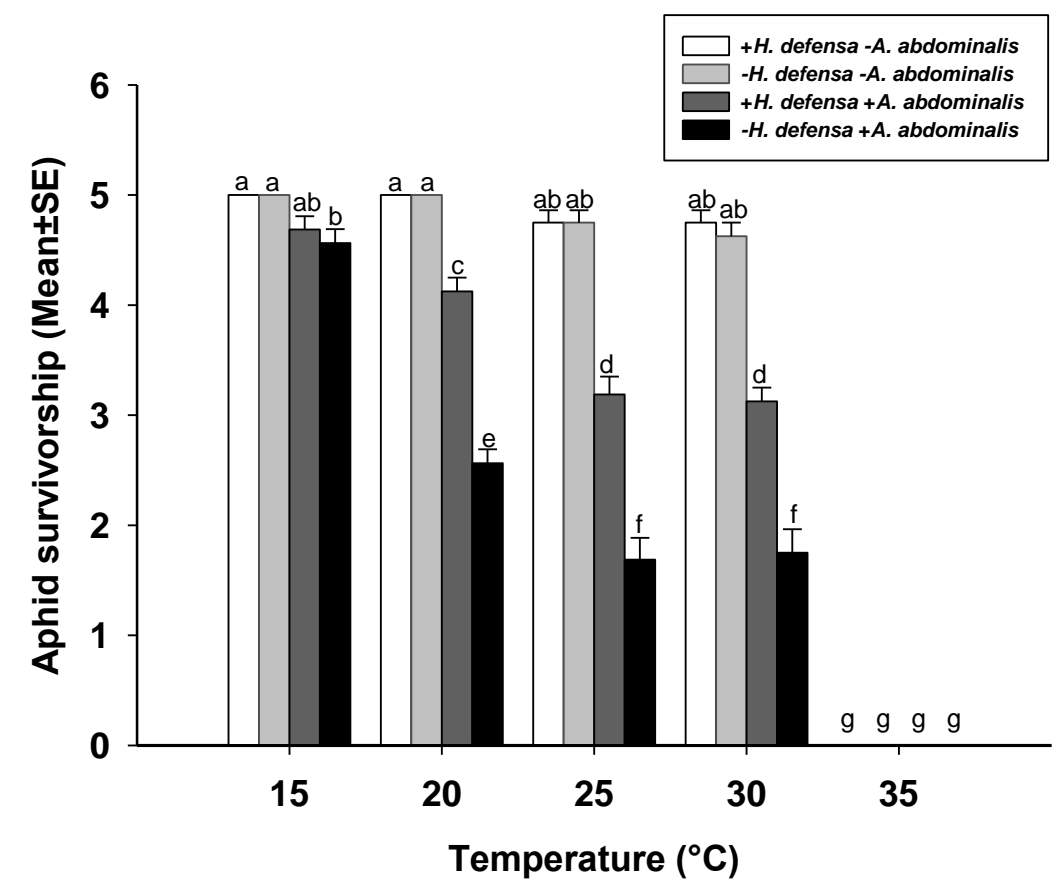

Figure 2a: Survivorship of S. avenae (with and without Hamiltonella defensa) against $A$. abdominalis host feeding at different temperatures.

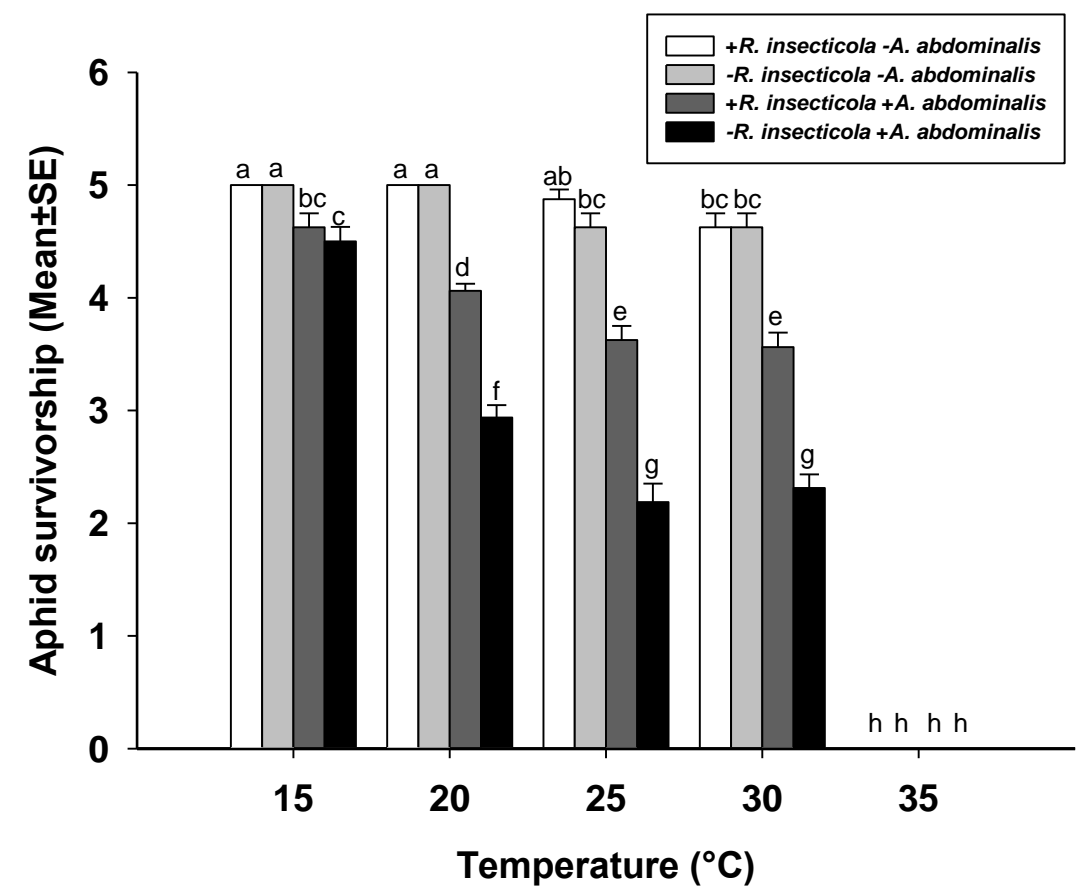

Figure 2b: Survivorship of S. avenae (with and without Regiella insecticola) against $A$. abdominalis host feeding at different temperatures. 


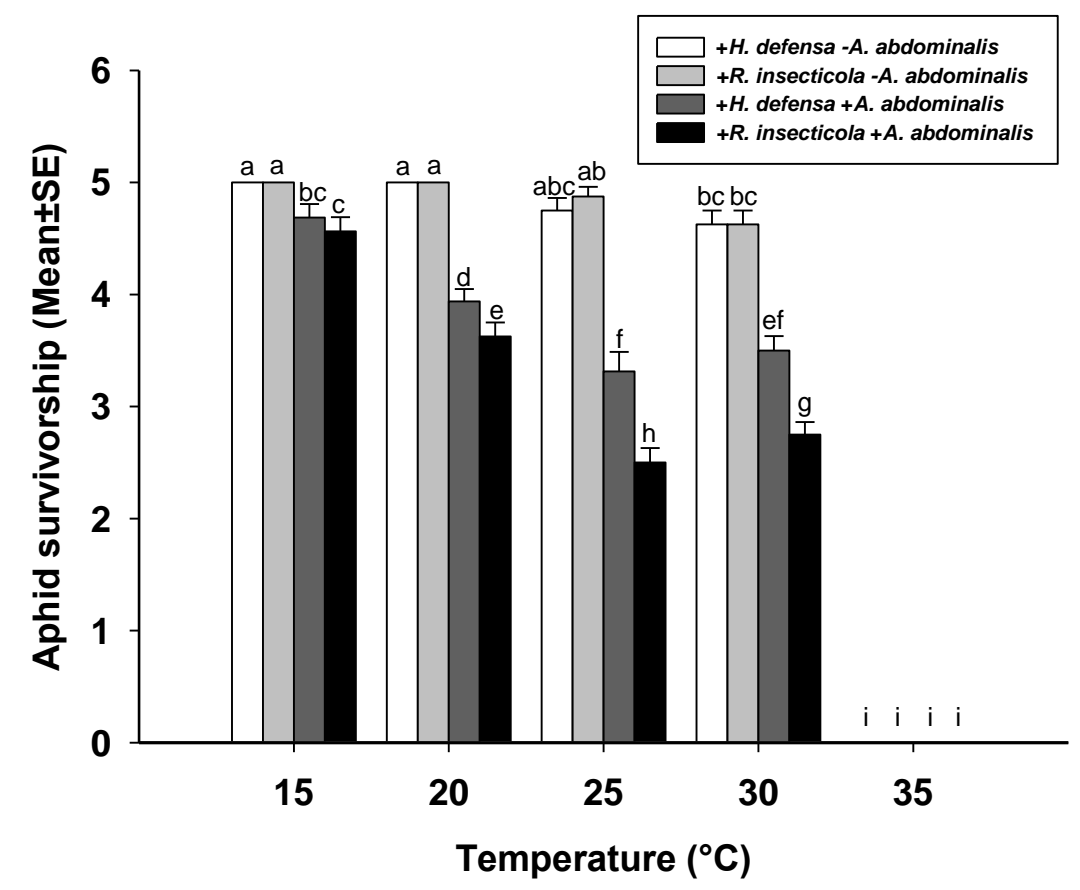

Figure 3a: Survivorship of S. avenae against A. abdominalis host feeding (with Hamiltonella defensa and Regiella insecticola) at different temperatures indicating clonal resistance.

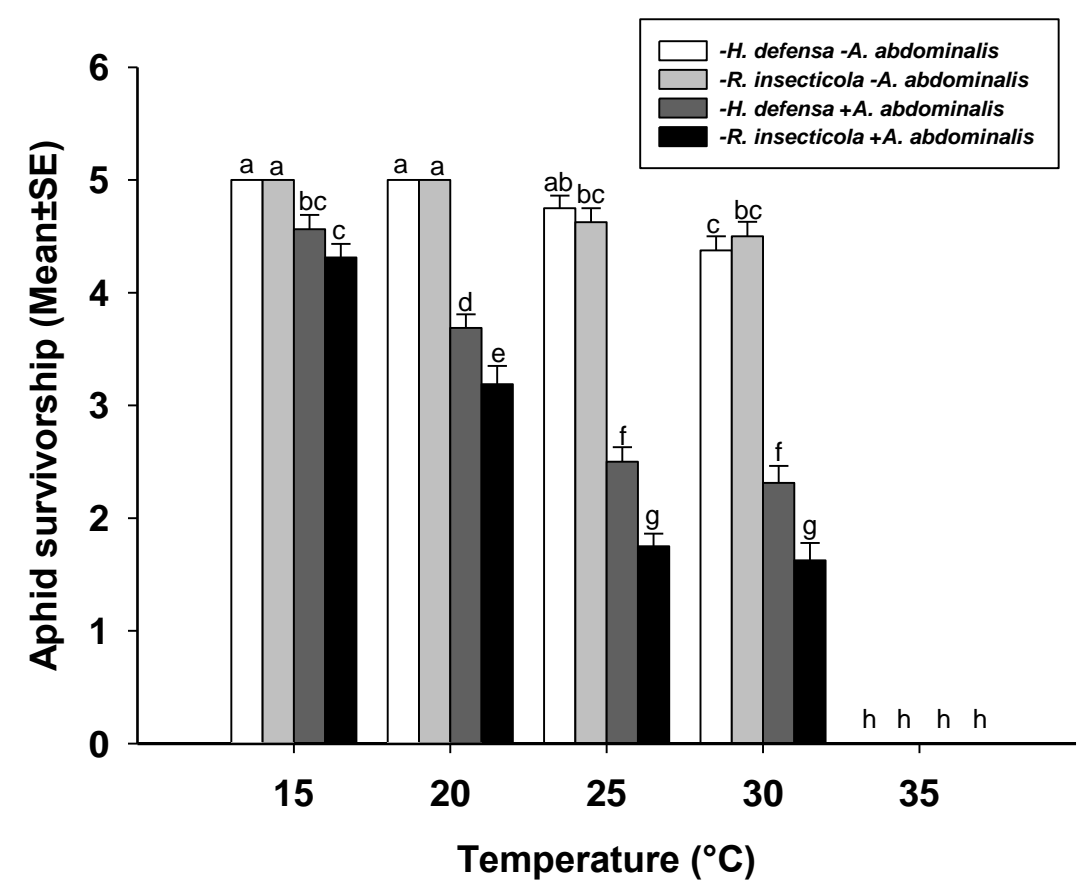

Figure 3b: Survivorship of S. avenae against A. abdominalis host feeding (without Hamiltonella defensa and Regiella insecticola) at different temperatures indicating clonal resistance. 
Table 1: Differences of corrected \% mortalities (Mean $\pm \mathrm{SE}$ ) in $S$. avenae by A. abdominalis host feeding in no choice and choice tests at variable temperatures.

\begin{tabular}{ccccc}
\hline & \multicolumn{2}{c}{ Clone 5 } & \multicolumn{2}{c}{ Clone 7 } \\
\hline Temp & No choice & Choice & No choice & Choice \\
\hline $\mathbf{1 5}^{\circ} \mathrm{C}$ & $-0.62 \pm 1.92 \mathrm{~b}$ & $2.51 \pm 4.42 \mathrm{a}$ & $0.62 \pm 1.71 \mathrm{~b}$ & $2.5 \pm 4.41 \mathrm{a}$ \\
$\mathbf{2 0}^{\circ} \mathrm{C}$ & $14.37 \pm 1.57 \mathrm{~b}$ & $31.25 \pm 4.06 \mathrm{a}$ & $18.75 \pm 1.79 \mathrm{~b}$ & $22.51 \pm 2.51 \mathrm{a}$ \\
$\mathbf{2 5}^{\circ} \mathrm{C}$ & $12.63 \pm 3.59 \mathrm{~b}$ & $32.51 \pm 5.71 \mathrm{a}$ & $17.43 \pm 2.03 \mathrm{~b}$ & $27.52 \pm 4.33 \mathrm{a}$ \\
$\mathbf{3 0}^{\circ} \mathrm{C}$ & $10.34 \pm 4.22 \mathrm{~b}$ & $28.75 \pm 4.59 \mathrm{a}$ & $13.75 \pm 4.2 \mathrm{~b}$ & $27.18 \pm 3.62 \mathrm{a}$ \\
$\mathbf{3 5}^{\circ} \mathrm{C}$ & $0.00 \pm 0.00 \mathrm{a}$ & $0.00 \pm 0.00 \mathrm{a}$ & $0.00 \pm 0.00 \mathrm{a}$ & $0.00 \pm 0.00 \mathrm{a}$ \\
\hline
\end{tabular}




\title{
Chapter 4
}

\section{Specificity of bacterial secondary symbionts of Sitobion avenae in resistance against host feeding and parasitism}

\author{
${\text { Sajjad } \mathrm{Ali}^{\mathrm{a}} \text {, Petr Karlovsky }}^{\mathrm{b}}$ and Stefan Vidal ${ }^{\mathrm{a}}$ \\ Department of Crop Sciences, Agricultural Entomology, Georg-August University, Göttingen, Germany ${ }^{\text {a }}$, Department of \\ Crop Sciences, Molecular Phytopathology and Mycotoxin Research, Georg-August University, Göttingen, Germany ${ }^{\text {b }}$
}

\begin{abstract}
Parasitoid-host interactions are highly specialized. Host behavioural and physical defences determine host ranges for parasitoids. Genetic variations among aphid populations present substantial resistance to a particular parasitoid but particular host genetic background can exhibit different levels of resistance against multiple parasitoids. Besides the innate defence system, the symbiotic microorganisms can also significantly alter the outcome of such interactions. Symbiont-parasitoid specificity in resistance may modify aphid-parasitoid interactions. Two parasitoids, Aphelinus abdominalis and Aphidius rhopalosiphi and genetically identical Sitobion avenae clones possessed Hamiltonella defensa and Regiella insecticola and lacked them were used to assess defence generality or specificity of these symbionts in this particular aphid-symbiont system. The results revealed that $H$. defensa conferred a general defence against both parasitoids but $R$. insecticola was significantly resistant against host feeding of A. abdominalis while it didn't provide defence to $S$. avenae against $A$. rhopalosiphi in no choice trials. In choice trials, A. abdominalis host preference behaviour was modified by $H$. defensa and $R$. insecticola towards symbionts free $S$. avenae but these symbionts didn't alter host preference of $A$. rhopalosiphi. Genetic variations in $S$. avenae provided resistance against A. abdominalis but it could not alter A. rhopalosiphi virulence. A. abdominalis development in $S$. avenae was negatively affected by both of these symbionts but $A$. rhopalosiphi got negative impact only from $H$. defensa. It is inferred that bacterial endosymbionts may drive host selection process by parasitoids depending upon genotype-by-genotype specificity. Bacterial endosymbionts might be a critical factor to reshape the aphid-parasitoid ecological interactions.
\end{abstract}

Keywords: Sitobion avenae, host feeding, parasitism, A. abdominalis, A. rhopalosiphi 


\section{Introduction}

Insect-microorganism symbiosis exists in nature with diverse interactions. Most of the insects in general, specifically aphids rely on symbiotic bacteria for their life activities like nutritional requirements [1,2], thermal tolerance [3], host defenses [4-7], insecticide detoxification [8], host plant adaptation [9,10], life history trait modifications [11,12], body colouration [13], male killing [14,15], sexual aberrations [16] and reproduction and development [17-20]. The fitness advantages to the insect hosts and the dynamic transmission over host generations favour the wide spread of heritable microbial symbionts [21,22]. Aphids have emerged as ideal organisms to study symbiotic interactions. For instance, Buchnera aphidicola, the primary bacterial symbiont in aphids, is associated with the provision of essential amino acid deficiencies in aphids' diet which improve the nutritional physiology in Hemiptera [2]. B. aphidicola is not the only bacterial symbiont harboured by aphid populations. The natural enemies are constant threat to the aphid's life. Despite natural clonal variations among aphid populations to resist the natural enemies [23], aphids require substantial investments in defense mechanisms for their survival. So, aphids have adapted a wide range of symbiotic microorganisms in addition to their obligate bacterial associates. Hamiltonella defensa and Regiella insecticola are among the major distribution [24]. They offer a wide variety of protection services to their insect hosts against their natural enemies including parasitic wasps, fungal pathogens and predators [4-7]. The protection mechanism adopted by $R$. insecticola is yet not clear but $H$. defensa rely on a toxin-encoding bacteriophage (APSE) for its virulence against parasitoids. These toxins appear to affect the parasitoids negatively [25]. In addition to protection services, $R$. insecticola is also linked with host plant utilization of many aphid species. It is widely associated with pea aphid populations feeding on Trifolium plants [9,10]. S. symbiotica and $H$. defensa confer higher fitness to pea aphids under high temperature [3]. Pea aphids, harbouring $S$. symbiotica and $H$. defensa, exceed their reproduction rate when they are confronted to alarm pheromones as an indicator of death risk [20]. Among natural enemies, hymenopteran parasitic wasps strongly curtail aphid populations in the ecosystem [26]. Parasitoids are key player in almost all terrestrial ecosystems. They are diverse, plentiful and good ecological exploiter to influence the host population dynamics [27,28]. They rely on successful parasitism in host for their existence as a part of their life cycle. Their hosts have developed certain defences to resist parasitoids attack under strong selection pressure and in turn parasitoids have to evolve counter-resistance system against these defences to exploit the host successfully $[29,30]$. 
Adoption, tolerance, maintenance, and transmission of bacterial secondary symbionts among aphid populations are important in defence strategies which are evolved over long time [31].

Parasitoid-host interactions are highly specialized and antagonistic interactions to exhibit the co-evolutionary relationships in nature [29,30]. Host behavioural response, parasitoid development in hosts and environmental factors specify host ranges for parasitoids. Host behavioural and physical defences determine recognition and orientation of parasitoids towards the host aphids. Once parasitoids overcome such defences and enter into the hosts, their virulence attributes directly interact with host immunity [32,33]. Besides the innate defence system, the symbiotic microorganisms can also significantly alter the outcome of such interactions [34]. Usually insect hosts are attacked by multiple parasitoids species. In return, hosts may evolve defences against these parasitoids that vary from general to specific. Many aphid species also face multiple parasitic wasp species and heritable bacterial endosymbionts confer resistance against some of these wasps [35]. Defence mechanisms are reshaped upon the recurrence of multiple parasitoids and host encounters and the rivalry of host and parasitoids can force the hosts to devise a general defence system against various parasitoids or to evolve a robust defence against a certain parasitoid and frail defence against other enemies [36-38].

Naturally, genetic or clonal variations among aphid populations present substantial differences to resist a particular parasitoid and a particular genetic background exhibits different levels of resistance against different parasitoid genotypes [23,39]. Particular bacterial symbiont in genetically identical host may or may not offer partial resistance against parasitism depending upon the genotypic backgrounds of the parasitoids indicating strong genotype $\mathrm{x}$ genotype specificity [40,41]. This symbiont-parasitoid specificity in resistance may modify aphid-parasitoid interactions which are, otherwise, not observed when defensive symbionts are not present in the aphid hosts [42]. Although there are ample evidences for genotype specificity in hosts-parasite interactions but the picture is less clear for generality of protection conferred by a particular symbiont in single host with identical genetic background against multiple species of parasitoid regarding host feeding and parasitism interactions. Whether $H$. defensa and $R$. insecticola in Sitobion avenae provide a general defence or they target only particular parasitoid species in this particular aphid-symbiont system? The answer can help to understand the driving forces promoting the wide occurrence of $H$. defensa and $R$. insecticola not only in S. avenae but also in many other aphid species. Genetically identical wheat aphid clones possessed $H$. defensa and $R$. Insecticola and lacked these symbionts were 
developed by injecting antibiotics to these aphid clones through micro injections to cure these symbionts. Ultimately, we were capable to explore the specificity of particular isolates of $H$. defensa and $R$. insecticola in genetically identical $S$. avenae for their resistance against host feeding and parasitism by exposing them to genetically different parasitoids Aphelinus abdominalis and Aphidius rhopalosiphi. Their ability to affect the development of these parasitoids was also evaluated.

\section{Materials and methods}

\section{Insects}

Sitobion avenae: Two genotypes of Sitobion avenae naturally harbouring Hamiltonella defensa (clone 5) and Regiella insecticola (clone 7) collected from Giessen (Germany) were maintained on wheat plants as described already [43].

Aphelinus abdominalis: Re-natur GmbH. (Germany) provided the parasitoid Aphelinus abdominalis. The parasitoids were allowed to feed on 50\% honey solution for 24 hours and female wasps were utilized next day for the host feeding trials.

Aphidius rhopalosiphi: Katz Biotech AG (Germany) provided the parasitoid Aphidius rhopalosiphi in the form of mummies. The mummies were stored at $24 \pm 1{ }^{\circ} \mathrm{C}$ for adult emergence. When the adults emerged, they were given $50 \%$ honey solution for 24 hours for feeding and mating and female wasps were utilized next day for the parasitism trials.

\section{Elimination of BSS by antibiotics}

H. defensa free clone 5 wheat aphids were obtained by injecting an antibiotic mixture of ampicillin, cefotaxime and gentamycin $(250 \mu \mathrm{g} / \mathrm{ml})$ through micro-injections with a dose of $0.1-0.2 \mu \mathrm{l} / \mathrm{mg}$ of aphid body weight [15]. Similarly, $R$. insecticola was cured from wheat aphids of clone 7 by injecting ampicillin $(1 \mu \mathrm{g} / \mathrm{mg}$ of the body weight of aphid) [44]. Antibiotic treatment was given to $\mathrm{CO}_{2}$ anaesthetized wheat aphids. The treated wheat aphids were allowed to reproduce for 3-4 days on wheat plants. DNA was extracted from newly born nymphs following CTAB protocol [45] to verify the BSS removal by diagnostic PCR. HDFn [5-ATGAAGTCGCGAGACCAAA-3] and HDRn [5-GCTTTCCCTCGCAGGTTC-3] were specific primers used for $H$. defensa and RIFn [5-GAAGGCGGTAAGAGTAATATGC-3] and RIRn [5-CCCCGAAGGTTAAGCTACCTA-3] for $R$. insecticola. PCR conditions were: 
$94^{\circ} \mathrm{C}$ for 3 minutes followed by 30 cycles of $94^{\circ} \mathrm{C}-30 \mathrm{~S} ; 60^{\circ} \mathrm{C}-40 \mathrm{~S} ; 72^{\circ} \mathrm{C}-90 \mathrm{~S}$. Finally products were incubated for 8 minutes at $72^{\circ} \mathrm{C}$. PCR reaction mixture was comprised of $1 \mu 1$ DNA template, $0.32 \mu \mathrm{M}$ of each primer, $2 \mathrm{mM} \mathrm{MgCl}_{2}, 200 \mu \mathrm{M}$ dNTPs, 1x PCR buffer and 0.25 units of Taq DNA polymerase in $25 \mu 1$ total volumes. $1.7 \%$ agarose gel was used to visualize PCR products using ethidium bromide. Eventually, we had wheat aphid clones 5 either possessed $H$. defensa (referred to as clone +5 ) or lacked $H$. defensa (referred to as clone -5 ) and 7 possessed $R$. insecticola (referred to as clone +7 ) or lacked $R$. insecticola (referred to as clone -7). BSS free wheat aphids were further maintained until $8^{\text {th }}$ generation to stabilize the curing of BSS before trials and diagnostic PCR was used to verify the BSS removal at each generation.

\section{Experiments}

\section{Response of bacterial secondary symbionts in Sitobion avenae against host feeding and parasitism (no choice trials)}

A. abdominalis and A. rhopalosiphi females were released in $90 \mathrm{~mm}$ Petri dishes containing 12 wheat aphids (second and third stage) from clone $+5,-5,+7$, and -7 each. The Petri dishes had filter papers and rooted wheat seedlings covered by wet cotton. The trial was conducted at $20 \pm 1{ }^{\circ} \mathrm{C}$ and $70 \pm 10 \% \mathrm{RH}$ with $16: 8$ photoperiod. The controls were also maintained without parasitoids. After 24 hours, parasitoids were removed and the dead aphids were counted after 24 and 48 hours for A. abdominalis host feeding and control treatments. While dead aphids were also counted for A. rhopalosiphi treatments and its controls for 5 days as unknown or natural mortality. The aphid mummies were collected on $6^{\text {th }}$ and $7^{\text {th }}$ day for $A$. rhopalosiphi treatments and total mortality was comprised of dead and mummified aphids. Replicates in which the introduced parasitoids escaped or died were discarded and set-up again for data collection.

\section{Host preference behaviour of parasitoids in response to BSS (choice trials)}

12 wheat aphids from clone +5 and -5 ( 6 aphids each) were released in the same Petri dish along with the parasitoid females. Tarsi of hind legs of the wheat aphids were trimmed by using sterilized blades under a magnifying glass to discriminate the wheat aphids possessed BSS and lacked BSS. The trimming of tarsi was done for BSS positive aphids in half of the replications and vice versa. Similarly, choice trial was conducted for cone +7 and -7 . The experimental conditions and data recording were the same as for no choice tests. The only 
difference was that wheat aphids possessed BSS and lacked BSS were separated after 24 hours and put into the separate Petri dishes.

\section{Host preference behaviour of parasitoids in response to clonal variation (choice trials)}

12 wheat aphids from genetically different [43] clones +5 and +7 (6 aphids each) were released in the same Petri dish along with the parasitoid females. The trimming of tarsi was done for the wheat aphids from clone +5 in half of the replications and for the wheat aphids from clone +7 in rest of replications. Similarly, another choice trial was also conducted for clones -5 and -7 . The experimental conditions and data recording were the same as for the above choice trials.

\section{Impact of BSS on larval development of parasitoids}

The lengths of hind tibia of emerged parasitoids were measured to assess the impact of BSS on larval development of parasitoids in aphids with and without BSS as an index of their body size [27] from mummified aphids (no choice trials) under a magnifying binocular (Stemi 2000-C, Carl Zeiss, Göttingen, Germany) with a predefined scale.

\section{Horizontal transmission of BSS via parasitoids}

Total DNA was extracted from all parasitoid females removed after exposure to wheat aphids and from 36 adult parasitoids emerged from wheat aphid mummies in no choice trials for BSS detection for both parasitoids species. Diagnostic PCR was performed in the same way as it was done for the wheat aphids to confirm BSS infection or contamination in the parasitoids.

\section{Data analyses}

All experiments were held with 16 replications over time. Factorial ANOVA (5\% significance level) was performed to analyse mortality in wheat aphids caused by the parasitoids with BSS and parasitoids as independent and mortality as dependent factors. Fisher's Least Significant Difference (LSD) test was applied to compare differences among \% mortality means. The data was square-root transformed [SQRT $(x+0.5)]$ for statistical analyses because mortalities in the controls were not normally distributed as compared to treatments. All graphic figures show mean values $( \pm \mathrm{SE})$ of $\%$ mortality in wheat aphids.

The ratios of corrected \% mortality means [46] in wheat aphids harboured BSS and lacked BSS in choice trials were compared by paired T-test at $5 \%$ significance level to no choice 
trials as an indicator of host preference behaviour in choice test. Ratios of corrected \% mortality was obtained by dividing corrected $\%$ mortality in aphids without BSS by corrected $\%$ mortality in aphids with BSS.

Parasitoid fitness in response to BSS presence or absence was evaluated by comparing the \% increase in the tibia of hind legs of the adults emerged from wheat aphids with and without BSS by running Fisher's Least Significant Difference (LSD) test after one-way ANOVA at $5 \%$ significance level. The means $( \pm \mathrm{SE})$ of $\%$ increase in the tibia are presented by plot box. All statistical analyses were performed by using software Statistix version 8.1.

\section{Results}

\section{Response of bacterial secondary symbionts in Sitobion avenae against host feeding and parasitism}

Wheat aphid sublines of clone 5 represent significant differences in susceptibility to both of the parasitoids. Clonal line +5 harbouring $H$. defensa showed significantly $(\mathrm{p}<0.005)$ less mortality against host feeding by A. abdominalis and parasitism by A. rhopalosiphi as compared to clonal line -5 . The partial resistance imparted by of $H$. defensa was consistent against both of the parasitoids and the mortality was decreased by $18 \%$ in wheat aphids harbouring $H$. defensa (Fig. 1a). Clonal lines of clone 7 showed significant $(\mathrm{p}<0.005)$ differences in susceptibility to host feeding by A. abdominalis but mortalities caused by $A$. rhopalosiphi parasitism didn't differ significantly $(\mathrm{p}>0.005)$. Clone +7 harbouring $R$. insecticola was more resistant against $A$. abdominalis as their mortality was lessen by ca. $18 \%$ as compared to clone -7 while the mortality was only $3 \%$ less in Clone +7 when they are exposed to A. rhopalosiphi which was not significant (Fig. 1b). The mortalities in all of the treatments were significantly higher than fatalities in control treatments. All control treatments showed zero mortality against host feeding by A. abdominalis while parasitism by A. rhopalosiphi caused nadir mortalities in controls (Fig. 1a \& 1b).

\section{Host preference behaviour of parasitoids in response to BSS}

The choice trials for wheat aphids from clone 5 (harbouring and lacking $H$. defensa) and clone 7 (harbouring and lacking $R$. insecticola) showed that BSS modified the host feeding pattern of A. abdominalis as compared to no choice trials. Wheat aphid fatalities were 
increased significantly $(\mathrm{p}<0.005)$ in wheat aphids without BSS and reduced in aphids harbouring BSS (Fig. 2a \& 2b). The mortalities among wheat aphids without BSS in choice tests were $30 \%$ more than the mortalities in wheat aphids harbouring BSS. This difference in $\%$ mortalities of wheat aphids with and without BSS was $18 \%$ in no choice trials. This larger difference in mortalities indicate that $A$. abdominalis preferred to feed more on wheat aphids without BSS. Furthermore, ratios of corrected $\%$ mortality means in wheat aphids lacked $H$. defensa and harboured $H$. defensa in choice trials were significantly $(\mathrm{p}<0.005)$ higher than no choice trials as an indicator of host preference behaviour in choice test (Table 1). While the trend of mortalities caused by A. rhopalosiphi in clone 5 and clone 7 in response to the presence or absence of $H$. defensa and $R$. insecticola was similar as we have seen in our no choice trials (Fig. 2a \& 2b). The difference in \% mortalities of wheat aphids with and without BSS was $19 \%$ in choice trials while it was $18 \%$ in no choice trials clone 5 sublines. In case of clone 7 sublines, the results of mortalities were same as we have observed in no choice trials. Additionally, ratios of corrected \% mortality means in wheat aphids lacked $R$. insecticola and harboured $R$. insecticola in choice and no choice trials were not different significantly (p>0.005). It indicates that A. rhopalosiphi did not prefer or rejected the wheat aphids on the basis of presence or absence of BSS (Table 1). All control treatments showed zero mortality against host feeding by A. abdominalis while parasitism by A. rhopalosiphi caused nadir mortalities in controls (Fig. 2a \& 2b).

\section{Host preference behaviour of parasitoids in response to clonal variation}

We further studied A. abdominalis host feeding and A. rhopalosiphi parasitism responses towards the wheat aphid host clonal or genotypic variations. The result showed that genetic or clonal variations among clone 5 and 7 with and without bacterial symbionts are also playing role to resist host feeding of A. abdominalis. Wheat aphids of clone 5 and -5 were significantly $(\mathrm{p}<0.005)$ less fed by A. abdominalis as compared to clone 7 and -7 irrespective of their bacterial facultative symbionts (Fig. 3a \& 3b). The mortalities in wheat aphid clones +5 and -5 were $11-13 \%$ less as compared to mortalities in wheat aphids of clones +7 and -7 . The genotypic expression of clone 5 present more vigorous response against A. abdominalis host feeding in presence or absence of bacterial facultative symbionts. When A. rhopalosiphi was exposed to the same genotypes of wheat aphids, it did not response towards the genotypic expressions of the clones 5 and 7 in both of the choice trials. Wheat aphid \% mortalities did not vary significantly $(\mathrm{p}>0.005)$ between these two clonal lines 5 and 7 with 
and without BSS (Fig. 3a \& 3b). All control treatments showed the zero or negligible dead aphids as compared to parasitoid treatments (Fig. 3a \& 3b).

\section{Impact of BSS on larval development of parasitoids}

Parasitoids development fitness is greatly affected by presence or absence of bacterial secondary symbionts in the host aphids [41,47]. LSD comparison of \% increase in the tibia length of hind leg of the adults, emerged from wheat aphids, in response to absence of $H$. defensa showed that $H$. defensa equally stressed the development of both parasitoids. But the impact of $R$. insecticola was significantly $(\mathrm{p}<0.005)$ different for both of the parasitoids (Fig. 4). $R$. insecticola suppressed the development of $A$. abdominalis in clone 7 as compared to the development of A. rhopalosiphi.

\section{Horizontal transmission of BSS via parasitoids}

Diagnostic PCR, for DNA extracted from parasitoids removed from no choice tests after 24 hours, showed that parasitoids were not infected with any of the bacterial facultative symbionts from wheat aphids harbouring BSS. A. abdominalis and A. rhopalosiphi emerged from mummies of wheat aphid clones $+5,-5,+7$, and -7 were also used to extract DNA for diagnostic PCR. The result was not different from the previous PCR result. It was obvious from PCR results that both of the parasitoids are not involved in horizontal transmission of BSS in S. avenae.

\section{Discussion}

To date, secondary symbiotic bacteria, in aphid populations, are widely known for variety of protective jobs for their hosts [48] but genetically identical host aphid possessing a certain strain of symbiotic bacterium may or may not vary in its resistance to different parasitoid species $[41,49]$ and it can affect host ranges for parasitoid species. Parasitoid host range is influenced by ecological responses of hosts [32] which are mediated by presence or absence of BSS [50]. Particular aphid-symbiont system may decide the host resistance specificity in a particular aphid-parasitoid interaction [42]. H. defensa, the most familiar bacterial secondary endosymbiont among aphids, is widely known to confer resistance against many hymenopteran parasitoids of aphids in addition to genetic variations among aphid hosts $[4,23,51]$. Our no choice trials did also revealed that $H$. defensa imparted protection to wheat 
aphids through partial resistance against A. abdominalis host feeding and A. rhopalosiphi parasitism is a general trend but $R$. insecticola differed in its resistive response conditional to genetic variations of the parasitoids involved in these specific host-parasitoids interactions. The partial resistance imparted to wheat aphids (genetically identical) by of $H$. defensa was consistent against both of the parasitoid species used which is in contradiction to the finding by Łukasik that $H$. defensa does not improve the defensive mechanism against parasitism by Aphidius ervi and Ephedrus plagiator in S. avenae [52] while H. defensa, in pea aphids, was highly resistant against Aphidius eadyi and weakly resistant against Aphidius ervi [10]. This reconfirms that $H$. defensa can or cannot impart resistance to host aphid species against parasitoids genotypes but it depends upon the genetic backgrounds of the partner species involved [23,35,42,49,51,51]. Even in genetically identical A. fabae, protection responses of the same $H$. defensa strain vary significantly against clonal lines of $L$. fabarum, a parasitoids of A. fabae [23,35,41,42,49,53]. R. insecticola was significantly resistant against host feeding by $A$. abdominalis but it did not show any resistance against parasitism done by $A$. rhopalosiphi unlike to $H$. defensa, but genetically identical peach aphids, Myzus persicae possessing a particular strain of $R$. insecticola were absolutely resistant against two different parasitoid species Aphidius colemani and specificity in our study by providing protection against A. abdominalis and A. rhopalosiphi parasitoids which was reflected as significant aphid-parasitoid interaction variation. So, the composition of aphid and parasitoid populations might be highly dynamic in local adaptations mediated by the endosymbiont communities in the host aphids. BSS can influence the parasitoid community structure in local biological system conditional to their protection services and long exposures can arouse genetic variations among parasitoid populations to overcome this resistance $[41,54]$.

Parasitoids prefer the best host by choosing aphids with lowest developmental cost over high cost aphids [55]. They are also able to discriminate the aphids harbouring BSS from those who are lacking them and modify their actions accordingly [56] to subsidise their feeding and reproduction. It might be possible that BSS can interfere the host preference behaviour of parasitoids to aid their hosts. So, in our choice trials, A. abdominalis significantly preferred wheat aphids lacked BSS over wheat aphids harboured BSS when it has an opportunity to choose between them in clone 5 and 7 respectively but A. rhopalosiphi did not exhibit this host preference behaviour. The trend of A. rhopalosiphi to exploit the host aphids was same as they have used the wheat aphids in no choice trials. Especially, R. insecticola in clone 7 was indifferent even to resist $A$. rhopalosiphi parasitism while it changed the feeding mode of 
A. abdominalis significantly. We conclude from these results that A. abdominalis prefers wheat aphids devoid of BSS over wheat aphids with BSS, which is more likely an escape from injuries caused by bacterial endosymbionts but $A$. rhopalosiphi response was vice versa. As no previous studies are available, we can relate it to the above discussion that specificity in genotype by genotype interactions are responsible for such behaviour deviations as well and BSS are modifying such preference behaviour deviations. Furthermore, host selection by parasitoids mainly depends upon environmental and host factors determined by chemical and physical interactions [57] which are mediated by bacterial endosymbionts [50].

Natural defences against susceptibility to parasitoids mainly depend upon genetic variations among target host populations $[39,58]$ which in turn change the phenotypic plasticity of the parasitoid populations [59]. Can host genetic variations resist the infectivity of parasitoids? This question has been addressed by many researchers with a conclusion that such genetic differences can also protect the aphids against parasitoids [23,30,39,58,59]. We tried to unveil this interaction in host feeding interaction of $A$. abdominalis and parasitism by $A$. rhopalosiphi by using genetically different clones +5 and +7 and clones -5 and -7 in a different way by choice assays. Interestingly A. abdominalis preferred to feed more on clone 7 with and with BSS than on clone 5. Wheat aphid clones +5 and -5 were significantly $(\mathrm{p}<0.05)$ resistant to host feeding by $A$. abdominalis as compared to clones +7 and -7 . A. rhopalosiphi was indifferent towards host selection being genetically different. It is inferred that it can be result of specificity in genotypic interactions because we used genetically different aphid clones with and without different BSS. So, we can assume that the genetic variations can modify the host feeding or parasitism preference behaviour of parasitoids in a specific way.

If parasitoid lays eggs after overcoming host resistance, offspring have to develop in anyway for its survival but offspring suffer with reduced fitness in terms of low emergence, decreased body weight or increased development period [41,47]. This may change the selection or preference behaviour of female parasitoids to avoid host aphids harbouring defensive symbionts [56]. Yet, few evidences about lower development of parasitoid larvae in BSS infected aphids are available [41,47]. But these studies were restricted to two species of parasitoids Aphidius ervi and L. fabarum in terms of their body mass while developing in pea and bean aphids. Impact of BSS was estimated on development of both parasitoids in wheat aphids in terms of length measurement of tibia from hind legs. Our results suggest that, although parasitoids can overcome host resistance mediated by the presence of BSS but their 
development fitness was reduced significantly $(\mathrm{p}<0.05)$ as BSS exerted negative effect on them by shorting their bodies. The length of hind tibia was significantly decreased in aphids harbouring BSS as compared to those lacking BSS. But this effect was also specific to genotypes involved in the interactions as A. abdominalis suffered equally by both bacterial endosymbionts but $A$. rhopalosiphi was negatively affected by $H$. defensa only.

Maternal or vertical transmission of BSS is thumb rule in aphid populations by manipulating the host reproductive machinery but horizontal transmission is also reported occurring rarely at very low rate [60-62]. This is why sometimes closely related BSS strains may also occur in distant relative of the insect host [63]. The potential routes for horizontal transmission of BSS in aphids can be sexual transfer [64]), transfer by parasitoids [61] and ingestion [65]. It is very rare or nadir for parasitoids to acquire BSS by host feeding on infected host aphids or during development in aphis hosts harbouring BSS [60]. In agreement to this study, $A$. abdominalis and A. rhopalosiphi did not show any uptake or contamination of BSS after exposure or emergence from wheat aphids harbouring BSS. It is suggested that these parasitoids did not present a common route for horizontal transmission of BSS among wheat aphids because it would have a negative effect on their own survival and fitness.

Unfortunately, no previous studies are available on host feeding aphid-parasitoid interactions so far. Here, genetically identical wheat aphids were used, hence it is inferred that facultative bacterial endosymbionts are driving the host selection process by parasitoids. Genotypic specificity of bacterial symbionts might be a critical factor to reshape the aphid-parasitoid ecological interactions with a high impact on host ranges of parasitoid species but parasitoids also possess genetic variations which may help them to overcome symbiotic protection aphids with recurrence of exposure [54,66]. It might also be concluded that bacterial symbionts may response differently toward different modes of risks to host aphids like host feeding or parasitism. Their evolutionary role to influence the parasitoids with regard to these findings remains open for future research.

\section{Acknowledgments}

Authors are thankful to Zaheer Abbas and Aamir Iqbal for their assistance in these experiments. Sajjad Ali is thankful to Higher Education Commission (HEC) of Pakistan and German Academic Exchange Service (DAAD) for financial support during this study. 


\section{References}

1. Bernays EA, Klein BA (2002) Quantifying the symbiont contribution to essential amino acids in aphids: the importance of tryptophan for Uroleucon ambrosiae. Physiol Entomol 27:275-284. doi:10.1046/j.1365-3032.2002.00297.x

2. Douglas AE (2003) The nutritional physiology of aphids. Adv Insect Physiol 31:73-140. doi:10.1016/S0065-2806(03)31002-1

3. Montllor CB, Maxmen A, Purcell AH (2002) Facultative bacterial endosymbionts benefit pea aphids Acyrthosiphon pisum under heat stress. Ecol Entomol 27:189-195. doi:10.1046/j.1365-2311.2002.00393.x

4. Oliver KM, Russell JA, Moran NA, Hunter MS (2003) Facultative bacterial symbionts in aphids confer resistance to parasitic wasps. Proc Natl Acad Sci 100:1803-1807. doi:10.1073/pnas.0335320100

5. Piel J, Höfer I, Hui D (2004) Evidence for a symbiosis island involved in horizontal acquisition of pederin biosynthetic capabilities by the bacterial symbiont of Paederus fuscipes beetles. J Bacteriol 186:1280-1286. doi:10.1128/JB.186.5.1280-1286

6. Scarborough CL, Ferrari J, Godfray HCJ (2005) Aphid protected from pathogen by endosymbiont. Sci 310:1781. doi:10.1126/science.1120180

7. Łukasik P, van Asch M, Guo H, Ferrari J, Godfray CJ (2013) Unrelated facultative endosymbionts protect aphids against a fungal pathogen. Ecol lett 16:214-218. doi: 10.1111/ele.12031

8. Kikuchi Y, Hayatsu M, Hosokawa T, Nagayama A, Tago K, Fukatsu T (2012) Symbiontmediated insecticide resistance. Proc Natl Acad Sci 109:8618-8622. doi:10.1073/pnas.1200231109

9. Tsuchida T, Koga R, Shibao H, Matsumoto T, Fukatsu T (2002) Diversity and geographic distribution of secondary endosymbiotic bacteria in natural populations of the pea aphid, Acyrthosiphon pisum. Mol Ecol 11:2123-2135. doi:10.1046/j.1365-294X.2002.01606.X

10. Ferrari J, Darby AC, Daniell TJ, Godfray HC, Douglas AE (2004) Linking the bacterial community in pea aphids with host-plant use and natural enemy resistance. Ecol Entomol 29:60-65. doi:10.1111/j.1365-2311.2004.00574.x

11. Leonardo TE, Mondor EB (2006) Symbiont modifies host life-history traits that affect gene flow. Proc R Soc B 273:1079-1084. doi:10.1098/rspb.2005.3408 
12. Castaneda LE, Sandrock C, Vorburger C (2010) Variation and covariation of life history traits in aphids are related to infection with the facultative bacterial endosymbiont Hamiltonella defensa. Biol J Linnean Soc 100:237-247. doi:10.1111/j.10958312.2010.01416.x

13. Tsuchida T, Koga R, Horikawa M, Tsunoda T, Maoka T, Matsumoto S, Simon JC, Fukatsu T (2010) Symbiotic bacterium modifies aphid body color. Sci 330:1102-1104. doi:10.1126/science. 1195463

14. Hurst GD, Jiggins FM (2000) Male-killing bacteria in insects: mechanisms, incidence, and implications. Emerg Infect Dis 6:329-336. doi:10.3201/eid0604.000402

15. Simon JC, Boutin S, Tsuchida T, Koga R, Gallic JF, Frantz A, Outreman Y, Fukatsu T (2011) Facultative symbiont infections affect aphid reproduction. PLoS One 6: e21831. doi:10.1371/journal.,pone.0021831

16. Kageyama D, Narita S, Watanabe M (2012) Insect sex determination manipulated by their endosymbionts: incidences, mechanisms and implications. Insects 3:161-199. doi:10.3390/insects3010161

17. Rousset F, Bouchon D, Pintureau B, Juchault P, Solignac M (1992) Wolbachia endosymbionts responsible for various alterations of sexuality in arthropods. Proc R Soc B 250:91-98. doi:10.1098/rspb.1992.0135

18. Stouthamer R, Breeuwer JAJ, Luck RF, Werren JH (1993) Molecular identification of microorganisms associated with parthenogenesis. Nature 361:66-68. doi:10.1038/361066a0

19. Hurst GD, Jiggins FM, von der Schulenburg JHG, Bertrand D, West SA, Goriacheva II, Zakharov IA, Werren JH, Stouthamer R, Majerus ME (1999) Male-killing Wolbachia in two species of insect. Proc R Soc B 266:735-740. doi:10.1098/rspb.1999.0698

20. Barribeau SM, Sok D, Gerardo NM (2010) Aphid reproductive investment in response to mortality risks. BMC Evol Biol 10:251. doi:10.1186/1471-2148-10-251

21. Sandström JP, Russell JA, White JP, Moran NA (2001) Independent origins and horizontal transfer of bacterial symbionts of aphids. Mol Ecol 10:217-228. doi:10.1046/j.1365-294X.2001.01189.x

22. Russell JA, Moran NA (2005) Horizontal transfer of bacterial symbionts: heritability and fitness effects in a novel aphid host. Appl Environ Microbiol 71:7987-7994. doi:10.1128/AEM.71.12.7987-7994.2005 
23. Vorburger C, Sandrock C, Gouskov A, Castañeda LE, Ferrari J (2009) Genotypic variation and the role of defensive endosymbionts in an all-parthenogenetic hostparasitoid interaction. Evol 63:1439-1450. doi:10.1111/j.1558-5646.2009.00660.x

24. Oliver KM, Degnan PH, Burke GR, Moran NA (2010) Facultative symbionts in aphids and the horizontal transfer of ecologically important traits. Annu Rev Entomol 55:247266. doi:10.1146/annurev-ento-112408-085305

25. Oliver KM, Degnan PH, Hunter MS, Moran NA (2009) Bacteriophages encode factors required for protection in a symbiotic mutualism. Sci 325:992-994. doi:10.1126/science. 1174463

26. Schmidt MH, Lauer A, Purtauf T, Thies C, Schaefer M, Tscharntke T (2003) Relative importance of predators and parasitoids for cereal aphid control. Proc R Soc B 270:19051909. doi:10.1098/rspb.2003.2469

27. Godfray, H. Charles (1994) Parasitoids: behavioral and evolutionary ecology. Princeton University Press.

28. Hassell MP (2000) Host-parasitoid population dynamics*. J Anim Ecol 69:543-566. doi:10.1046/j.1365-2656.2000.00445.x

29. Kraaijeveld AR, Godfray HC (2009) Evolution of host resistance and parasitoid counterresistance. Adv Parasitol 70:257-280. doi:10.1016/S0065-308X(09)70010-7

30. Li S, Falabella P, Giannantonio S, Fanti P, Battaglia D, Digilio MC, Völkl W, Sloggett JJ, Weisser W, Pennacchio F (2002) Pea aphid clonal resistance to the endophagous parasitoid Aphidius ervi. J Insect Physiol 48:971-980. doi:10.1016/S00221910(02)00176-2

31. Haine ER (2008) Symbiont-mediated protection. Proc R Soc B 275:353-361. doi:10.1098/rspb.2007.1211

32. Antolin MF, Bjorksten TA, Vaughn TT (2006) Host-related fitness trade-offs in a presumed generalist parasitoid, Diaeretiella rapae (Hymenoptera: Aphidiidae). Ecol Entomol 31:242-254. doi:10.1111/j.1365-2311.2006.00769.x

33. Pennacchio F, Strand MR (2006) Evolution of developmental strategies in parasitic Hymenoptera. Annu Rev Entomol 233-258. doi:10.1146/annurev.ento.51.110104.151029

34. Kaltenpoth M, Engl T (2014) Defensive microbial symbionts in Hymenoptera. Funct Ecol 28:315-327. doi:10.1111/1365-2435.12089 
35. Cayetano L, Rothacher L, Simon JC, Vorburger C (2015) Cheaper is not always worse: strongly protective isolates of a defensive symbiont are less costly to the aphid host. Proc R Soc B 282:20142333. doi:10.1098/rspb.2014.2333

36. Nuismer SL, Thompson JN (2006) Coevolutionary alternation in antagonistic interactions. Evol 60:2207-2217. doi:10.1111/j.0014-3820.2006.tb01858.x

37. Poitrineau K, Brown SP, Hochberg ME (2003) Defence against multiple enemies. J Evol Biol 16:1319-1327. doi:10.1046/j.1420-9101.2003.00585.x

38. Taraschewski H (2006) Hosts and parasites as aliens. J Helminthol 80:99-128. doi:10.1079/JOH2006364

39. von Burg S, Ferrari J, Müller CB, Vorburger C (2008) Genetic variation and covariation of susceptibility to parasitoids in the aphid Myzus persicae: no evidence for trade-offs. Proc R Soc B 275:1089-1094. doi:10.1098/rspb.2008.0018.

40. Cayetano L, Vorburger C (2013) Genotype-by-genotype specificity remains robust to average temperature variation in an aphid/endosymbiont/parasitoid system. J Evol Biol 26:1603-1610. doi:10.1111/jeb.12154

41. Schmid M, Sieber R, Zimmermann Y, Vorburger C (2012) Development, specificity and sublethal effects of symbiont-conferred resistance to parasitoids in aphids. Funct Ecol 26:207-215. doi:10.1111/j.1365-2435.2011.01904.x

42. Sandrock C, Gouskov A, Vorburger C (2010) Ample genetic variation but no evidence for genotype specificity in an all-parthenogenetic host-parasitoid interaction. J Evol Biol 23:578-585. doi:10.1111/j.1420-9101.2009.01925.x

43. Alkhedir H, Karlovsky P, Vidal S (2013) Relationship between water soluble carbohydrate content, aphid endosymbionts and clonal performance of Sitobion avenae on cocksfoot cultivars. PLoS One 8:e54327. doi:10.1371/journal.,pone.0054327

44. Koga R, Tsuchida T, Fukatsu T (2003) Changing partners in an obligate symbiosis: a facultative endosymbiont can compensate for loss of the essential endosymbiont Buchnera in an aphid. Proc R Soc B 270:2543-2550. doi:10.1098/rspb.2003.2537

45. Chen H, Rangasamy M, Tan SY, Wang H, Siegfried BD (2010) Evaluation of five methods for total DNA extraction from western corn rootworm beetles. PLoS One 5:e11963. doi:10.1371/journal.,pone.0011963

46. Abbott WS (1925) A method of computing the effectiveness of an insecticide. J Econ Entomol 18: 265-267.

47. Nyabuga FN, Outreman Y, Simon J, Heckel DG, Weisser WW (2010) Effects of pea aphid secondary endosymbionts on aphid resistance and development of the aphid 
parasitoid Aphidius ervi: a correlative study. Entomol Exp Appl 136:243-253. doi:10.1111/j.1570-7458.2010.01021.x

48. Brownlie JC, Johnson KN (2009) Symbiont-mediated protection in insect hosts. Trends Microbiol 17:348-354. doi:10.1016/j.tim.2009.05.005

49. Cayetano L, Vorburger C (2015) Symbiont-conferred protection against Hymenopteran parasitoids in aphids: how general is it? Ecol Entomol 40:85-93. doi:10.1111/een.12161

50. Feldhaar H (2011) Bacterial symbionts as mediators of ecologically important traits of insect hosts. Ecol Entomol 36:533-543. doi:10.1111/j.1365-2311.2011.01318.x

51. Desneux N, Barta RJ, Hoelmer KA, Hopper KR, Heimpel GE (2009) Multifaceted determinants of host specificity in an aphid parasitoid. Oecol 160:387-398. doi:10.1007/s00442-009-1289-X

52. Łukasik P, Dawid MA, Ferrari J, Godfray HC (2013) The diversity and fitness effects of infection with facultative endosymbionts in the grain aphid, Sitobion avenae. Oecol 173:985-996. doi:10.1007/s00442-013-2660-5

53. Rouchet R, Vorburger C (2012) Strong specificity in the interaction between parasitoids and symbiont-protected hosts. J Evol Biol 25:2369-2375. doi:10.1111/j.14209101.2012.02608.x

54. Dion E, Zele F, SIMON J, Outreman Y (2011) Rapid evolution of parasitoids when faced with the symbiont-mediated resistance of their hosts. J Evol Biol 24:741-750. doi:10.1111/j.1420-9101.2010.02207.x

55. Chau A, Mackauer M (2001) Preference of the aphid parasitoid Monoctonus paulensis (Hymenoptera: Braconidae, Aphidiinae) for different aphid species: female choice and offspring survival., Biol Control 20:30-38. doi:10.1006/bcon.2000.0881

56. Oliver KM, Noge K, Huang EM, Campos JM, Becerra JX, Hunter MS (2012) Parasitic wasp responses to symbiont-based defense in aphids. BMC Biol 10:11. doi:10.1186/1741-7007-10-11

57. Rehman A, Powell W (2010) Host selection behaviour of aphid parasitoids (Aphidiidae: Hymenoptera). J Plant Breed Crop Sci 2:299-311.

58. Ferrari J, Müller CB, Kraaijeveld AR, Godfray HC (2001) Clonal variation and covariation in aphid resistance to parasitoids and a pathogen. Evol 55:1805-1814. doi:10.1111/j.0014-3820.2001.tb00829.x

59. Salvaudon L, Héraudet V, Shykoff JA (2007) Genotype-specific interactions and the trade-off between host and parasite fitness. BMC Evol Biol 7:189. doi:10.1186/14712148-7-189 
60. Chiel E, Zchori-Fein E, Inbar M, Gottlieb Y, Adachi-Hagimori T, Kelly SE, Asplen MK, Hunter MS (2009) Almost there: transmission routes of bacterial symbionts between trophic levels. PLoS One 4:e4767. doi:10.1371/journal.,pone.0004767

61. Gehrer L, Vorburger C (2012) Parasitoids as vectors of facultative bacterial endosymbionts in aphids. Biol lett rsbl20120144. doi:10.1098/rsbl.2012.0144

62. Jaenike J, Polak M, Fiskin A, Helou M, Minhas M (2007) Interspecific transmission of endosymbiotic Spiroplasma by mites. Biol lett 3:23-25. doi:10.1098/rsbl.2006.0577

63. Russell JA, Latorre A, Sabater-Muñoz B, Moya A, Moran NA (2003) Side-stepping secondary symbionts: widespread horizontal transfer across and beyond the Aphidoidea. Mol Ecol 12:1061-1075. doi:10.1046/j.1365-294X.2003.01780.x

64. Moran NA, Dunbar HE (2006) Sexual acquisition of beneficial symbionts in aphids. Proc Natl Acad Sci 103:12803-12806. doi:10.1073/pnas.0605772103

65. Darby AC, Douglas AE (2003) Elucidation of the transmission patterns of an insect-borne bacterium. Appl Environ Microbiol 69:4403-4407. doi:10.1128/AEM.69.8.44034407.2003

66. Vorburger C (2014) The evolutionary ecology of symbiont-conferred resistance to parasitoids in aphids. Insect Sci 21:251-264. doi:10.1111/1744-7917.12067 

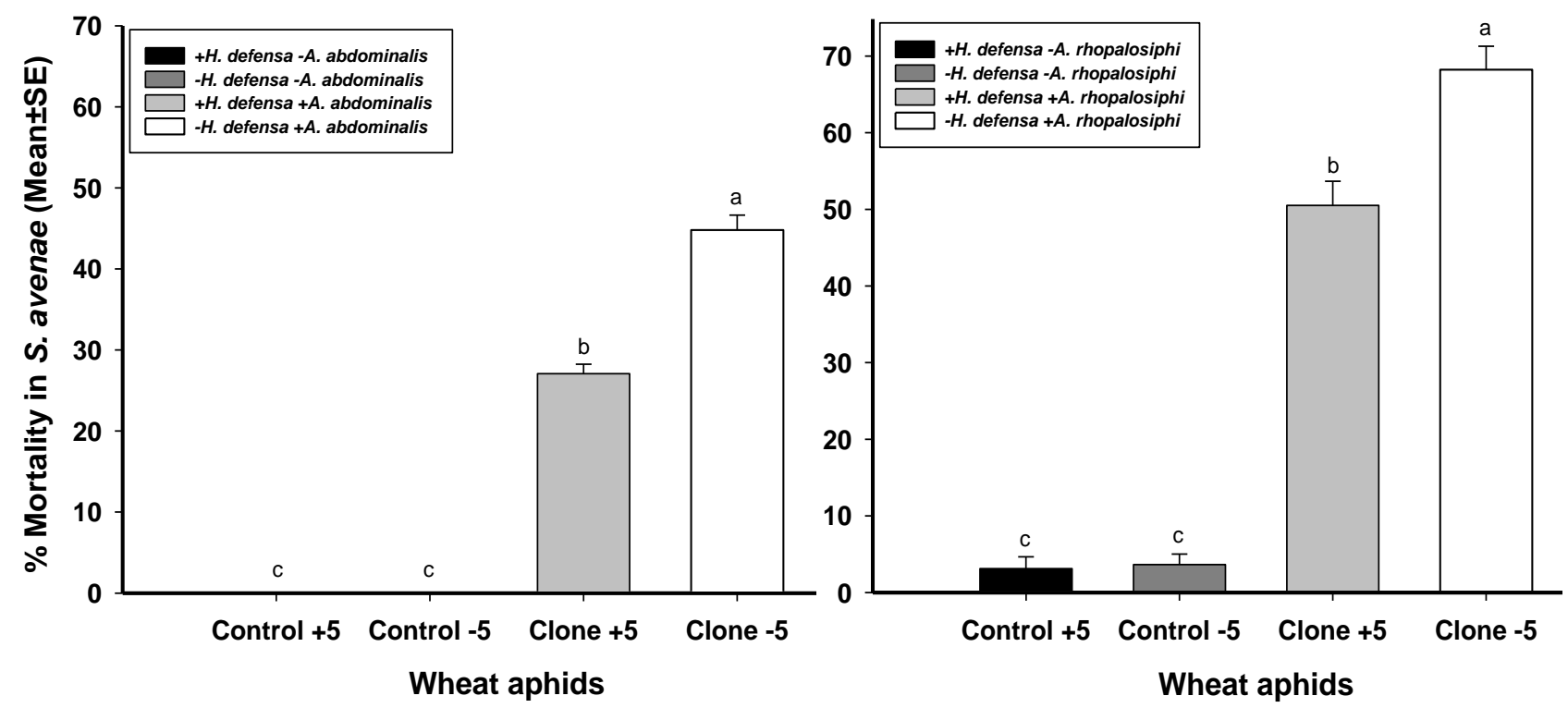

Fig. 1a. \% mortality in S. avenae (with and without Hamiltonella defensa) in response to host feeding and parasitism (no choice trial)
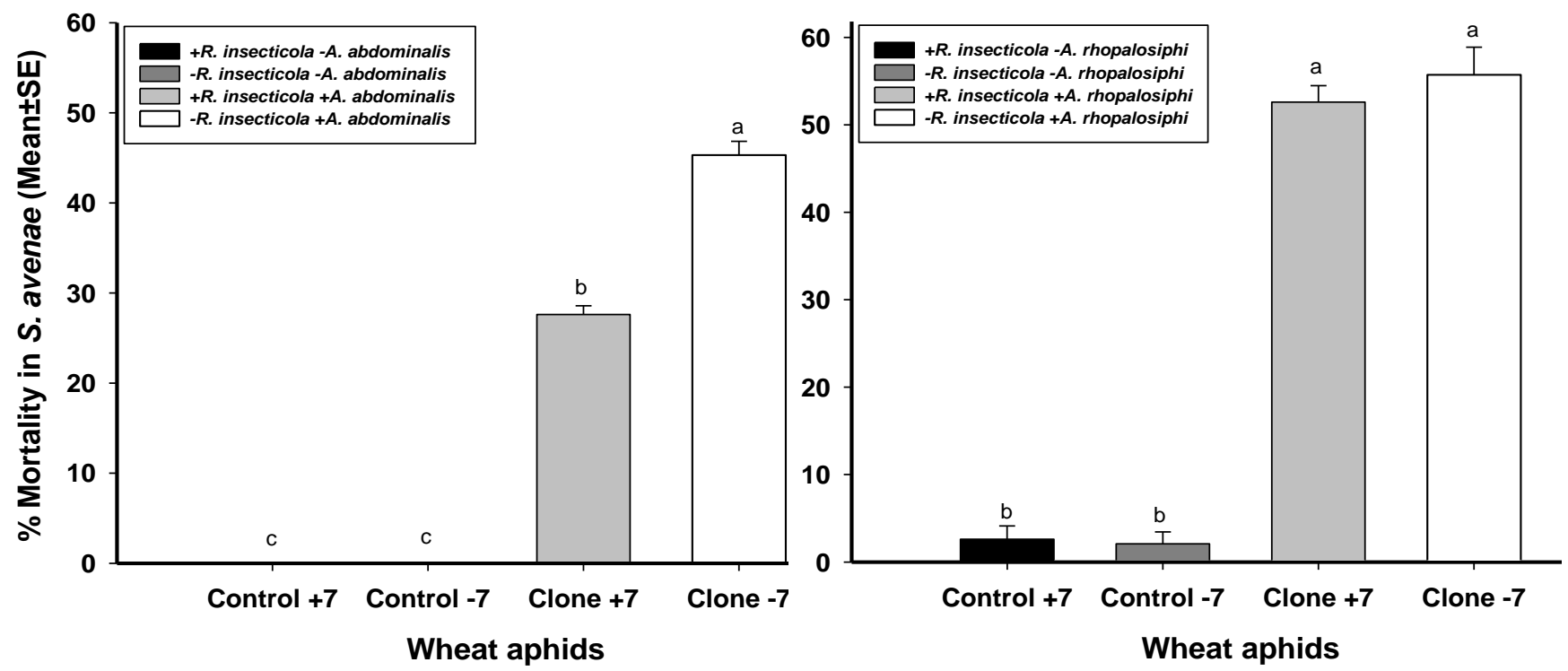

Fig. 1b. \% mortality in S. avenae (with and without Regiella insecticola) in response to host feeding and parasitism (no choice trial) 


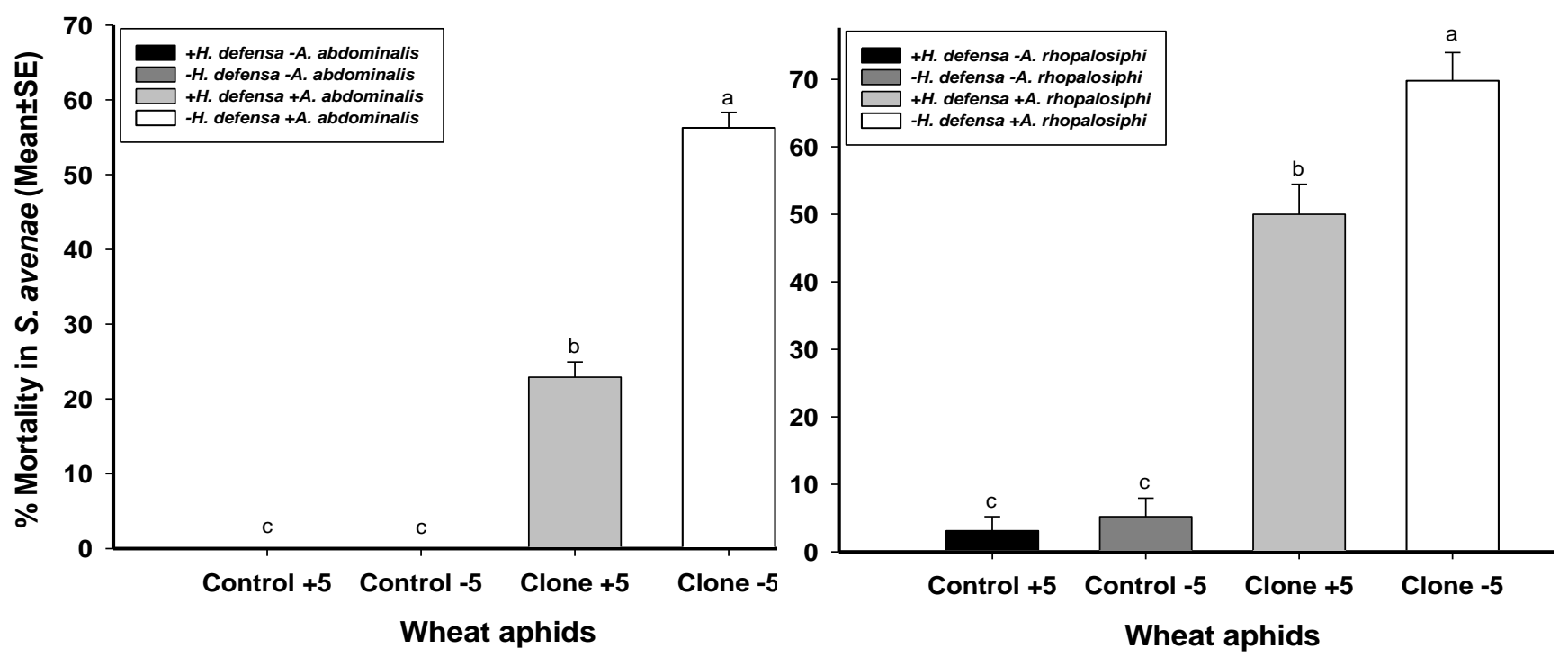

Fig. 2a. \% mortality in S. avenae (with and without Hamiltonella defensa) in response to host feeding and parasitism (choice trial)
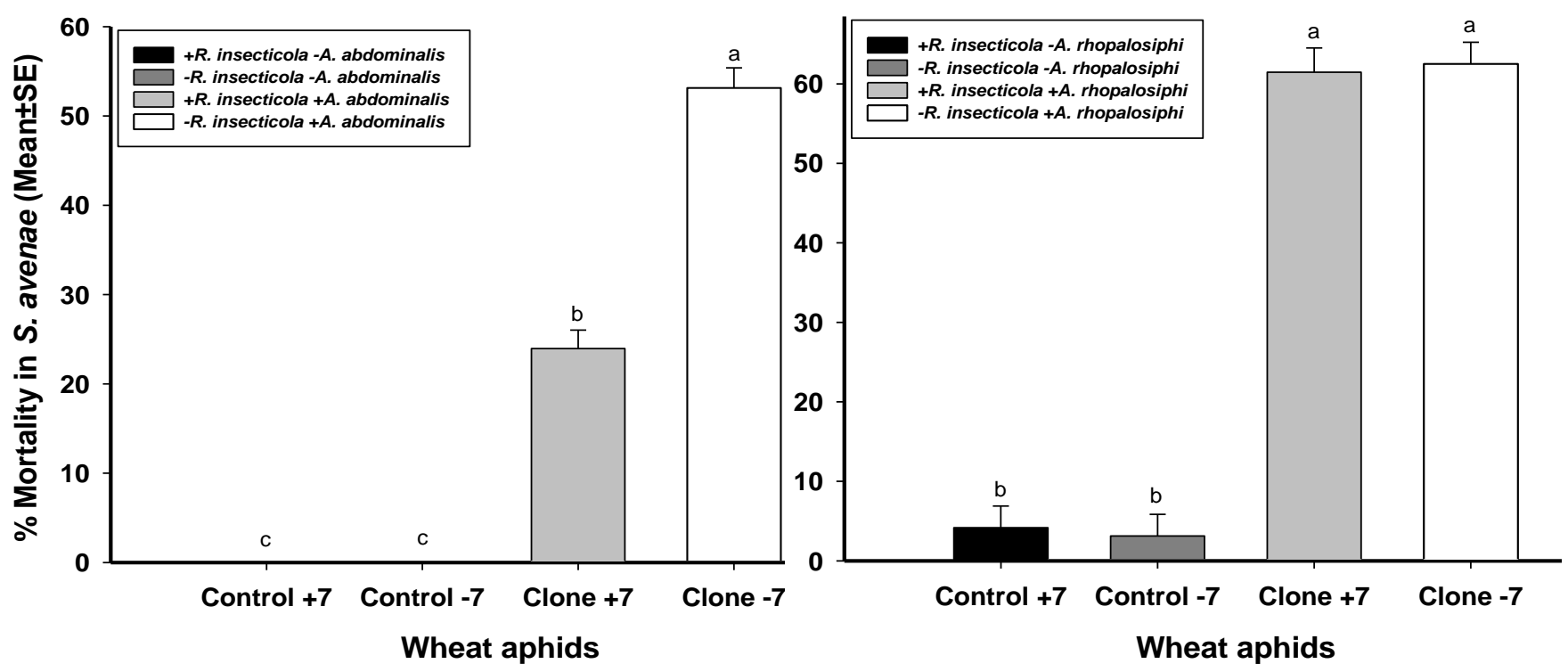

Fig. 2b. \% mortality in S. avenae (with and without Regiella insecticola) in response to host feeding and parasitism (choice trial) 

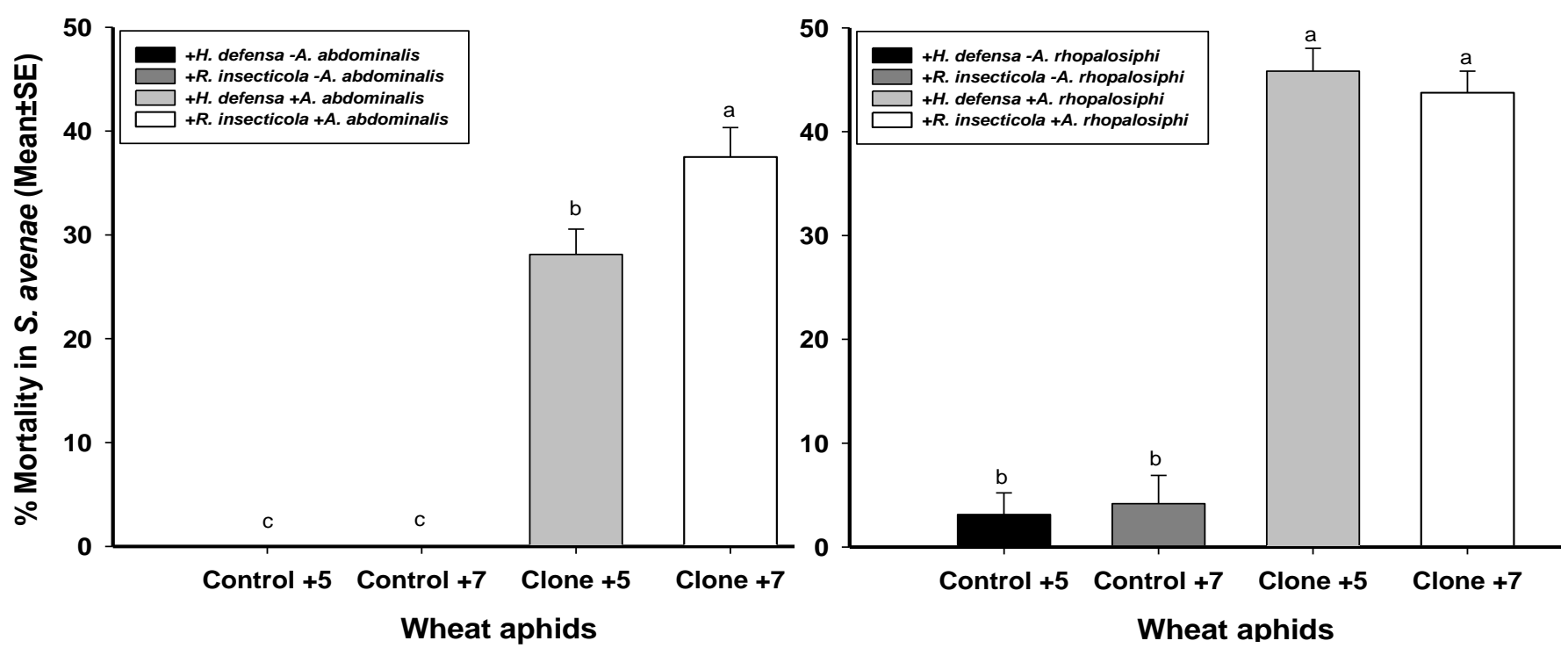

Fig. 3a. \% mortality in S. avenae (with Hamiltonella defensa and Regiella insecticola) in response to host feeding and parasitism (choice trial)
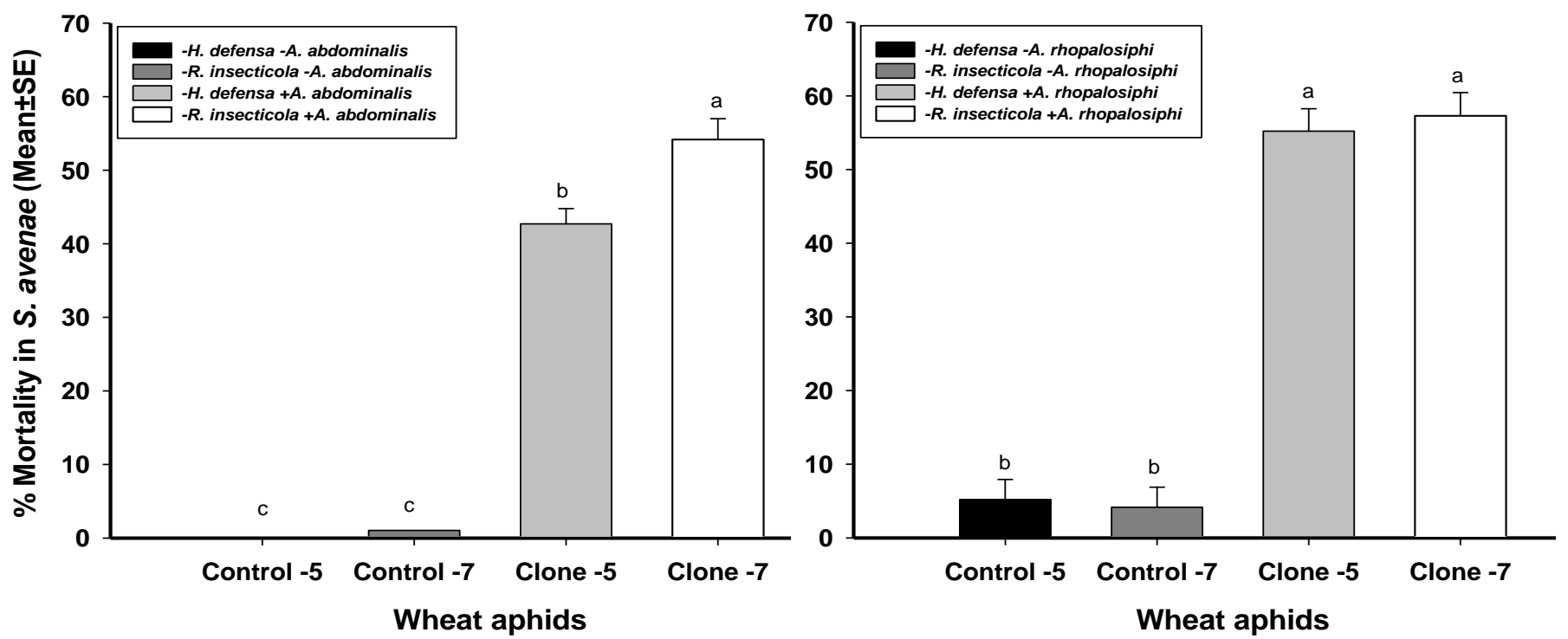

Fig. 3b. \% mortality in S. avenae (without Hamiltonella defensa and Regiella insecticola) in response to host feeding and parasitism (choice trial) 


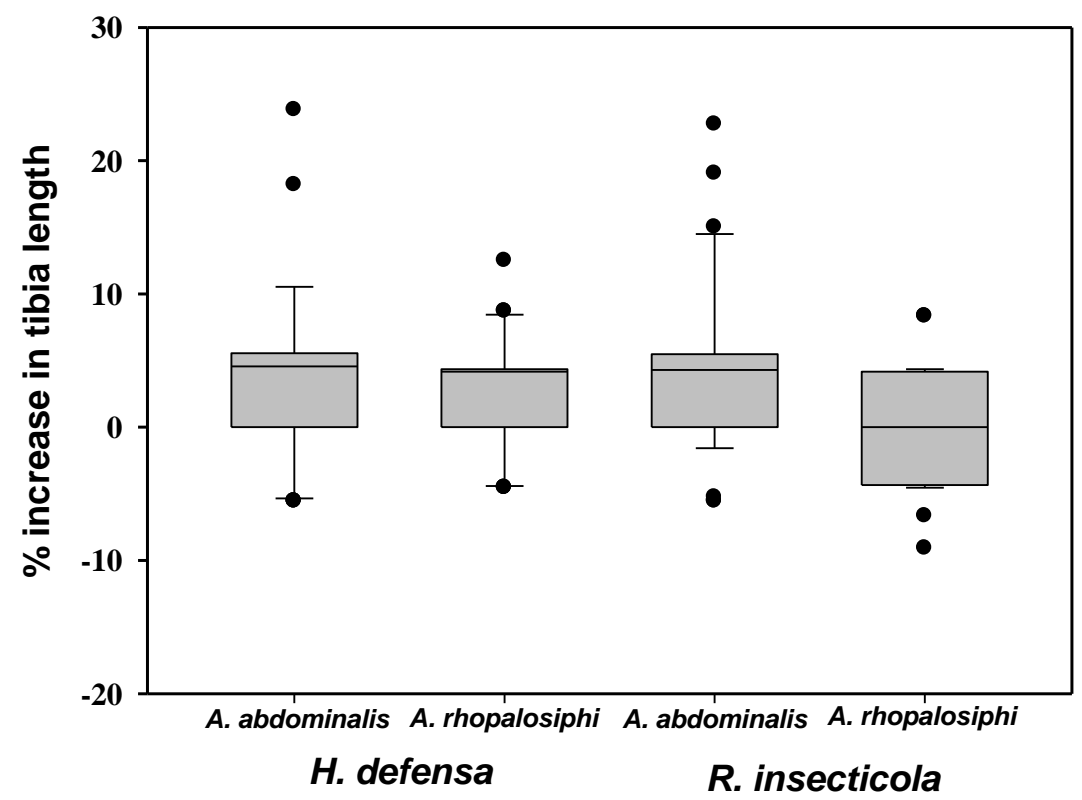

Figure 4: \% increase in hind tibia length of parasitoids developed in S. avenae (without Hamiltonella defensa and Regiella insecticola) 


\section{Chapter 5}

\section{General Discussion and Conclusion}

Literature is piled up with studies on effects of bacterial endosymbiont infection on insect hosts. These effects are divided into reproductive manipulation and mutualism. The beneficial effects facilitate the wide spread of bacterial endosymbionts over host insect populations, by increasing symbiont infected host frequencies at the cost of uninfected ones (Oliver \& Moran, 2009). Extensive work has been reported to show that bacterial secondary endosymbionts confer resistance to insect hosts against predators, pathogens and parasitoids (Haine, 2008; Brownlie \& Johnson, 2009; Oliver \& Moran, 2009). More focused work is needed to widen our understanding about the quick spread and broad occurrence of bacterial endosymbiont in insect populations.

The benefits of bacterial secondary endosymbionts may vary in a context depending upon environmental factors. Maintenance of endosymbionts is correlated to the presence of natural enemies because it is costly to have and maintain them. Otherwise, facultative endosymbionts may be vanished from host insect populations (Feldhaar, 2011). Thus, their persistence in insect populations requires diverse fitness benefits with no or minimal cost for their quick and wide dispersal in host insects (Oliver et al., 2008). In case of parasitoid-aphid-endosymbiont interactions, research workers focused on parasitism studies in the last decade. This study was designed to explore the possibilities that facultative endosymbionts may also confer resistance against host feeding behaviour of parasitoids with regard to wheat aphid Sitobion avenae (F.), Aphelinus abdominalis (Dalman) and Aphidius rhopalosiphi interactions.

Hymenoptera parasitic wasps host feeding directly depends upon host population densities (Rosenheim \& Rosen, 1992) to secure protein nutrients for better fecundity and longevity (Kidd \& Jervis, 1989). We demonstrated for first time in our study that A. abdominalis host feeding linearly depends upon the wheat aphid host densities but it is also negatively affected by the presence of defensive bacterial endosymbionts $H$. defensa and $R$. insecticola. The symbiont-host density interactions did not affect the aphid-parasitoid host feeding interactions at all the population levels tested. In addition to defensive bacterial endosymbionts, host genetic variations were also able to influence the host preference behaviour of A. abdominalis.

Temperature is one of the most important factors influencing the outcome of aphid-parasitoid interactions. Environmental variables like temperature may influence the decisions of female 
parasitic wasps for host feeding (Hansen \& Jensen, 2002). Bacterial endosymbionts persistently conferred resistance to wheat aphids against host feeding damages done by $A$. abdominalis at all the temperatures provided but host feeding was positively correlated with increasing temperatures. Host preference behaviour of $A$. abdominalis was not affected by temperature variations.

$H$. defensa did also confer resistance against parasitism of $A$. rhopalosiphi but $R$. insecticola was not able to serve this function in wheat aphids. Bacterial endosymbionts might be one of the important factors in reshaping the ecological responses and evolutionary processes on the side of parasitoids in aphid-parasitoid interactions. The degree of defensive specificity provided by facultative endosymbionts to host aphids exerts a strong influence on host population for resistance variations and determines the evolution of host ranges for a certain parasitoid. In our study, degree of protection conferred by the two bacterial endosymbionts $H$. defensa and $R$. insecticola largely depended on the genotypic backgrounds of the attacking parasitoids. This could be a possible explanation that why most of the parasitoids specialize on a single or few aphid hosts and it is also a way for the maintenance of genetic variations (Vorburger, 2014). Bacterial endosymbionts may increase the genetic specificity in aphidparasitoid interactions.

This defensive specificity also explain that a parasitoid genotype should able to recognize and establish after disseminating host variations for bacterial endosymbionts and genotypes in genetically variable populations (Oliver et al., 2012). This was clearly demonstrated when two genetically different parasitoids A. abdominalis and A. rhopalosiphi were exposed to genetically identical wheat aphids with and without bacterial endosymbionts or genetically different wheat aphids in choice tests. The same genotypic specificity was also depicted through parasitoids developmental variations in wheat aphids infected by same strains of bacterial symbionts. This genotype-genotype specificity has been resulted from particular defensive bacterial endosymbionts existing with same genetic background of their hosts and different genetic background of parasitoids (Schmid et al., 2012).

Based on our findings, we might conclude that $H$. defensa and $R$. insecticola not only confer resistance to their hosts against parasitism but also against host feeding strategy of $A$. abdominalis in wheat aphids. Parasitoid can still be negatively affected by BSS during development after parasitizing wheat aphids. In addition, BSS and genetic variations both can change the host preference behaviour of parasitoids. These fitness advantages confer to their host aphids by these endosymbiotic bacteria expound the adaptive significance of their 
heritable and successful spread over many insect populations especially in aphids. It is also inferred that bacterial endosymbionts may drive host selection process by parasitoids depending upon genotype-by-genotype specificity. Defensive role of bacterial endosymbionts is problematic in biological control of aphid pests and the outcome of parasitoid-aphidendosymbiont interactions may reshape biological control success and should be addressed for risk assessments while formatting IPM policies. More ecological trait studies at population level with regard to prevalence of bacterial endosymbionts will uncover the more subtle effects in future. 


\section{References}

Brownlie, J. C., \& Johnson, K. N. (2009). Symbiont-mediated protection in insect hosts. Trends in microbiology, 17(8), 348-354.

Feldhaar, H. (2011). Bacterial symbionts as mediators of ecologically important traits of insect hosts. Ecological Entomology, 36, 533-543.

Haine, E. R. (2008). Symbiont-mediated protection. Proceedings of the Royal Society B: Biological Sciences, 275(1633), 353-361.

Hansen, L.S. and Jensen, K.M.V. (2002). Effect of temperature on parasitism and hostfeeding of Trichogramma turkestanica (Hymenoptera: Trichogrammatidae) on Ephestia kuehniella (Lepidoptera: Pyralidae). Journal of Economic Entomology, 95, 50-56.

Kidd, N.A.C. \& Jervis, M.A. (1989). The effects of host feeding behaviour on the dynamics of parasitoid-host interactions, and the implications for biological control. Researches in Population Ecology, 31, 235-274.

Oliver, K. M., Campos, J., Moran, N. A., \& Hunter, M. S. (2008). Population dynamics of defensive symbionts in aphids. Proceedings of the Royal Society B: Biological Sciences, 275(1632), 293-299.

Oliver, K. M., \& Moran, N. A. (2009). Defensive symbionts in aphids and other insects. Defensive mutualism in microbial symbiosis, 129-148.

Oliver, K.M., Noge, K., Huang, E.M., Campos, J.M., Becerra, J.X. \& Hunter, M.S. (2012). Parasitic wasp responses to symbiont-based defense in aphids. BMC Biology, 10, 11.

Rosenheim, J.A. and Rosen, D. (1992). Influence of egg load and host size on host-feeding behavior of the parasitoid Aphytis lingnanensis. Ecological Entomology, 17, 263-272.

Schmid, M., Sieber, R., Zimmermann, Y-S. \& Vorburger, C. (2012). Development, specificity and sublethal effects of symbiont conferred resistance to parasitoids in aphids. Functional Ecology, 26, 207-215.

Vorburger, C. (2014). The evolutionary ecology of symbiont-conferred resistance to parasitoids in aphids. Insect science, 21(3), 251-264. 